\title{
Lattice-constant prediction and effect of vacancies in aliovalently doped perovskites
}

\author{
R. Ubic, ${ }^{\text {a }}{ }^{\text {K. }}$ Tolman ${ }^{\mathrm{a}}$, K. Talley ${ }^{\mathrm{a}}$, B. Joshi ${ }^{\mathrm{a}}$, J. Schmidt ${ }^{\mathrm{a}}$, E. Faulkner ${ }^{\mathrm{a}}$, J. Owens ${ }^{\mathrm{a}}$,

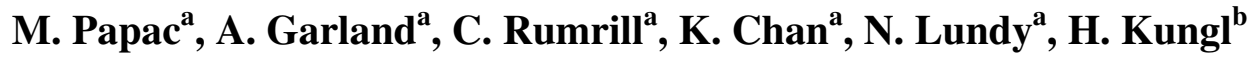

${ }^{\mathrm{a}}$ Department of Materials Science \& Engineering, Boise State University, 1910 University Drive, Boise, Idaho, 83725, USA

tel. +12084262309

fax +12084264466

RickUbic@BoiseState.edu

${ }^{\mathrm{b}}$ Forschungszentrum Juelich, Institute for Energy and Climate Research IEK-9, Ostring 10, 52425 Juelich, Germany

\begin{abstract}
Processing-structure relationships are at the heart of materials science, and predictive tools are essential for modern technological industries insofar as structure dictates properties. Point defects can have a profound effect on structure and consequently properties, but their effect on crystal chemistry is still not generally known or understood. None of the very few theoretical models which exist for perovskites are suited to the doped and defective ceramics most commonly used in commercial devices; therefore, a new
\end{abstract}

\footnotetext{
* Corresponding author
} 
empirical approach is presented here. A predictive model for the effective size of anions as well as cation vacancies and ultimately the pseudocubic lattice constant of such perovskites, based solely on published ionic radii data, has been developed here. The model can also be used to derive ionic radii of cations in twelvefold coordination. Vacancies have an effective size due to both bond relaxation and mutual repulsion of coordinating anions, and as expected this size scales with the host cation radius, but not in a straightforward way. The model is able to predict pseudocubic lattice constants, calculate the effective size of anions and cation vacancies, and identify the effects of both cation ordering and second-order Jahn Teller distortions. A lower limit on the tolerance factor of stable oxide perovskites is proposed.

Keywords: Oxide materials; Solid state reactions; Point defects; x-ray diffraction

\section{Introduction}

The mineral perovskite is $\mathrm{CaTiO}_{3}$; however, the term is more generally applied to any $\mathrm{ABX}_{3}$ compound which shares its structure, the key feature of which is corner-sharing of anion octahedra, each containing a single B-site cation, with larger A-site cations residing in cuboctahedral sites between the octahedra. Perovskites are ubiquitous in modern devices because their wide compositional range and structural variability gives rise to useful properties like ferroelectricity, superconductivity, colossal magnetoresistance, and spin-dependent transport. The design of materials with these properties is aided by an understanding of the relationship between chemical composition and crystal structure. In particular, the prediction of the cubic or pseudocubic lattice constant of perovskite materials is of importance partially for their use as substrates or buffer layers for compound semiconductor epitaxy [1-2] or as strain layers in ceramic superlattice structures. [3-7] An 
example of the latter is $\mathrm{BaTiO}_{3} / \mathrm{SrTiO}_{3}$ superlattices in which the tensile and compressive properties of each alternating layer of ferroelectric $\mathrm{BaTiO}_{3}$ induces ferroelectric properties in the $\mathrm{SrTiO}_{3}$, and the $\mathrm{SrTiO}_{3}$ layers compensate for the relaxation of the strain in $\mathrm{BaTiO}_{3}$ with film thickness, making it possible to grow thicker ferroeletirc films and enabling the tuning of properties by varying the thickness of each layer.

The conventional perovskite tolerance factor is defined as:

$$
t_{*}=\frac{r_{\mathrm{A}(\mathrm{id})}+r_{\mathrm{X}(\mathrm{id})}}{\sqrt{2}\left(r_{\mathrm{B}}+r_{\mathrm{X}(\mathrm{id})}\right)}
$$

where $r_{\mathrm{A}(i d)}, r_{\mathrm{B}}$, and $r_{\mathrm{X}(i d)}$ are the effective ionic radii of $\mathrm{A}, \mathrm{B}$, and $\mathrm{X}$ ions, respectively, as reported by Shannon. [8] Where sites are occupied by more than one species, the effective ionic size is calculated as a weighted average. If stoichiometric vacancies are present, their size is assumed to be 0 .

In 2007 Ubic [9] published a revised method of calculating pseudocubic lattice constants, $a_{p c}$, of stoichiometric perovskites based on 132 compositions found in the literature. That model (Eq. (2)) used effective ionic radii assuming sixfold coordination for all ionic species because, even though that coordination is incorrect for $\mathrm{A}$ and $\mathrm{X}$ ions, those values resulted in the best fit for $a_{p c}$ (average relative error $=0.60 \%$ ).

$$
a_{p c}=0.06741+0.49052\left(r_{\mathrm{A}(i d)}^{V I}+r_{\mathrm{X}(i d)}^{V I}\right)+1.29212\left(r_{\mathrm{B}}+r_{\mathrm{X}}^{V I}\right)
$$


where $r_{\mathrm{A}(i d)}^{V I}, r_{\mathrm{B}}$, and $r_{\mathrm{X}(i d)}^{V I}$ are the effective ionic radii of $\mathrm{A}, \mathrm{B}$, and $\mathrm{X}$ ions in sixfold coordination.

Although this model has proven extremely accurate in predicting cubic/pseudocubic lattice constants (and hence $\mathrm{ABX}_{3}$ unit volume) in stoichiometric perovskites, in order to quantitatively study the effect of defects on crystal structure, a model which involves the actual sizes of ions (in their correct coordinations) is required. Towards that end, the same linear regression method and revised lattice constants reported in that work can be used to derive a new equation in which $\mathrm{A}, \mathrm{B}$, and $\mathrm{X}$ ions are assumed in $\mathrm{XII}, \mathrm{VI}$, and II coordinations, respectively. As it happens, this new model (Eq. (3)) yields results only slightly less accurate than the original (average relative error $=0.77 \%$ ):

$$
a_{p c}=0.01173 \dashv 0.50977\left(r_{\mathrm{A}(i d)} \dashv r_{\mathrm{X}(i d)}\right) \dashv 1.26954\left(r_{\mathrm{B}} \dashv r_{\mathrm{X}(i d)}\right)
$$

where $r_{\mathrm{A}(i d)}$ and $r_{\mathrm{X}(i d)}$ are the effective ionic radii of $\mathrm{A}$ and $\mathrm{X}$ ionic species in XII and II coordination, respectively.

Eq. (3) can be solved for $t$ according to Eq. (1) above:

$$
t_{1}=\frac{a_{p c}-0.011730139}{0.7209203\left(r_{\mathrm{B}}+r_{\mathrm{X}(i d)}\right)}-1.760998
$$

Ideally $t_{1}=t_{*}$. Eq. (4) is similar to that reported previously $[10,11]$ but, as it was derived from corrected lattice-constant data, is slightly more accurate than the earlier version. Significantly, Eq. (4) removes the necessity of calculating effective or average A-site ionic 
radii for compositions for which this value is ambiguous to define (e.g., compositions with mixed occupancies or A-site vacancies). The required $a_{p c}$ value in this expression can either be calculated via Eq. (2) (in the case of stoichiometric perovskites) or experimentally measured. Lafaso and Woodward [12] introduced the concept of a bond-valence based tolerance factor, $t_{\mathrm{BV}}$, which relies on bond-valence data and thus does not support polyatomic ions, some cation species, or compositions with stoichiometric vacancies As it happens, Eq. (4) yields results similar to $t_{\mathrm{BV}}$ in most cases. Eq. (4) is also more accurate than Eq. (1) in predicting structure and can be used to show that, for example, the $t *=0.9729$ calculated for $\mathrm{CaTiO}_{3}$ via Eq. (1) and corresponding to a structure with antiphase tilting of octahedra [13] would become $t_{1}=0.9552$ according to Eq. (4), indicating the presence of both in-phase and anti-phase tilting, [13] in agreement with the established structure. [14] In the case of $\mathrm{Ba}\left(\mathrm{Sm}_{\frac{1}{2}} \mathrm{Sb}_{\frac{1}{2}}\right) \mathrm{O}_{3}$, Eq. (1) yields $t_{*}=0.9831$, corresponding to a structure with slight antiphase octahedral tilting; whereas Eq. (4) would yield $t_{1}=0.9886$, corresponding to the correct untilted structure. An even more extreme example is that of $\mathrm{MgSiO}_{3}$, for which uncertainty in the size of $\mathrm{Mg}^{2+}$ results in a $t *$ of 1.0436 , suggesting an untilted structure. In this case Eq. (4) unambiguously predicts a tolerance factor of $t_{1}=0.9546$, again in keeping with the tilted Pbnm structure reported experimentally. [15] By re-writing Eq. (4), $a_{p c}$ can now be expressed as a function of $t_{1}$ :

$$
a_{p c}=0.7209203 t_{1}\left(r_{\mathrm{B}} \dashv r_{\mathrm{X}(\mathrm{id})}\right) \dashv 0.011730139
$$

Ideally, the cubic/pseudocubic lattice constant can be defined in terms of either the B-X bond length or the A-X bond length: 


$$
\begin{gathered}
a_{p c}^{\prime}=\sqrt{2}\left(r_{\mathrm{A}(i d)}+r_{\mathrm{X}(i d)}\right) \\
a_{p c}^{\prime \prime}=2\left(r_{\mathrm{B}}+r_{\mathrm{X}(i d)}\right)
\end{gathered}
$$

Because of the various influences on ionic radii, both definitions are approximations and only in the case that $t_{*}=1$ does $a_{p c}^{\prime}=a_{p c}^{\prime \prime}$. This phenomenon was noted previously, $[9,11]$ but its cause was never investigated. In fact, the reason for the anomaly is based on the fact that ionic radii are affected by four factors. Valence and coordination are the two most commonly cited influences on ionic radii and are the only factors considered by Shannon; [8] however, covalency and the cation/anion radius ratio are also important. As this ratio approaches the critical value for anion-anion contact, the repulsion between anions will increase, effectively distending the structure and increasing the apparent radii of the component ions. [16] Although commonly neglected, this effect is by no means always negligible. In the case of compounds like perovskites, there are two cation/anion ratios, both of which can be neatly expressed by the tolerance factor.

Although an untilted cubic phase in $P m \overline{3} m$ was reported for $\mathrm{Sr}_{1-3 x} \mathrm{La}_{2 x} \mathrm{TiO}_{3}$ ( $x \leq 0.1$ ) by Howard et al. [17] and $x \leq 0.2$ by Battle et al., [18] Ubic et al. [19] found antiphase octahedral tilting consistent with the $R \overline{3} c$ space group for $\mathrm{Sr}_{1-3 x} \mathrm{Ce}_{2 x} \mathrm{TiO}_{3}$ $(0<x<0.2)$ via a mixture of electron diffraction and neutron diffraction. Antiphase octahedral tilting consistent with the $R \overline{3} c$ space group is almost undetectable via XRD in low- $x$ compositions of $\mathrm{Sr}_{1-3 x} \mathrm{Ln}_{2 x} \mathrm{TiO}_{3}$, which is why refinements were conducted in space 
group $P m \overline{3} m$ in previous work; [11] however, Ubic et al. [10] has shown that such tilting may begin at infinitesimally small $x$ values. Space group $R \overline{3} c$ is not adequate to describe compositions for which $x \geq 0.2$, and a better fit can be achieved in $C 2 / c$ [20] provided that a subtle, probably short-range doubling of the $c$ axis is neglected. A short-range tetragonal distortion has been observed for $0.15 \leq x<0.25$ via $x$-ray and neutron diffraction by Howard et al. [17] and via high-resolution TEM by Battle et al., [18] who also observed vacancy pairing at these compositions. At still higher $x$ values, long-range cation/vacancy ordering reportedly occurs and an orthorhombic form has been reported in Pban $(x=0.25)$ by Battle et al.; [18] although not all reflections in electron diffraction patterns could be accounted for in this structure. Howard et al. [17] reported an orthorhombic structure in Cmmm for $x=0.275$. Abe \& Uchino [21] reported a very slightly oxygen-deficient form of the $x=1 / 3$ end-member $\left(\mathrm{La}_{2 / 3} \mathrm{TiO}_{3}\right)$ with charge compensation conferred by $\mathbf{T i}^{4+}$ reduction, $\mathrm{La}_{\frac{2}{3}} \mathrm{Ti}_{1-2 \lambda}^{4+} \mathrm{Ti}_{2 \lambda}^{3+} \mathrm{O}_{3-\lambda}(0.007 \leq \lambda \leq 0.079)$, but they conducted their synthesis under reduced oxygen partial pressure using a mixture of $\mathrm{CO}_{2}$ and $\mathrm{H}_{2}$ gases. Under these conditions, such reduction and oxygen loss is to be expected. Although a schematic of the structure is shown in their paper, no crystallographic model (e.g., space group, atomic coordinates, etc.) was ever published. The XRD pattern of the resultant product (PDF 26-827) is markedly different from that reported by Gönen $e t$ $a l$. , [22] who used a wet chemical route in air to synthesize $\mathrm{La}_{2 / 3} \mathrm{TiO}_{3}$ from either $\mathrm{HLa}_{2} \mathrm{Ti}_{3} \mathrm{O}_{9}$ or $\mathrm{KLa}_{2} \mathrm{La}_{3} \mathrm{O}_{9}$ and found the resultant composition in very good agreement with the ideal stoichiometry. Their structural model (ICSD collection code 240300) in space group $\mathrm{I4} / \mathrm{mmm}$ consists of shifted $\left(\mathrm{La}_{2} \mathrm{Ti}_{3} \mathrm{O}_{9.5}\right)^{1-}$ slabs with $5 \%$ oxygen vacancies, yielding a $\mathrm{La}_{2 / 3} \mathrm{TiO}_{3}$ compound with a layered structure in which successive 
planes are either La- or vacancy-rich This model gave superior Rietveld fits to XRD data and is "consistent with expectations based on the $\mathrm{K}_{2} \mathrm{O}$ elimination in the formation of $\mathrm{KLa}_{2} \mathrm{Ti}_{3} \mathrm{O}_{9.5}$ and the fact that $\mathrm{La}_{2} \mathrm{Ti}_{3} \mathrm{O}_{9}$ readily reacts with $\mathrm{KNO}_{3}$ to reform the $\mathrm{K}_{2} \mathrm{La}_{2} \mathrm{Ti}_{3} \mathrm{O}_{10}$ starting material." As this model is the only one listed in the ICSD for a La-deficient titanate perovskite, it was the one used in this work.

Compositions in the system $\mathrm{Ca}_{1-3 x} \mathrm{La}_{2 x} \mathrm{TiO}_{3}$ have been reported in space group Pnma by Vashook et al. [23] for $x \leq 0.067$ and by Zhang et al. [24] for $x=0.1$. The $\mathrm{Pb}_{1-3 x} \mathrm{La}_{2 x} \mathrm{TiO}_{3}$ analogues have been reported in space group $P 4 m m(0 \leq x \leq 0.125)[25-26]$ and $P m \overline{3} m(x \geq 0.15)$. [26] Undoped $\mathrm{Pb}_{1-3 x} \mathrm{La}_{2 x}\left(\mathrm{Zr}_{0.6} \mathrm{Ti}_{0.4}\right) \mathrm{O}_{3}$ reportedly $[27,28]$ crystallizes in space group $R 3 c$ and transforms to a tetragonal form [29-31] in $P 4 m m$ for $0.03<x<0.05$ and finally $P m \overline{3} m$ at $x>0.06$. [30,31] While it has been reported previously $[32,33]$ that $\mathrm{La}^{3+}$ substitution for $\mathrm{Ba}^{2+}$ in $\mathrm{BaTiO}_{3}$ is charge-compensated by $\mathrm{Ti}^{4+}$ reduction at low concentrations $(\leq 0.5 \mathrm{~mol} \%$ La or $x \leq 0.0025)$ and via $\mathrm{Ti}^{4+}$ vacancies at higher dopant levels, a more recent study [34] reportedly showed compensation via $\mathrm{Ba}^{2+}$ vacancy formation. The compound $\operatorname{Sr}\left(\mathrm{Mg}_{1 / 3} \mathrm{Nb}_{2 / 3}\right) \mathrm{O}_{3}$ was reported [35] in space group $P \overline{3} m l$, whilst $(\mathrm{Na}, \mathrm{K})_{(1-3 x) / 2} \mathrm{La}_{(1+x) / 2}\left(\mathrm{Mg}_{1 / 2} \mathrm{~W}_{1 / 2}\right) \mathrm{O}_{3}$ was reported [36] in $P 2_{1} / m$.

\section{Experimental details}

A total of 11 compositions in the system $\mathrm{Sr}_{1-3 x} \mathrm{Ln}_{2 x} \mathrm{TiO}_{3}(\mathrm{Ln}=\mathrm{La}, \mathrm{Nd})$ corresponding to $0<x \bullet 0.25$ were prepared via the conventional mixed-oxide route as described elsewhere. [11] This formulation is convenient in that $x$ is equal to the concentration of Asite vacancies, [V]. In addition, 13 compositions in the system $\mathrm{Ca}_{1-3 x} \mathrm{Ln}_{2 x} \mathrm{TiO}_{3}(\mathrm{Ln}=\mathrm{La}, \mathrm{Nd}$, Y), two compositions in the system $\mathrm{Pb}_{1-3 x} \mathrm{La}_{2 x} \mathrm{TiO}_{3}$, four compositions in the system $\mathrm{Ba}_{1}$. 
${ }_{3 x} \mathrm{La}_{2 x} \mathrm{TiO}_{3}$, six compositions in the system $\mathrm{Pb}_{1-3 x} \mathrm{La}_{2 x}\left(\mathrm{Zr}_{0.6} \mathrm{Ti}_{0.4}\right) \mathrm{O}_{3}$ (PLZT), five compositions in the system $\left[\left(\mathrm{Ca}_{0.252} \mathrm{Sr}_{0.748}\right)_{1-3 x} \mathrm{La}_{2 x}\right] \mathrm{TiO}_{3}$, and $\mathrm{Sr}_{0.97} \mathrm{La}_{0.02}\left(\mathrm{Mg} . \mathrm{Nb}_{.}\right) \mathrm{O}_{3}$ were all produced in a similar manner. Raw materials included $\mathrm{SrCO}_{3}$ (99.99\%, Alfa-Aesar), $\mathrm{CaCO}_{3}(99.5 \%$, Fisher Scientific), $\mathrm{PbO}$ (99.9\%, Fisher Scientific), $\mathrm{BaCO}_{3}\left(99.95 \%\right.$, Alfa-Aesar), $\mathrm{La}_{2} \mathrm{O}_{3}$ (99.9\%, Alfa-Aesar), $\mathrm{Nd}_{2} \mathrm{O}_{3}$ (99.9\%, Meldform Rare Earths), $\mathrm{TiO}_{2}$ (99.5\%, Fisher Scientific), $\mathrm{Y}_{2} \mathrm{O}_{3}\left(99.9 \%\right.$, Alfa-Aesar), and $\mathrm{ZrO}_{2}$ (99.5\%, Alpha Aesar). A further 11 PLZT compositions $(0 \leq x \leq 0.03)$ were processed via attrition milling according to the method previously described by Tolman et al. [37]

Powder samples were prepared for x-ray diffraction from post-calcined batches or, in the case of the 11 attrition-milled PLZT samples, pulverized pellets. For $\operatorname{Sr}_{1-3 x} \operatorname{Ln}_{2 x} \mathrm{TiO}_{3}$ samples, synchrotron x-ray data were acquired on the high-resolution beamline 11-BM at the Advanced Photon Source, Argonne National Laboratory. Le Bail fits to these data were conducted using the General Structure Analysis System (GSAS). [38,39] For all other compositions, diffraction was conducted using a Miniflex 600 (Rigaku, Woodlands, TX) in Bragg-Brentano theta-2 theta geometry $\left(\mathbf{1 0}^{\mathbf{6}}\right.$ cps on Si standard (111) peak), and refinements conducted using DiffracPLUS TOPAS 4.2 (Bruker AXS Inc., Madison, WI). In addition to the cubic/pseudocubic lattice constants and average crystallite size, nonstructural parameters, including background, peak shape, zero-point, and instrument line profile were also refined. The instrument line profile was characterized as the convolution of both equatorial and axial profiles. Equatorial divergence was refined using the receiving-slit width and the fixed-divergence slit angle parameters, while axial divergence was modeled using the Finger et al. [40] asymmetry correction. Background was fitted with a fourth-order Chebychev polynomial and a $1 / x$ function to fit the rise in the background at low angles caused by scatter from the direct beam. 
Refinements in the system $\operatorname{Sr}_{1-3 x} \mathrm{Ln}_{2 x} \mathrm{TiO}_{3}$ were conducted in either $R \overline{3} c$ $(0<x<0.2)$ or $C 2 / c(0.2 \leq x \leq 0.25)$, while refinements in the system $\mathrm{Ca}_{1-3 x} \mathrm{Ln}_{2 x} \mathrm{TiO}_{3}$ $(x<0.2)$ were all conducted in space group Pnma. Analogues in the $\mathrm{Pb}_{1-3 x} \mathrm{La}_{2 x} \mathrm{TiO}_{3}$ system were refined in either $P 4 m m(x<0.15)$ or $P m \overline{3} m(x=0.15)$. The $\mathrm{Pb}_{1-3 x} \mathrm{La}_{2 x}\left(\mathrm{Zr}_{0.6} \mathrm{Ti}_{0.4}\right) \mathrm{O}_{3}$ compositions were refined in $R 3 c(0 \leq x \leq 0.025), P 4 m m(0.03 \leq x \leq 0.05)$, or $P m \overline{3} m$ $(0.06 \leq x \leq 0.1)$. The system $\operatorname{Sr}_{1-3 x} \mathrm{La}_{2 x}\left(\mathrm{Mg}_{1 / 3} \mathrm{Nb}_{2 / 3}\right) \mathrm{O}_{3}$ was refined in space group $P \overline{3} m 1$, whilst $(\mathrm{Na}, \mathrm{K})_{(1-3 x) / 2} \mathrm{La}_{(1+x) / 2}\left(\mathrm{Mg}_{1 / 2} \mathrm{~W}_{1 / 2}\right) \mathrm{O}_{3}$ was refined in $P 2_{1} / m$.

Calcined powders of $\mathrm{Ba}_{1-3 x} \mathrm{La}_{2 x} \mathrm{TiO}_{3}$ were pelletized as described elsewhere [11] and sintered at $1315^{\circ} \mathrm{C}$ in flowing oxygen for six hours. Pellets were then polished, thermally etched at $1250^{\circ} \mathrm{C}$ for 10 minutes, and finally coated with a thin conductive layer using a carbon evaporator (K950X, Quorum Technologies, Ashford, UK) in preparation for analysis via SEM (S-3400-II, Hitachi High Technology, USA).

Samples for transmission electron microscopy (TEM) were first pressed into cylindrical pellets as described elsewhere [11] and sintered in flowing oxygen at $1525^{\circ} \mathrm{C}$ for four hours. TEM specimens were then prepared by thinning pellets to electron transparency using conventional ceramographic techniques followed by ion thinning (Model 600, Gatan, Pleasanton, CA) to electron transparency for observation in the TEM (JEM-2100HR, JEOL, Tokyo, Japan).

\section{Theory, results, and discussion}

\subsection{Perovskites Generally}

In order to develop a workable model for the effect of A-site vacancies in perovskites, one must first start by assuming that $r_{\mathrm{B}}$ remains unaffected by A-site doping (a 
reasonable approximation), then the effective value of $r_{\mathrm{X}}$ can be calculated from a pseudocubic lattice constant (derived from refined real lattice constants) as:

$$
r_{\mathrm{X}}=\frac{a_{p c}}{2}-r_{\mathrm{B}}
$$

With this definition of $r_{\mathrm{X}}$, the effective $r_{\mathrm{A}}$ can now be calculated as:

$$
r_{\mathrm{A}}=\frac{a_{p c}}{\sqrt{2}}-r_{X}=\left(\frac{\sqrt{2}-1}{2}\right) a_{p c}+r_{\mathrm{B}}
$$

The ratio of $r_{\mathrm{X}}$ (from Eq. (8)) to $r_{\mathrm{X}(i d)}$ as well as the difference between this $r_{\mathrm{A}}$ (from Eq. (9)) and $r_{\mathrm{A}(i d)}$ can be quantified using the same data set used by Ubic, [9] as shown graphically in Fig. 1.

The equations which describe this behavior are:

$$
\begin{gathered}
\frac{r_{\mathrm{X}}}{r_{\mathrm{X}(i d)}}=0.43269+0.56393 t_{*} \quad\left(\mathrm{R}^{2}=0.80439\right) \\
r_{A}-r_{\mathrm{A}(i d)}=7.4801-12.3139 t_{*}+4.8257 t_{*}^{2} \quad\left(\mathrm{R}^{2}=0.97079\right)
\end{gathered}
$$


The values of $\mathrm{R}^{2}$ indicate the goodness of fit. As Fig. 2 and Eq. (12) show, the fit for $r_{\mathrm{X}} / r_{\mathrm{X}(i d)}$ can be improved significantly by using $t_{1}$ (Eq. (4)) rather than $t_{*}$ (Eq. (1)), but as $t_{1}$ requires a foreknowledge of $a_{p c}$, it cannot be used as an input for a predictive model.

The equation which describes this behavior is:

$$
\frac{r_{\mathrm{X}}}{r_{\mathrm{X}(i d)}}=0.42983+0.56696 t_{1} \quad\left(\mathrm{R}^{2}=0.99548\right)
$$

For compositions without stoichiometric vacancies, $t_{\mathrm{BV}} \sim t_{1}$, so it would be possible in theory to use bond-valence parameters instead of $t_{1}$ to refine $r_{\mathrm{X}}$ and ultimately $a_{p c}$ in the cases where bond-valence parameters are known. Unfortunately, using this method as a predictive model is complicated by the fact that, in the cases where bond-valence parameters are known, multiple $r_{0}$ values have been reported, making predications ambiguous at best. Where such predictions are possible for the data points shown in Figs. 1 and 2 , the average relative error is $>1 \%$ - not as good as that achieved with Eq. (2).

In the unique case for which $t_{*}=1, r_{\mathrm{A}}=r_{\mathrm{A}(i d)}$ so the difference $r_{\mathrm{A}}-r_{\mathrm{A}(i d)}=0$; and $r_{\mathrm{X}}=r_{\mathrm{X}(\mathrm{id})}$ so the ratio $r_{\mathrm{X}} / r_{\mathrm{X}(i d)}=1$. In the cases where $t *<1, \mathrm{~A}-\mathrm{X}$ bonds are stretched whilst B-X bonds are compressed, resulting in underestimations in $a_{p c}^{\prime}$ (Eq. (6)) but overestimations in $a_{p c}^{\prime \prime}$.(Eq. (7)). This effect can be interpreted for the purposes of this model as a large increase in $r_{\mathrm{A}}$ and a simultaneous smaller decrease in $r_{\mathrm{X}}$. Conversely, when $t *>1$, it is A-X bonds which are compressed and B-X bonds which are stretched, an effect interpreted in this model as an increase in $r_{\mathrm{X}}$ and a simultaneous larger decrease in $r_{\mathrm{A}}$ (Fig. 1).

Because of this stretching/compressing, it is not strictly possible to use only ideal values for effective ionic radii to calculate $a_{p c}$ in most perovskites; however, because 
Eq. (4) is explicitly a function of $a_{p c}, t_{1}$ accounts for the effective ionic size variation as well as the effects of any non-stoichiometry, which is why it is more accurate than Eq. (1) at predicting structure.

It is now possible to revise Eq. (3) to account for the general non-ideal nature of both the A site and anion size. In fact, as $a_{p c}$ is much more sensitive to the B-X bond length than to the A-X bond length, it is only necessary to combine Eqs. (7) and (10) to yield a model with an average relative error of $0.74 \%$ :

$$
a_{p c}^{\prime \prime}=2\left[r_{\mathrm{B}}+r_{\mathrm{X}(i d)}\left(0.43269+0.56393 t_{*}\right)\right] \quad\left(\mathrm{R}^{2}=0.99354\right)
$$

The results are shown in Fig. 3.

Eq. (13) can also be re-arranged as:

$$
t_{2}=\frac{a_{p c} / 2-r_{\mathrm{B}}}{0.56393 r_{\mathrm{X}(i d)}}-0.76728
$$

which yields results very similar to those of Eq. (4). Like $t_{1}$ (Eq. (4)), $t_{2}$ (Eq. (14)) is explicitly a function of $a_{p c}$ so accounts for both the effective ionic size variation (Fig. 1) as well as the effects of any non-stoichiometry; however, also like Eq. (4), it requires the foreknowledge of $a_{p c}$ and so cannot be used in a predictive model.

3.2 Application to $\mathrm{A}_{1-3 x}^{2+} \mathrm{A}_{2 x}^{3+} \mathrm{B}^{4+} \mathrm{X}_{3}^{2-}$ Perovskites

All of the compositions processed were verified to be single-phase via x-ray diffraction. The results of Le Bail refinements of all the compositions produced in this 
work are shown in Tables 1 - 6 supplemented with additional data from open literature. In all cases involving non-cubic crystal systems, pseudocubic lattice constants were calculated as:

$$
a_{p c(\text { expl })}=\left(\frac{V}{Z}\right)^{1 / 3}
$$

where $V$ is the unit cell volume and $Z$ is the number of $\mathrm{ABX}_{3}$ formula units per unit cell.

In agreement with previous work on $\mathrm{Sr}_{1-3 x} \mathrm{Ce}_{2 x} \mathrm{TiO}_{3}$, [19] superlattice reflections consistent with an $a^{-} a^{-} a^{-}$tilt system in $R \overline{3} c$ were observed here for $\mathrm{Sr}_{1-3 x} \mathrm{Nd}_{2 x} \mathrm{TiO}_{3}$ (Fig. 4), and using the curve derived elsewhere, [10] the tilt angle about the pseudocubic [111] can be estimated at just $0.2^{\circ}$ for $x=0.01$, reaching $2.6^{\circ}$ by $x=0.2$.

As with all systems studied, doped $\mathrm{BaTiO}_{3}$ compositions were formulated assuming compensation by A-site vacancies according to the stoichiometry $\mathrm{Ba}_{1-3 \mathrm{x}} \mathrm{La}_{2 \mathrm{x}} \mathrm{TiO}_{3}$, and no secondary phases were observed (Fig. 5). If compensation had been via either $\mathrm{Ti}$ reduction or $\mathrm{Ti}$ vacancies, $\mathrm{La}^{3+}$ doping would have left an appreciable amount of unreacted $\mathrm{TiO}_{2}$ secondary phase according to:

$$
\mathrm{Ba}_{1-3 x} \mathrm{La}_{2 x} \mathrm{TiO}_{3} \rightarrow(1-x)\left[\left(\mathrm{Ba}_{\frac{1-3 x}{1-x}} \mathrm{La} \frac{2 x}{1-x}\right)\left(\mathrm{Ti}_{\frac{1-3 x}{1-x}}^{4+} \mathrm{Ti}_{\frac{2 x}{1-x}}^{3+}\right) \mathrm{O}_{3}\right]+x \mathrm{TiO}_{2}
$$

or

$$
\mathrm{Ba}_{1-3 x} \mathrm{La}_{2 x} \mathrm{TiO}_{3} \rightarrow(1-x)\left[\left(\mathrm{Ba}_{\frac{1-3 x}{1-x}} \mathrm{La} \frac{2 x}{1-x}\right) \mathrm{Ti}_{\frac{3-\frac{1}{1-x}}{2}} \mathrm{O}_{3}\right]+\frac{3 x}{2} \mathrm{TiO}_{2}
$$

At $x=0.04$ these reactions would yield $2-3$ vol $\% \mathrm{TiO}_{2}$, a quantity easily detectable via XRD especially given the likely intensity of the $\mathrm{TiO}_{2}(110)$ peak and the very large $\mathrm{x}$ - 
ray flux achieved in the Miniflex. Similarly, if the $\mathrm{Ba}_{6-3 y} \mathrm{La}_{8+2 y} \mathrm{Ti}_{18} \mathrm{O}_{54}$ solid-solution phase had formed (e.g., $\left.\mathrm{BaLa}_{2} \mathrm{Ti}_{4} \mathrm{O}_{12}\right)$, it would also result in a multiphase microstructure according to either:

$$
\mathrm{Ba}_{1-3 x} \mathrm{La}_{2 x} \mathrm{TiO}_{3} \rightarrow x\left(\mathrm{BaLa}_{2} \mathrm{Ti}_{4} \mathrm{O}_{12}\right)+(1-4 x) \mathrm{BaTiO}_{3}
$$

where $x \leq 0.25$, or, assuming that the perovskite phase would be Ti-deficient $\left(e . g ., \mathrm{Ba}_{0.95} \mathrm{La}_{0.05} \mathrm{Ti}_{0.9875} \mathrm{O}_{3}\right)$ :

$$
\begin{gathered}
\mathrm{Ba}_{1-3 x} \mathrm{La}_{2 x} \mathrm{TiO}_{3} \rightarrow \frac{12.3 x-0.3}{11.1}\left(\mathrm{BaLa}_{2} \mathrm{Ti}_{4} \mathrm{O}_{12}\right)+\frac{2-8 x}{1.85}\left(\mathrm{Ba}_{0.95} \mathrm{La}_{0.05}\right) \mathrm{Ti}_{0.9875} \mathrm{O}_{3} \\
+(0.04053-0.1621 x) \mathrm{TiO}_{2}
\end{gathered}
$$

where $0.02439 \leq x \leq 0.25$. In the former scenario, all of the $\mathrm{La}^{3+}$ is accommodated in the ternary phase; therefore, no change in lattice constants would have been detectable in the perovskite phase. In the latter scenario, the $\mathrm{La}^{3+}$ dopant is assumed to cause Ti vacancies in the perovskite but simultaneously requires the presence of both the $\mathrm{Ba}_{1-3 y} \mathrm{La}_{2 y} \mathrm{Ti}_{18} \mathrm{O}_{54}$ phase and excess $\mathrm{TiO}_{2}$. Experimental results to the contrary showing the absence of both $\mathrm{Ba}_{6-3 y} \mathrm{La}_{8+2 \mathrm{y}} \mathrm{Ti}_{18} \mathrm{O}_{54}$ and $\mathrm{TiO}_{2}(\mathrm{Fig} 5)$ as well as the perovskite lattice constants changing with $x$ (Table 4) verify that a small amount of $\mathrm{La}_{2} \mathrm{O}_{3}$ solubility in $\mathrm{BaTiO}_{3}$ is possible without causing Ti reduction or vacancy formation on calcining in air. It is suggested that, while the large size of $\mathrm{Ba}^{2+}$ (and consequently $\mathrm{Ba}^{2+}$ vacancies) energetically inhibits the formation/stabilization of these vacancies, it is still possible to engineer them into the structure extrinsically such that their concentration slightly exceeds that which would be thermodynamically expected intrinsically. 
In order to apply either Eq. (6) or Eq. (7) to perovskites of the form $\mathrm{A}_{1-3 x}^{2+} \mathrm{A}_{2 x}^{3+} \mathrm{B}^{4+} \mathrm{X}_{3}^{2-}$ which contain stoichiometric extrinsic vacancy concentrations, it is still necessary to first assume that $r_{\mathrm{B}}$ remains identical to the Shannon radius and then to determine appropriate values for $r_{\mathrm{A}}$ and $r_{\mathrm{X}}$, neither of which will retain their ideal values. [11] In the case of $r_{\mathrm{A}}$, the effective size contains four distinct components: the ideal (Shannon) size of the A-site cation(s), the bond deformation caused when $t \neq 1$, partial covalency, and the effective size of A-site vacancies. The bond deformation (i.e., stretching/compression) and covalency effect can be calculated as a single parameter from Eq. (11); however, the effective size of vacancies requires additional data.

In Fig. 6, $r_{\mathrm{A}}-r_{\mathrm{A}(i d)}$ represents the sum of bond deformation, covalency, and effective vacancy size. In all cases data for $\mathrm{La}_{2} / 3 \mathrm{TiO}_{3}$ and all of the $x=0$ compositions were obtained from the open literature. $[22,14,25,41,43]$ The result is clearly linear for each system, and each line can be generally defined in terms of $t_{0}$ (the tolerance factor for that system corresponding to $x=0$, calculated via Eq. (1)):

$$
r_{\mathrm{A}}-r_{\mathrm{A}(i d)}=\left(2.4866-8.8433 t_{0}+7.8922 t_{0}^{2}\right) x-10.249+22.492 t_{0}-12.223 t_{0}^{2}
$$

It should be noted here that, while a single parameter can conveniently capture both covalency and bond deformation, covalency alone cannot explain the trends observed in Fig. 6. According to Pauling's formula [44] and electronegativity values as revised by Allred, [45] the percent covalency of A-O bonds in $\mathrm{CaTiO}_{3}, \mathrm{SrTiO}_{3}, \mathrm{PbTiO}_{3}$, and $\mathrm{BaTiO}_{3}$ is $23 \%, 21 \%, 73 \%$, and $20 \%$, respectively - clearly inconsistent with the trend illustrated in Fig. 6. 
It is also interesting to note that data points corresponding to different trivalent dopants fall on the same line in each system, suggesting that $r_{\mathrm{A}}-r_{\mathrm{A}(i d)}$ is independent of dopant species; therefore, it is not necessary to normalize by $r_{\mathrm{A}(i d)}$ as was done in previous work. [11] It is also possible to define these linear trends by using Eq. (11) to define their intercepts (which correspond to the combined effect of bond deformation and covelency) and the common data point at $x=1 / 3$ (which corresponds to the composition $\mathrm{La}_{2} / 3 \mathrm{TiO}_{3}$ ), in which case the following expression is obtained:

$$
r_{\mathrm{A}}-r_{\mathrm{A}(i d)}=\left(-20.8983+36.9417 t_{0}-14.477 \mathrm{t}_{0}^{2}\right) x+\left(7.4801-12.3139_{0}+4.8257 t_{0}^{2}\right)
$$

The first term on the right-hand side of Eq. (17) corresponds to the vacancy-size effect whilst the second term is recognizable from Eq. (11) as the bond deformation/covalency component. The coefficient of $x$ is the effective vacancy size, $r_{\mathrm{V}}$, which can be written as:

$$
r_{V}=-20.8796+36.9049 t_{0}-14.4590 t_{0}^{2}
$$

and illustrated in Fig. 7.

In most cases studied here, $r_{\mathrm{V}}>r_{\mathrm{A}^{2+}}$. The exceptions include $\mathrm{CaTiO}_{3}$, in which case $r_{\mathrm{A}^{2+}} \sim r_{\mathrm{V}}$, and $\operatorname{Sr}\left(\mathrm{Mg}_{1 / 3} \mathrm{Nb}_{2 / 3}\right) \mathrm{O}_{3}$, in which $r_{\mathrm{V}}$ is slightly smaller than $r_{A^{2+}}$. Eq. (18) uniquely defines $r_{\mathrm{V}}$ for any $\mathrm{A}_{1-3 x}^{2+} \mathrm{Ln}_{2 x}^{3+} \mathrm{BO}_{3}$ perovskite, including complex perovskites.

As shown by Eqs. (11) and (18), both the bond deformation/covalency and vacancy size for a given system are approximated as functions of $t_{0}$ only and do not vary with $x$ in this model. A comparison of $r_{\mathrm{A}(i d)}$ and $r_{\mathrm{V}}$ in the various systems $(\mathrm{A}=\mathrm{Ca}, \mathrm{Sr}, \mathrm{Pb}, \mathrm{Ba})$ is shown in Fig. 8a; and Fig. 8b shows the same effect but accounting for the bond 
deformation (BD). As can be seen, all curves in Fig. $\mathbf{8 b}$ tend towards convergence at $[\mathrm{V}]=0$ with a value of $\sim 1.4 \AA$, which corresponds well with the ideal size of $\mathrm{Sr}^{2+}$ in this coordination (1.44 $\AA$ ). [8] $\mathrm{As}^{\mathrm{SrTiO}} 3$ has a tolerance factor extremely close to unity $\left(t_{*}=1.0091\right)$, it seems clear that the effect of bond deformation in undoped samples is to bring the effective tolerance factors as close to unity as possible.

As Fig. $8 \mathrm{~b}$ demonstrates, in the case of $\left(\mathrm{Ca}_{1-3 x} \mathrm{Ln}_{2 x}\right) \mathrm{TiO}_{3}$, the stretching of $\mathrm{A}-\mathrm{X}$ bonds means that A-site vacancies allow a very slight pull on coordinating anions for $x \leq 0.05$, as can be demonstrated by their effective size (1.3396 $\AA$ ) being not only slightly smaller than the Shannon effective ionic radius of $\mathrm{Ca}^{2+}(1.34 \AA)$ but also smaller than the effective radius of $\mathrm{Ca}^{2+}$ including bond deformation/covalency effects $(1.3971 \AA$ in $\left.\mathrm{CaTiO}_{3}\right)$. On the other hand, the A-X bonds in $\left(\mathrm{A}_{1-3 x} \mathrm{La}_{2 x}\right) \mathrm{TiO}_{3}(\mathrm{~A}=\mathrm{Sr}, \mathrm{Pb}, \mathrm{Ba})$ are rather compressed, resulting in A-site vacancies which always push against coordinating anions, as demonstrated by their effective size (1.6379 $\mathrm{A}, 1.7729 \AA$ A, $2.0581 \AA$, respectively) being larger than either Shannon effective ionic radii (1.44 $\AA$, $1.49 \AA, 1.61 \AA$, respectively) or effective radii of $\mathrm{A}^{2+}$ ions including bond deformation/covalency effects (1.408 $\AA, 1.4130$ $\AA$, $1.4380 \AA$, respectively). The larger the $r_{\mathrm{A}^{2+}}$ the larger the push.

The effective size of $r_{\mathrm{A}}$ is now the sum of the three terms:

$$
r_{\mathrm{A}}=r_{\mathrm{A}(i d)}+\left(7.4801-12.3139_{0}+4.8257 t_{0}^{2}\right)-\left(20.8983-36.9417 t_{0}+14.477 \mathrm{t}_{0}^{2}\right) x
$$

In order to calculate the appropriate values of $r_{X}$ to use in Eqs. (6) and (7) for defective perovskites, Eq. (10) can be used; however, it then becomes necessary to define an appropriate expression for $t$. Using $t *$ for defective perovskites results in large errors. As it 
happens, using either $t_{1}$ (Eq. (4)) or $t_{2}$ (Eq. (14)) works very well because both incorporate the effects of bond deformation/covalency and vacancies, but both also require preknowledge of $a_{p c}$. What is required is a way to relate $t_{1}$ (or $t_{2}$ ) to $t_{*}$. Such a relationship can be defined as shown in Fig. 9.

Each curve in Fig. 9 can be described as a quadratic equation of the form

$$
t_{1}=A+B t_{*}+C t_{*}^{2}
$$

The coefficients $A, B$, and $C$ can be defined in terms of $r_{\mathrm{A}(i d)}$ for the $x=0$ compositions $\left(r_{\mathrm{A}(i d) 0}\right)$, as shown in Fig. 10. The equations which describe these curves are:

$$
\begin{gathered}
A=-50.978+84.274 r_{A(i d) 0}-32.411 r_{A(i d) 0}^{2} \\
B=130.35-205.44 r_{A(i d) 0}+77.539 r_{A(i d) 0}^{2} \\
C=-81.294+124.73 r_{A(i d) 0}-46.185 r_{A(i d) 0}^{2}
\end{gathered}
$$

According to Eq. (18), when $t_{0}=1, r_{\mathrm{V}}=1.5663 \AA$; and $r_{\mathrm{V}}=0$ only if $t_{0}=0.8465$ (or unrealistically 1.7059). As oxide perovskites with $t_{0}<\sim 0.85$ have only rarely, if ever, been reported, the value of $t_{0}=0.8465$ may represent the theoretical lower limit for their stability. Compounds with lower values of $t_{0}$ would presumably crystallize in the ilmenite system. It is noteworthy again that $t_{*}$ is a less reliable indicator of structure than is $t_{1}$, as the case of geikielite $\left(\mathrm{MgTiO}_{3}\right)$ demonstrates. Geikielite takes the ilmenite structure, [46] but using Shannon ionic radii data, including an extrapolation for the twelvefold radius of $\mathrm{Mg}^{2+}$ 
$(\sim 1.23 \AA)$, the $t *$ for this compound would be 0.9341 - well within the tilted perovskite range. Solving equations (1), (9), and (11) simultaneously, a similar value (1.17 $⿱$ Å) can be derived, corresponding to $t * \mathbf{0 . 9 1 1 5}$, again within the tilted perovskite range. Interestingly, using Eqs. (4), (6), and (12), and the unit cell reported by Dobson and Jacobsen [15] for $\mathrm{MgSiO}_{3}$ (the equations are not valid for the ilmenite structure of $\mathrm{MgTiO}_{3}$ ), a more realistic ionic radius for $\mathrm{Mg}^{2+}$ in twelvefold coordination can be derived

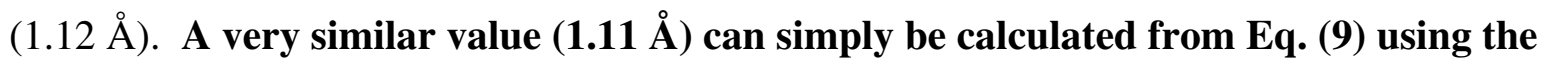
$\mathrm{MgTiO}_{3}$ unit cell reported by Wechsler and von Dreele [46]. Using either of these values, $t^{*}=0.8934$ for $\mathrm{MgTiO}_{3}$, still corresponding to a tilted perovskite. Meanwhile, the $t_{1}$ value (Eq. (4)) of $\mathrm{MgTiO}_{3}$ based on the model of Wechsler and von Dreele [46] is just 0.8673 , better explaining its ilmenite structure.

With Eqs. $(21-23)$ the correct $t_{1}$ vs $t_{*}$ curve can be calculated and appropriate values of $t_{1}$ inserted into Eq. (10) in order to calculate the effective anion size, which can in-turn be used in Eqs. (5), (6), and/or (7) to calculate $a_{p c}$ values. For example, Fig. 11 illustrates the results when Eq. (5) is used to calculate $a_{p c}$ for $\mathrm{A}_{1-3 x} \operatorname{Ln}_{2 x} \mathrm{TiO}_{3}(\mathrm{~A}=\mathrm{Ca}, \mathrm{Sr}, \mathrm{Pb}$, Ba) and PLZT. Values of BD (Eq. (11)), which includes covalency effects, for $\mathrm{A}_{1-3 x} \mathrm{Ln}_{2 x} \mathrm{TiO}_{3}(\mathrm{~A}=\mathrm{Ca}, \mathrm{Sr}, \mathrm{Pb}, \mathrm{Ba})$ and PLZT are $0.0675 \AA$, $-0.0320 \AA,-0.0770 \AA$, and $0.17203 \AA$, and $0.0135 \AA$, respectively. Positive values signify A-X stretching while negative values signify A-X compression. The corresponding values of $r_{\mathrm{V}}$ (Eq. (18)) are $1.3396 \AA, 1.6379 \AA, 1.7729 \AA, 2.0581 \AA$, and $1.5014 \AA$, respectively. The average relative errors in $a_{p c}$ for each series are all $<0.59 \%$ despite the fact that the PLZT end member is not $\mathrm{La}_{2} / \mathrm{TiO}_{3}$ and so Eqs. (17)-(23) are not exactly applicable. 


\subsection{Second-Order Jahn Teller Distortions}

These results seem very straightforward, and Eq. (5) seems adequate in all cases to calculate pseudocubic lattice constants. As Tables 7 - 9 show, for the $\mathrm{A}_{1-3 x} \mathrm{Ln}_{2 x} \mathrm{TiO}_{3}$ $(\mathrm{A}=\mathrm{Ca}, \mathrm{Sr}, \mathrm{Ba})$ cases, there is little to gain by invoking either Eq. (6) for $a_{p c}^{\prime}$ or Eq. (7) for $a_{p c}^{\prime \prime}$; however, in other cases the ability to calculate lattice constants as either a function of A-X bond length ( $a_{p c}^{\prime}$, Eq. (6)) or B-X bond length $\left(a_{p c}^{\prime \prime}\right.$, Eq. (7)) independently can yield further structural information.

Table 10 shows the results of Eqs. (5) - (7) in the $\mathrm{Pb}_{1-3 x} \mathrm{La}_{2 x} \mathrm{TiO}_{3}$ system. The absolute relative errors in both $a_{p c}^{\prime}$ and $a_{p c}^{\prime \prime}$ are both very low, but while the errors in $a_{p c}^{\prime \prime}$ are all positive, like those in $a_{p c}$, those in $a_{p c}^{\prime}$ are almost all negative. As this anomaly occurs only in $a_{p c}^{\prime}$, the discrepancy is likely due to an underestimation of $r_{\mathrm{A}}$ rather than $r_{\mathrm{O}}$ or $r_{\mathrm{B}}$ The calculated values of $r_{\mathrm{A}}$ include components from $r_{\mathrm{A}(i d) \text {, bond }}$ deformation/covalency, and vacancies. As the last two terms are functions of $t_{*}$, all three terms are clearly affected by the value of $r_{\mathrm{Pb}_{(i d)}^{2+}}$. An antiferrodistortive instability is unlikely to be the cause of the discrepancy, as it would give rise to octahedral tilting which is forbidden in the $P 4 m m$ form of bulk $\mathrm{PbTiO}_{3}$ and which is vanishingly weak in the $R 3 \mathrm{c}$ form of $\mathrm{Pb}\left(\mathrm{Zr}_{0.6} \mathrm{Ti}_{0.4}\right) \mathrm{O}_{3}$. In any event, such tilting is present in most of the examples in Tables 7 - 9 and does not cause anomalies in lattice-constant errors. On the other hand, the ferroelectric distortion in $\mathrm{PbTiO}_{3}$ is much stronger than in, for example, $\mathrm{BaTiO}_{3}$. In $\mathrm{BaTiO}_{3}$, the stretching of octahedra caused by the large size of $\mathrm{Ba}^{2+}$ stabilizes the secondorder Jahn-Teller (SOJT) distortion of $\mathrm{Ti}^{4+}$ (due to its $d^{0}$ electronic configuration and 
octahedral coordination) resulting in a fairly small $(\sim 0.06 \AA)$ antiparallel $<001>$ displacement of the cations with respect to the $\mathrm{O}^{2-}$ sublattice; however, such ferroelectric displacements do not seem to affect the accuracy of the model or give rise to any anomalies in the errors. In $\mathrm{PbTiO}_{3}, \mathrm{~Pb}^{2+}$ also has a SOJT instability which turns its $6 s^{2}$ valence electrons into a stereoactive lone pair, distorting the ion and consequently the unit cell such that the net displacement of $\mathrm{Pb}^{2+}$ and $\mathrm{Ti}^{4+}$ with respect to the $\mathrm{O}^{2-}$ sublattice is $\sim 0.47 \AA$ and $\sim 0.35 \AA$, respectively. The larger distortion is observable in the fact that the tetragonality of $\mathrm{PbTiO}_{3}(c / a=1.0592)$ is larger than that of $\mathrm{BaTiO}_{3}(c / a=1.0046)$; however, as the ionic displacements do not seem to adversely affect $a_{p c}$ or $a_{p c}$ in either case, it is the distortion of the $\mathrm{Pb}^{2+}$ ion itself which may explain the negative errors observed in $a_{p c}^{\prime}$.

With Eq. (6) it is possible to semiquantify the distortion effect for various structures/ions. In the case of $\mathrm{Pb}_{1-3 x} \mathrm{La}_{2 x} \mathrm{TiO}_{3}$, an increase of $0.34 \%$ in the radius of $\mathrm{Pb}^{2+}$ $(\sim 0.0051 \AA)$ in $<110>$ directions $\left(r_{110}\right)$ combined with a simultaneous $0.34 \%$ decrease in the isotropic radius $\left(r_{\text {iso }}\right)$ of $\mathrm{Pb}^{2+}$ is sufficient to significantly improve the errors on $a_{p c}, a_{p c}^{\prime}$, and $a_{p c}^{\prime \prime}$, as shown in Table 11, with just over half of the errors in $a_{p c}^{\prime}$ remaining negative. A similar phenomenon can be observed for $\mathrm{Pb}_{1-3 x} \mathrm{La}_{2 x}\left(\mathrm{Zr}_{0.6} \mathrm{Ti}_{0.4}\right) \mathrm{O}_{3}$ in Table 12. In this case $\mathrm{BD}=0.0135 \AA$ and $r_{\mathrm{V}}=1.5014 \AA$. While the absolute relative errors in both $a_{p c}$ and $a_{p c}^{\prime \prime}$ are all positive, those in $a_{p c}^{\prime}$ are all negative. Whereas a symmetrical increase in $r_{\mathrm{A}}$ alone results in improvements in $a_{p c}^{\prime}$, it also significantly increases errors in both $a_{p c}$ and $a_{p c}^{\prime \prime}$ (>0.8\%); however, a $1.21 \%$ increase in $r_{110}(\sim 0.018 \AA)$ combined with a simultaneous 
$1.28 \%$ decrease in $r_{\text {iso }}$ is sufficient to significantly improve the errors on $a_{p c}, a_{p c}^{\prime}$, and $a_{p c}^{\prime \prime}$, as shown in Table 13, with fewer than half of the errors in $a_{p c}^{\prime}$ remaining negative.

The coordinations of $\mathrm{Pb}^{2+}$ ions in both $\mathrm{PbTiO}_{3}$ and $\mathrm{Pb}\left(\mathrm{Zr}_{0.6} \mathrm{Ti}_{0.4}\right) \mathrm{O}_{3}$ are essentially the same $(\mathrm{CN}=12)$, but their site symmetries are quite different. Whereas $\mathrm{Pb}^{2+}$ in $\mathrm{PbTiO}_{3}$ has $4 m m$ point symmetry at the $1 a$ position in space group $P 4 m m$, [24] in $\mathrm{Pb}\left(\mathrm{Zr}_{0.6} \mathrm{Ti}_{0.4}\right) \mathrm{O}_{3}$ it has point symmetry 3 , residing in the $6 a$ position of space group $R 3 c$; [27] therefore, it is likely that the difference in point symmetry contributes to the different SOJT distortions of $\mathrm{Pb}^{2+}$ in these two cases. The chemistry of the $\mathrm{B}$ site also probably plays a part, as both $\mathrm{Pb}_{1-3 x} \mathrm{La}_{2 x} \mathrm{TiO}_{3}$ and $\mathrm{Pb}_{1-3 x} \mathrm{La}_{2 x}\left(\mathrm{Zr}_{0.6} \mathrm{Ti}_{0.4}\right) \mathrm{O}_{3}$ share the same tetragonal or cubic structures for parts of their compositional ranges. While Eq. (6) cannot be used to predict this distortion, it can potentially be used to identify and even semiquantify it; and the effect is small enough not to result in large errors anyway, as Tables 10 and 12 demonstrate.

\subsection{Effect of B-Site Ordering}

This model depends on randomness both in the distribution of vacancies as well as cations. Any kind of chemical ordering (e.g., of vacancies on the A site or cations on the B site) will affect the effective size of the relevant site and so require a new parameter in the model. The effect of chemical ordering on the B-site can be inferred from differences in $a_{p c}^{\prime}$ and $a_{p c}^{\prime \prime}$ as well as large errors in $a_{p c}$. Table 14 shows the results for three sets of order double perovskites. In all cases, large positive errors in $a_{p c}^{\prime \prime}$ are indicative of an overestimation of $r_{\mathrm{B}}$, causing a consequent overestimation of $r_{\mathrm{O}}$ and hence $a_{p c}^{\prime \prime}$. It is well known that ordered structures pack more efficiently than disordered ones, so it follows that 
an ordered arrangement of cations on the B-site should result in an overall shrinkage which, in terms of this model, is translated into reduced ionic radii for these cations. In the case of $\left(\mathrm{Sr}_{1-3 x} \mathrm{La}_{2 x}\right)\left(\mathrm{Mg}_{13} \mathrm{Nb}_{\gamma_{3}}\right) \mathrm{O}_{3}\left(\mathrm{BD}=0.0521 \AA, r_{\mathrm{V}}=1.3858 \AA\right)$, simply using the weighted average of the size of B-site cations ( $0.6667 \AA$ ) for $r_{\mathrm{B}}$ results in an average errors of $0.92 \%$, $0.46 \%, 0.90 \%$ for $a_{p c}, a_{p c}^{\prime}$, and $a_{p c}^{\prime \prime}$, as shown in Table 14; however, by reducing the value of $r_{\mathrm{B}}$ by just $3.5 \%$ to $0.6432 \AA$, the average errors drop to just $0.15 \%, 0.58 \%$, and $0.15 \%$ for $a_{p c}, a_{p c}^{\prime}$, and $a_{p c}^{\prime \prime}$, respectively. The effective $r_{\mathrm{O}}$ values simultaneously increase slightly.

This $3.5 \%$ decrease in the effective $r_{\mathrm{B}}$ value is a measure of the ordering on the B site. Assuming this value corresponds to a fully ordered structure, smaller percent reductions would correspond to smaller degrees of order. This effect could theoretically be calibrated and quantified as an easy means of estimating cation order from lattice constants alone.

A similar analysis is possible in the $(\mathrm{Na}, \mathrm{K})_{(1-3 x) / 2} \mathrm{La}_{(1+x) / 2}\left(\mathrm{Mg}_{1 / 2} \mathrm{~W}_{1 / 2}\right) \mathrm{O}_{3}$ systems reported by Arillo et al. [36] Without accounting for $r_{\mathrm{B}}$ shrinkage average errors are quite large for both $\mathrm{Na}$ and $\mathrm{K}$ analogues, as shown in Table 14. By shrinking $r_{\mathrm{B}}$ by $4.6 \%$ (to $0.6295 \AA)$ in the case of $\mathrm{Na}_{(1-3 x) / 2} \mathrm{La}_{(1+x) / 2}\left(\mathrm{Mg}_{1 / 2} \mathrm{~W}_{1 / 2}\right) \mathrm{O}_{3}\left(\mathrm{BD}=0.1103 \AA, r_{\mathrm{V}}=1.2112 \AA\right)$ and $13.7 \%$ (to $0.5694 \AA$ ) in the case of $\mathrm{K}_{(1-3 x) / 2} \mathrm{La}_{(1+x) / 2}\left(\mathrm{Mg}_{1 / 2} \mathrm{~W}_{1 / 2}\right) \mathrm{O}_{3}(\mathrm{BD}=-0.0150 \AA$, $\mathrm{rV}=1.5871 \AA$ ), average errors are drastically reduced, as shown in Table 15. It is unclear why different amounts of shrinkage are required in these two analogous systems with the same B-site composition unless they are indeed ordered to different degrees, which seems unlikely given the size and charge differences involved. A potential complicating factor in these cases is that $\mathrm{Na}_{1 / 2} \mathrm{La}_{1 / 2}\left(\mathrm{Mg}_{1 / 2} \mathrm{~W}_{1 / 2}\right) \mathrm{O}_{3}$ is typically reported $[47,48]$ with cation ordering on both A and B sublattices. It is unclear how the effect of A-site order influences the model, but it may have the same shrinkage effects as B-site ordering. Because of the dependence 
of both $a_{p c}^{\prime}$ and $a_{p c}^{\prime \prime}$ on $r_{\mathrm{O}}$, which itself is a function of $t_{1}$ and so ultimately both $r_{\mathrm{A}(i d)}$ and $r_{\mathrm{B}}$, it is not possible to independently solve for the effects of order on both sublattices simultaneously. Although the model proposed can be used in this way to explain and even semiquantify B-site ordering, it cannot yet be used to predict the effect of such ordering on $a_{p c}$ or structure.

\subsection{Anomalies}

This same model can be used successfully to analyze the vacancy behavior of other systems previously reported in the literature as well. For example, Ruiz et al. [49] reported that the cell volume of $\mathrm{Na}_{(1-3 x) / 2} \mathrm{La}_{(1+x) / 2} \mathrm{TiO}_{3}$ (Table 16) seemed to increase slightly as the number of vacancies increased from $5.3 \%$ to $17.3 \%$ whilst the degree of tilt simultaneously decreased. Eq. (18) shows that in either case $r_{\mathrm{V}}=1.6379 \AA$, which is larger than either the weighted average of Shannon radii or the effective radius including bond distortion/covalency, suggesting that vacancies push against anions. The bond deformation (Eq. (11)) in this system is $-0.0320 \AA$. The unit-cell expansion was previously explained $[10,11]$ by an increased effective $r_{\mathrm{V}}$; however, it can now be understood more completely as an increase in $x r_{\mathrm{V}}$ (i.e., the contribution of vacancies to $\left.r_{\mathrm{A}}\right)$. With a constant $r_{\mathrm{V}}=$ $1.6379 \AA, x r_{\mathrm{V}}$ increases from $0.0868 \AA(x=0.053)$ to $0.2834(x=0.173)$. It was also previously reported $[10,11]$ that $\bar{r}_{\mathrm{O}}$ simultaneously decreased slightly; however, it can now be shown that $\bar{r}_{\mathrm{O}}$ actually increases slightly from $1.3348 \AA$ to $1.3446 \AA$, further contributing to the increase in lattice constant. The effective increase in $r_{\mathrm{A}}$ also explains why the tolerance factor $\left(t_{1}\right)$ is higher for $x=0.173\left(t_{1}=0.9800\right)$ than for $x=0.053\left(\mathrm{t}_{1}=\right.$ 0.9784), thus further explaining why the degree of tilt was seen to decrease with increasing 
vacancy concentration. Pseudocubic lattice constants calculated with this model are accurate to an average absolute relative error of $0.24 \%\left(a_{p c}\right)$ and $0.14 \%\left(a_{p c}{ }^{\prime \prime}\right)$.

What can also be seen in Table 16 are fairly large relative errors in $a_{p c}^{\prime}$ which are not only all negative but which decrease (i.e., become less negative) as $x$ increases. A large error in $a_{p c}^{\prime}$ without a correspondingly large error in $a_{p c}^{\prime \prime}$ might be attributable to an underestimation of $r_{\mathrm{A}}$, but the cause of such an underestimation is unclear. The effective $r_{\mathrm{A}}$ of $(\mathrm{Na}, \mathrm{K})_{(1-3 x) / 2} \mathrm{La}_{(1+x) / 2}\left(\mathrm{Mg}_{1 / 2} \mathrm{~W}_{1 / 2}\right) \mathrm{O}_{3}$ was calculated from Shannon data and used with accuracy in Table 15, so the difference in the case of $\mathrm{La}_{(1+x) / 2} \mathrm{Na}_{(1-3 x) / 2} \mathrm{TiO}_{3}$ presumably lies in a structural difference between these two systems rather than a purely chemical one.

Ordering is the natural hypothesis, especially given that the errors in $a_{p c}^{\prime}$ decrease (become less negative) as the stoichiometry moves away from the 1:1 ratio of La:Na, where the order would be expected to break down; however, that explanation requires a volume increase upon ordering, which does not agree with conventional wisdom. Nevertheless, by increasing the total $r_{\mathrm{A}}$ by $0.0498 \AA(\sim 3.6 \%)$ at $x=0$, a minimum in the absolute error occurs with the relative error just $-0.30 \%$. Smaller increases in $r_{\mathrm{A}}$ of $0.0494 \AA, 0.0207 \AA$, and $0.0002 \AA$ as $x$ increases to $0.0533,0.1733$, and 0.225 , respectively, are required to yield errors of $0.00 \%$. The physical explanation for these seemingly anomalous observations is still unclear.

\subsection{Crystal Chemistry of Vacancies}

It might be noted that the compound $\mathrm{La}_{2} / 3 \mathrm{TiO}_{3}$ appears in Tables $7-10$ but with slightly different values of $a_{p c}, a_{p c}^{\prime}$, and $a_{p c}^{\prime \prime}$. This compound corresponds to the end 
member $x=1 / 3$ so can be attributed to any $(\mathrm{Ca}, \mathrm{Sr}, \mathrm{Pb}, \mathrm{Ba})_{1-3 x} \mathrm{La}_{2 x} \mathrm{TiO}_{3}$ system, each with its own effective bond deformations and $r_{\mathrm{V}}$ values. All such compositional families converge here. As there is no divalent species in this unique case, it no longer makes sense to interpret bond deformation values as $\mathrm{A}^{2+}-\mathrm{O}$ bond deformation or covalency, as there is no $\mathrm{A}^{2+}$ present; and $r_{\mathrm{V}}$ values become notional.

For all $\mathrm{ATiO}_{3}(\mathrm{~A}=\mathrm{Ca}, \mathrm{Sr}, \mathrm{Pb}, \mathrm{Ba})$ perovskites, the effective vacancy size scales not only with A cation size but also with A cation bond valence sum (2.08, 2.11, 2.12, 2.74 for $\mathrm{A}=\mathrm{Ca}, \mathrm{Sr}, \mathrm{Pb}, \mathrm{Ba}$, respectively). Vacancies obviously decrease the bond valence of coordinating anions, so the push can help restore their bond valence sum (BV) by reducing the other bond lengths. These results are somewhat counterintuitive, as the difference in cationic sizes would mean that coordinating anions in $\mathrm{CaTiO}_{3}$ would be much closer to the A site than those in $\mathrm{BaTiO}_{3}$. As a consequence, A-site vacancies might be expected to push anions away in $\mathrm{CaTiO}_{3}$ due to Coloumbic repulsion $\left(r_{\mathrm{V}}>r_{\mathrm{A}}\right)$ but allow overbonded anions to relax towards the vacant site $\left(r_{\mathrm{V}}<r_{\mathrm{A}}\right)$ in $\mathrm{BaTiO}_{3}$. Instead, it seems that vacancies in $\mathrm{SrTiO}_{3}, \mathrm{PbTiO}_{3}$, and $\mathrm{BaTiO}_{3}$ push anions while vacancies in $\mathrm{CaTiO}_{3}(x \leq 0.05)$, $\mathrm{Pb}\left(\mathrm{Zr}_{0.6} \mathrm{Ti}_{0.4}\right) \mathrm{O}_{3}$, and $\mathrm{Sr}\left(\mathrm{Mg}_{1 / 3} \mathrm{Nb}_{2 / 3}\right) \mathrm{O}_{3}$ pull on them.

A more useful way of demonstrating the effect of vacancies on structure might be to

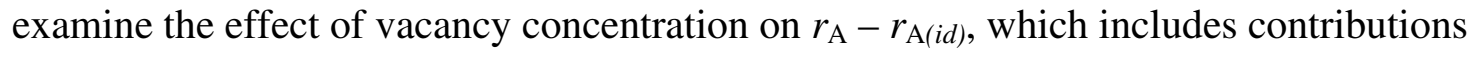
from bond deformation, covalency, and vacancies. It is convenient to artificially incorporate all of these contributions into a single virtual size parameter, $S$, such that:

$$
S=\frac{\left(r_{A}-r_{\mathrm{A}(i d)}\right)}{x}
$$


When $S$ is normalized by $r_{\mathrm{A}(i d)}$, the effect of vacancies on bond valence can be demonstrated (Fig. 12). In this case, all values above unity should represent cases where the effective A-site size is greater than the ideal A-site size (i.e., that derived from Shannon radii alone). Such compositions would correspond to underbonding of the A-site species, whereas values below unity would correspond to overbonding. This prediction is borne out in the cases of $\mathrm{A}_{1-3 x} \mathrm{Ln}_{2 x} \mathrm{TiO}_{3}(\mathrm{~A}=\mathrm{Sr}, \mathrm{Pb}, \mathrm{Ba})$. For example, based on published [19] Rietveld refinements of $\mathrm{Sr}_{1-3 x} \mathrm{Ce}_{2 x} \mathrm{TiO}_{3}$, the A site is slightly overbonded for $x=0.0833$ $\left(\mathrm{BV}=2.0118, \mathrm{~S} / r_{\mathrm{A}(\mathrm{id})}=0.9598\right)$ but underbonded for $x=0.125(\mathrm{BV}=1.9745$, $\left.\mathrm{S} / r_{\mathrm{A}(\mathrm{id})}=1.1146\right)$. Similarly, according to published structural data [42] the A site in $\mathrm{Pb}_{1-3 x} \mathrm{La}_{2 x} \mathrm{TiO}_{3}$ is overbonded at $x=0.125\left(\mathrm{BV}=2.0778, \mathrm{~S} / r_{\mathrm{A}(\mathrm{id})}=0.9103\right)$ but underbonded at $x=0.15\left(\mathrm{BV}=1.9836, \mathrm{~S} / r_{\mathrm{A}(\mathrm{id})}=1.0263\right)$. Insufficient structural data exists to make a definitive argument either way in the case of $\mathrm{Ba}_{1-3 x} \mathrm{Ln}_{2 x} \mathrm{TiO}_{3}$; however, published data $[22,43]$ do show for the end members that $\mathrm{Ba}^{2+}$ is overbonded in $\mathrm{BaTiO}_{3}(\mathrm{BV}=2.74)$ whilst $\mathrm{La}^{3+}$ is underbonded in $\mathrm{La}_{2 / 3} \mathrm{TiO}_{3}(\mathrm{BV}=2.6723)$. The case of $\mathrm{Ca}_{1-3 x} \mathrm{Ln}_{2 x} \mathrm{TiO}_{3}$ is different in that, according to published structural data, $[23,24]$ the $\mathrm{Ca}^{2+}$ in $\mathrm{CaTiO}_{3}$ is slightly overbonded $(\mathrm{BV}=2.08)$ despite having an $S / r_{\mathrm{A}(\mathrm{id})}$ ratio $>>1$. This apparent anomaly might be explained by octahedral tilting.

The octahedra in $\mathrm{CaTiO}_{3}$ are tilted both in-phase and anti-phase. [22,23] Using the average $\mathrm{Ca}-\mathrm{O}$ nearest-neighbor bond length, the bond valence sum for $\mathrm{Ca}$ would be 1.5446 , showing $\mathrm{Ca}^{2+}$ to be severely underbonded, in agreement with the prediction above; however, the effect of the tilts is to slightly lengthen four of the $\mathrm{Ca}-\mathrm{O}$ nearest-neighbor bonds but shorten the remaining eight such that the overall bond valence sum increases to the point that $\mathrm{Ca}^{2+}$ becomes slightly overbonded. 
In the case of $\mathrm{SrTiO}_{3}$, the cubic structure allows no tilting or distortion of octahedra; but antiphase tilting is triggered for $x$ values at least as low as 0.01 (Fig. 4), in which case some Sr-O bond lengths begin to lengthen until eventually $\mathrm{Sr}^{2+}$ becomes underbonded $(0.0833<x<0.125)$. In the cases of tetragonal $(P 4 m m) \mathrm{BaTiO}_{3}$ and $\mathrm{PbTiO}_{3}$, the single degree of freedom in each oxygen position allows only octahedral distortion, not tilting. The extent of that distortion is significant in $\mathrm{PbTiO}_{3}(\leq 0.5536 \AA)$ and $\mathrm{Pb}-\mathrm{O}$ bond lengths are such that $\mathrm{Pb}^{2+}$ is overbonded. As $x$ increases in $\left(\mathrm{Pb}_{1-3 x} \mathrm{La}_{2 x}\right) \mathrm{TiO}_{3}$, the $\mathrm{Pb}-\mathrm{O}$ bond lengths gradually increase (the degree of distortion decreases) until, at $x=0.15$, the structure becomes cubic and $\mathrm{Pb}^{2+}$ becomes slightly underbonded.

Although insufficient structural data exists for $\mathrm{Ba}_{1-3 x} \mathrm{Ln}_{2 x} \mathrm{TiO}_{3}$ to be sure, a similar phenomenon would probably be active in that system. The octahedral distortion in $\mathrm{BaTiO}_{3}$ is already extremely small $(<0.0643 \AA)$ and $\mathrm{Ba}^{2+}$ very overbonded $(\mathrm{BV}=2.74)$, so as $x$ increases $(0 \leq \mathrm{x} \leq \sim 0.2)$ that distortion would likely increase in order to reduce the BV.

The system $\mathrm{Pb}_{1-3 x} \mathrm{La}_{2 x}\left(\mathrm{Zr}_{0.6} \mathrm{Ti}_{0.4}\right) \mathrm{O}_{3}$ also seems to obey this trend. Its curve (not shown in Fig. 12) is similar to that for $\mathrm{Ca}_{1-3 x} \mathrm{Ln}_{2 x} \mathrm{TiO}_{3}$, which can be explained by the fact that, unlike in $\mathrm{PbTiO}_{3}$, the $\mathrm{Pb}$ in $\mathrm{Pb}\left(\mathrm{Zr}_{0.6} \mathrm{Ti}_{0.4}\right) \mathrm{O}_{3}$ is actually underbonded $(\mathrm{BV}=1.55)$.

It is interesting to note the apparent effect vacancies have on the effective size of oxygen ions. From Tables 7-14 it is apparent that vacancies increase the effective $r_{\mathrm{O}^{2-}}$ for small A-site cations including $\mathrm{Ca}^{2+}$ and $\mathrm{Sr}^{2+}(x \leq 0.15)$ but decrease $r_{\mathrm{O}^{2-}}$ in systems with larger A-site species including $\mathrm{Sr}^{2+}(x>0.15), \mathrm{Pb}^{2+}$, and $\mathrm{Ba}^{2+}$.

Using the Shannon radii data it is possible to define a composition for which $t^{*}=t_{0}=1$, as in $\left[\left(\mathrm{Ca}_{0.252} \mathrm{Sr}_{0.748}\right)_{1-3 x} \mathrm{La}_{2 x}\right] \mathrm{TiO}_{3}$. The results are shown in Table 17 and agree very well with the model. In this case BD is very small $(-0.0081 \AA)$. Ideally there should 
be no bond distortion/covalency component (i.e., the effects of both bond distortion and covalency exactly cancel out) so the difference between the weighted average of Shannon radii $(1.4148 \AA$ ) and the effective radius including bond distortion/covalency (1.4109 $\AA$ ) should be $\sim 0$, i.e., $r_{\mathrm{A}}-r_{\mathrm{A}}(\mathrm{id}) \sim 0$. The effective vacancy size $(1.5663 \AA)$ in this system is larger than either value, again indicating a push against coordinating anions. Although the model works well for even the extreme case of $x \leq 1 / 3$ in $\mathrm{Sr}_{1-3 x} \mathrm{La}_{2 x} \mathrm{TiO}_{3}$, in this system it begins to break down slightly at $x=0.3\left(\mathrm{Sr}_{0.0726} \mathrm{Ca}_{0.0274} \mathrm{La}_{0.6} \mathrm{TiO}_{3}\right)$, in which case $t_{1}$ would have to be $\sim 0.98$, which is below the minimum possible here given Eqs. (20) - (23). The model instead yields $t_{1}=1.020554$ and $a_{p c}, a_{p c}{ }^{\prime}$, and $a_{p c}$ " values with errors of $1.26 \%$, $1.25 \%$ and $1.27 \%$, respectively.

\section{Conclusions}

A predictive model for the pseudocubic lattice constant of $\mathrm{A}_{1-3 x} \mathrm{Ln}_{2 x} \mathrm{BX}_{3}$ perovskites, based solely on published ionic radii data, has been developed and applied with great accuracy to many such perovskite systems. Using this model it is also possible to calculate the effective size of anions and A-site cation vacancies as well as to semiquantify the effects of both B-site cation ordering and second-order Jahn Teller distortions. A lower limit for the tolerance factor of oxide perovskites is proposed $(t=0.8465)$.

\section{Acknowledgements}

This work has been supported by the National Science Foundation (DMR 1052788). The authors are grateful to G. Subodh and M.T. Sebastian, National Institute of Interdisciplinary 
Science \& Technology (NIIST), Trivandrum, India for providing the $\mathrm{Sr}_{1-3 x} \mathrm{Ce}_{2 x} \mathrm{TiO}_{3}$

samples and to Dr. Karthik Chinnathambi of the Boise State Center for Materials Characterization (BSCMC) for TEM analysis. . 


\section{References}

[1] M.I. Kotelyanski, I.M. Kotelyanski, V.B. Kravchenko, Tech. Phys. Lett. 26 (2000) 163.

[2] K. Eisenbeiser, R. Emrickm, R. Droopad, Z. Yu, J. Finder, S. Rockwell, J. Holmes, C. Overgaard, W. Ooms, IEEE Electron Dev. Lett. 23 (2002) 300.

[3]. Y. L. Li, S. Y. Hu, D. Tenne, A. Soukiassian, D. G. Schlom, L. Q. Chen, X. X. Xi, K. J. Choi, C. B. Eom, A. Saxena, T. Lookman, Q. X. Jia, Appl. Phys. Lett. 91 (2007) 3 .

[4]. A. Soukiassian, W. Tian, V. Vaithyanathan, J.H. Haeni, L.Q. Chen, X.X. Xi, D.G. Schlom, D.A. Tenne, H.P. Sun, X.Q. Pan, K.J. Choi, C.B. Eom, Y.L. Li, Q.X. Jia, C. Constantin, R.M. Feenstra, M. Bernhagen, P. Reiche, R. Uecker, J. Mater. Res. 23 (2008) 1417.

[5]. D.A. Tenne and X.X. Xi, Journal of the American Ceramic Society 91 (2008) 1820.

[6]. D.A. Tenne, H.N. Lee, R.S. Katiyar and X.X. Xi, Journal of Applied Physics 105 (5), 5 (2009).

[7]. J. Hlinka, V. Zelezny, S. M. Nakhmanson, A. Soukiassian, X. X. Xi and D. G. Schlom, Physical Review B 82 (22), 5 (2010).

[8] R.D. Shannon, Acta Crystallogr., Sect. A: Cryst. Phys., Diffr. Theor. Gen. Crystallogr. 32 (1976) 751.

[9] R. Ubic, J. Am. Ceram. Soc. 90 (2007) 3326.

[10] R. Ubic, G. Subodh, M.T. Sebastian, D. Gout, T. Proffen, Ceram. Trans. 204 (2009) 177.

[11] R. Ubic, K. Tolman, K. Chan, N. Lundy, S. Letourneau, W. Kriven, J. Alloys Compd. 575 (2013) 239.

[12] M.W. Lafaso, P.M. Woodward, Acta Crystallogr., Sect. B: Struct. Sci. 57 (2001) 725 .

[13] I.M. Reaney, E.L. Colla, N. Setter, Jpn. J. Appl. Phys., Part 133 (1994) 3984.

[14] H.F. Kay, P.C. Bailey, Acta Cryst. 10 (1957) 219.

[15] D.P. Dobson, S.D. Jacobsen, Am. Mineral. 89 (2004) 807. 
[16] R.C. Evans, An Introduction to Crystal Chemistry, $2^{\text {nd }}$ edition, p. 44-45, Cambridge University Press, 1964.

[17] C.J. Howard, G.R. Lumpkin, R.I. Smith, Z. Zhang, J. Solid State Chem. 177 (2004) 2726.

[18] P.D. Battle, J.E. Bennett, J. Sloan, R.J.D. Tilley, J.F. Vente, J. Solid State Chem. 149 (2000) 360.

[19] R. Ubic, G. Subodh, M.T. Sebastian, D. Gout, T. Proffen, Chem.Mater. 20 (2008) 3127.

[20] R. Ubic, G. Subodh, M.T. Sebastian, D. Gout, T. Proffen, Chem. Mater. 21 (2009) 4706.

[21] M. Abe, K. Uchino, Mater. Res. Bull. 9 (1974) 147.

[22] Z.S. Gönen, D. Paluchowski, P. Yu Zavalii, B.W. Eichhorn, J. Gopalakrishnan Inorg. Chem. 45 (2006) 8736.

[23] V. Vashook, L. Vasylechko, M. Knapp, H. Ullmann, U. Guth, J. Alloys Compd. 354 (2003) 13.

[24] Z.M. Zhang, G.R. Lumpkin, C.J. Howard, K.S. Knight, K.R. Whittle, K. Osaka, J. Solid State Chem. 180 (2007) 1083.

[25] J. Joseph, T.M. Vimala, V. Sivasubramanian, V.R.K. Murthy, J. Mater. Sci. 35 (2000) 1571.

[26] J. Chen, X. Xianran, Y. Ranbo, L. Guirong, W. Li, C.X. Long, J. Mater. Res. 19 (2004) 3614.

[27] A.M. Glazer, S.A. Mabud, Acta Crystallogr., Sect. B: Struct. Crystallogr. Cryst. Chem. 34 (1978) 1065.

[28] D.L. Corker, A.M. Glazer, R.W. Whatmore, A. Stallard, F. Fauth, J. Phys.: Condens. Matter 10 (1998) 6251.

[29] G. Shirane, K. Suzuki, J. Phys. Soc. Jpn. 7 (1952) 333.

[30] G.H. Haertling, C.E. Land, J. Am. Ceram. Soc. 54 (1971) 1.

[31] N. Wonderling, E. Breval, J.P. Dougherty, Powder Diffr. 17 (2002) 295.

[32] M.T. Buscaglia, V. Buscaglia, M. Viviani, P. Nanni, M. Hanuskova, J. Eur. Ceram. Soc. 20 (2000) 1997. 
[33] D. Makovec, Z. Samardžija, U. Delalut, D. Kolar, J. Am. Ceram. Soc. 78 (1995) 2193.

[34] M. Ganguly, S.K. Rout, T.P. Sinha, S.K. Sharma, H.Y. Park, C.W. Ahn, I.W. Kim, J. Alloys Compd. 579 (2013) 473.

[35] F. Galasso, J. Pyle. J. Phys. Chem. 67 (1963) 1561.

[36] M.A. Arillo, J. Gómez, M.L. López, C. Pico, M.L. Veigo, Solid State Ionics 95 (1997) 241.

[37] K.R. Tolman, R. Ubic, M. Papac, W.M. Kriven, S.J. McCormack, H. Kungl, J. Solid. StateChem. 225 (2015) 359.

[38] A.C. Larson, R.B. Von Dreel (2004) Los Alamos National Laboratory Report No. LAUR-86-748.

[39] B.H. Toby, J. Appl. Cryst. 34 (2001) 210.

[40] L.W. Finger, D.E. Cox, A.P. Jephcoat, J. Appl. Crystallogr. 27 (1994) 892.

[41] H.D. Megaw, Proc. Phys. Soc. (London) 58 (1946) 133.

[42] C. Jun, X. Xianran, Y. Ranbo, L. Guirong, W. Li, C.X. Long, J. Mater. Res. 19 (2004) 3614.

[43] H.E. Swanson, R.K. Fuyat, Natl. Bur. Stand. (U.S.), Circ. 5393 (1954) 45.

[44] L. Pauling, J. Am. Chem. Soc. 54 (1932) 3570.

[45] A.L. Allred, J. Inorg. Nucl. Chem. 17 (1961) 215.

[46] B.A. Wechsler, R.B. von Dreele, Acta Crystallogr., Sect. B: Struct. Sci. 45 (1989) 542.

[47] M.C. Knapp, P.M. Woodward, J. Solid State Chem. 179 (2006) 1076.

[48] S. Li, Q. Gao, J. Li, X. He, Q. Zhang, C. Li, Y. Shen, L. Gu, Y. Yao, Y. Wang, R. Yu, X. Duan, Y. Ikuhara, Mater. Express 2 (2012) 51.

[49] A.I. Ruiz, M.L. Lopez, C. Pico, M.L. Veiga, J. Solid State Chem. 163 (2002) 472.

[50] Y. Li, S. Qin, F. Seifert, J. Solid State Chem. 180 (2007) 824. 


\section{Fig. Captions}

Fig. 1. Non-ideality of the effective A- and X-site sizes calculated for the $\mathbf{1 3 2}$ compositions reported in Ref. [9].

Fig. 2. Non-ideality of the effective anion size as a function of $t_{1}$ (Eq. (4)) calculated for the 132 compositions reported in Ref. [9].

Fig. 3. Calculated values of $a_{p c}^{\prime \prime}$ (Eq. (13)) vs experimental values.

Fig. 4. Selected-area electron-diffraction pattern of $\mathrm{Sr}_{0.97} \mathrm{Nd}_{0.02} \mathrm{TiO}_{3}$ parallel to the pseudocubic [110] showing osuperlattice reflections consistent with an $a^{-a} a^{-}$tilt system in space group $R \overline{3} c$.

Fig. 5. X-ray diffraction traces of $\mathrm{Ba}_{1-3 x} \mathrm{La}_{2 x} \mathrm{TiO}_{3}(0.01 \leq x \leq 0.04)$ showing the absence of $\mathrm{TiO}_{2}$ (solid lines) and $\mathrm{BaLa}_{2} \mathrm{Ti}_{4} \mathrm{O}_{12}$. (dashed line). For simplicity, lines are only shown for some major $\mathrm{TiO}_{2} / \mathrm{BaLa}_{2} \mathrm{Ti}_{4} \mathrm{O}_{12}$ peaks. (b) Back-scattered electron image of the $x=0.04$ composition showing phase-purity.

Fig. 6. Divergence of effective A-site size from ideal.

Fig. 7. Effective vacancy size vs tolerance factor. Data includes $\left(\mathrm{A}_{1-3 x} \mathrm{Ln}_{2 x}\right) \mathrm{TiO}_{3}(\mathrm{~A}=\mathrm{Ca}$, $\mathrm{Sr}, \mathrm{Pb}, \mathrm{Ba}),\left(\mathrm{Pb}_{1-3 x} \mathrm{La}_{2 x}\right)\left(\mathrm{Zr}_{0.6} \mathrm{Ti}_{0.4}\right) \mathrm{O}_{3}$, and $\left(\mathrm{Sr}_{1-3 x} \mathrm{La}_{2 x}\right)\left(\mathrm{Mg}_{\frac{1}{3}} \mathrm{Nb}_{2 / 3}\right) \mathrm{O}_{3}$.

Fig. 8. (a) The effect of [V] on $r_{\mathrm{A}(i d)}$ with effective vacancy sizes overlaid. (b) The effect of [V] on $r_{\mathrm{A}(i d)}$ accounting for bond deformation (BD) with effective vacancy sizes overlaid. The convergence at $[\mathrm{V}]=0$ is at $\sim 1.4 \AA$, which corresponds well with the ideal size of $\mathrm{Sr}^{2+}$ and $t_{*} \sim 1$.

Fig. 9. Relationship between $t_{1}$ (Eq. (4)) and $t_{*}$ (Eq. (1)) in $\mathrm{A}_{1-3 x} \mathrm{La}_{2 x} \mathrm{TiO}_{3}(\mathrm{~A}=\mathrm{Ca}, \mathrm{Sr}, \mathrm{Pb}$, $\mathrm{Ba})$.

Fig. 10. Coefficients of the formula $t_{1}=A+B t_{*}+C t_{*}^{2}$. Data points on each curve correspond to (from left to right) $\mathrm{A}=\mathrm{Ca}, \mathrm{Sr}, \mathrm{Pb}$, and $\mathrm{Ba}$.

Fig. 11. Comparison of $a_{p c}$ calculated via Eq. (5) and experimental $a_{p c}$ values. The average relative errors for each series are all $<0.59 \%$. 
Fig. 12 The effect of vacancies on A-site bond valence in $\mathbf{A}_{1-3 x} \mathbf{L n}_{2 x} \mathbf{T i O}_{3}(\mathrm{~A}=\mathbf{C a}, \mathbf{S r}, \mathbf{P b}$, Ba; B = La, Ce, Nd, Y). 
Table $1 \mathrm{Ca}_{1-3 x} \mathrm{Nd}_{2 x} \mathrm{TiO}_{3}$ refinement results

\begin{tabular}{lllllll}
\hline Composition & SG & $\boldsymbol{a}(\AA)$ & $\boldsymbol{b}(\mathbf{\AA})$ & $\boldsymbol{c}(\AA)$ & $\mathbf{Z}$ & $\boldsymbol{a}_{\text {pc(exptl) }}(\mathbf{\AA})$ \\
\hline $\mathrm{CaTiO}_{3}{ }^{\dagger}$ & Pnma & 5.4425 & 7.6410 & 5.3805 & 4 & 3.8245 \\
\hline $\mathrm{Ca}_{0.97} \mathrm{La}_{0.02} \mathrm{TiO}_{3}$ & Pnma & 5.4447 & 7.6536 & 5.3911 & 4 & 3.8296 \\
\hline $\mathrm{Ca}_{0.94} \mathrm{La}_{0.04} \mathrm{TiO}_{3}$ & Pnma & 5.4434 & 7.6500 & 5.3891 & 4 & 3.8282 \\
\hline $\mathrm{Ca}_{0.91} \mathrm{La}_{0.06} \mathrm{TiO}_{3}$ & Pnma & 5.4454 & 7.6577 & 5.3960 & 4 & 3.8316 \\
\hline $\mathrm{Ca}_{0.7} \mathrm{La}_{0.2} \mathrm{TiO}_{3}$ & Pnma & 5.4454 & 7.6784 & 5.4242 & 4 & 3.8417 \\
\hline $\mathrm{Ca}_{0.55} \mathrm{La}_{0.3} \mathrm{TiO}_{3}$ & Pnma & 5.4462 & 7.6968 & 5.4449 & 4 & 3.8499 \\
\hline $\mathrm{Ca}_{0.4} \mathrm{La}_{0.4} \mathrm{TiO}_{3}$ & Pnma & 5.4887 & 7.7279 & 5.4666 & 4 & 3.8702 \\
\hline $\mathrm{La}_{23} \mathrm{TiO}_{3}{ }^{*}$ & I4/mmm & 3.8565 & 3.8565 & 24.645 & 6 & 3.9384 \\
\hline $\mathrm{Ca}_{0.97} \mathrm{Nd}_{0.02} \mathrm{TiO}_{3}$ & Pnma & 5.4469 & 7.6529 & 5.3899 & 4 & 3.8297 \\
\hline $\mathrm{Ca}_{0.94} \mathrm{Nd}_{0.04} \mathrm{TiO}_{3}$ & Pnma & 5.4459 & 7.6541 & 5.3908 & 4 & 3.8299 \\
\hline $\mathrm{Ca}_{0.91} \mathrm{Nd}_{0.06} \mathrm{TiO}_{3}$ & Pnma & 5.4459 & 7.6548 & 5.3937 & 4 & 3.8307 \\
\hline $\mathrm{Ca}_{0.85} \mathrm{Nd}_{0.1} \mathrm{TiO}_{3}$ & Pnma & 5.4510 & 7.6632 & 5.40145 & 4 & 3.8351 \\
\hline $\mathrm{Ca}_{0.97} \mathrm{Y}_{0.02} \mathrm{TiO}_{3}$ & Pnma & 5.4422 & 7.6421 & 5.3814 & 4 & 3.8248 \\
\hline $\mathrm{Ca}_{0.94} \mathrm{Y}_{0.04} \mathrm{TiO}_{3}$ & Pnma & 5.4466 & 7.6490 & 5.3859 & 4 & 3.8280 \\
\hline $\mathrm{Ca}_{0.85} \mathrm{Y}_{0.1} \mathrm{TiO}_{3}$ & Pnma & 5.4457 & 7.6381 & 5.3734 & 4 & 3.8230 \\
\hline$\dagger=[14]$ & & & & & &
\end{tabular}

Table $2 \mathrm{Sr}_{1-3 x} \mathrm{Ln}_{2 x} \mathrm{TiO}_{3}$ refinement results

\begin{tabular}{llllllll}
\hline Composition & $\mathbf{S G}$ & $\boldsymbol{a}(\mathbf{\AA})$ & $\boldsymbol{b}(\stackrel{\AA}{\mathbf{A}})$ & $\boldsymbol{c}(\mathbf{\AA})$ & $\boldsymbol{\beta}$ & $\mathbf{Z}$ & $\boldsymbol{a}_{\boldsymbol{p c}(\text { exptl })}(\mathbf{\AA})$ \\
\hline $\mathrm{SrTiO}_{3}{ }^{\dagger}$ & $P m \overline{3} m$ & 3.9050 & 3.9050 & 3.9050 & $90^{\circ}$ & 1 & 3.9050 \\
\hline $\mathrm{Sr}_{0.97} \mathrm{La}_{0.02} \mathrm{TiO}_{3}$ & $R \overline{3} c$ & 5.5255 & 5.5255 & 13.5388 & $90^{\circ}$ & 6 & 3.9075 \\
\hline $\mathrm{Sr}_{0.85} \mathrm{La}_{0.1} \mathrm{TiO}_{3}$ & $R \overline{3} c$ & 5.5201 & 5.5201 & 13.5248 & $90^{\circ}$ & 6 & 3.9036 \\
\hline $\mathrm{Sr}_{0.7} \mathrm{La}_{0.2} \mathrm{TiO}_{3}$ & $R \overline{3} c$ & 5.5124 & 5.5124 & 13.5085 & $90^{\circ}$ & 6 & 3.8984 \\
\hline $\mathrm{Sr}_{0.55} \mathrm{La}_{0.3} \mathrm{TiO}_{3}$ & $R \overline{3} c$ & 5.5078 & 5.5078 & 13.4886 & $90^{\circ}$ & 6 & 3.8943 \\
\hline $\mathrm{Sr}_{0.5} \mathrm{La}_{0.33} \mathrm{TiO}_{3}$ & $R \overline{3} c$ & 5.5062 & 5.5062 & 13.4834 & $90^{\circ}$ & 6 & 3.8931 \\
\hline $\mathrm{Sr}_{0.4} \mathrm{La}_{0.4} \mathrm{TiO}_{3}$ & $C 2 / c$ & 9.5340 & 5.5005 & 5.5007 & $125.26^{\circ}$ & 4 & 3.8905 \\
\hline $\mathrm{Sr}_{0.33} \mathrm{La}_{0.44} \mathrm{TiO}_{3}$ & $C 2 / c$ & 9.5261 & 5.4995 & 5.5036 & $125.29^{\circ}$ & 4 & 3.8894 \\
\hline $\mathrm{Sr}_{0.25} \mathrm{La}_{0.5} \mathrm{TiO}_{3}$ & $C 2 / c$ & 9.5214 & 5.4969 & 5.4993 & $125.28^{\circ}$ & 4 & 3.8872 \\
\hline $\mathrm{La}_{23} \mathrm{TiO}_{3}{ }^{*}$ & $I 4 / m m m$ & 3.8565 & 3.8565 & 24.645 & $90^{\circ}$ & 6 & 3.9384 \\
\hline $\mathrm{Sr}_{0.97} \mathrm{Nd}_{0.02} \mathrm{TiO}_{3}$ & $R \overline{3} c$ & 5.5247 & 5.5247 & 13.5340 & $90^{\circ}$ & 6 & 3.9067 \\
\hline $\mathrm{Sr}_{0.94} \mathrm{Nd}_{0.04} \mathrm{TiO}_{3}$ & $R \overline{3} c$ & 5.5202 & 5.5202 & 13.5218 & $90^{\circ}$ & 6 & 3.9034 \\
\hline $\mathrm{Sr}_{0.91} \mathrm{Nd}_{0.06} \mathrm{TiO}_{3}$ & $R \overline{3} c$ & 5.5196 & 5.5196 & 13.5192 & $90^{\circ}$ & 6 & 3.9028 \\
\hline $\mathrm{Sr}_{0.8} \mathrm{Ce}_{0.13} \mathrm{TiO}_{3}{ }^{*}$ & $R \overline{3} c$ & 5.5091 & 5.5091 & 13.5071 & $90^{\circ}$ & 6 & 3.8967 \\
\hline $\mathrm{Sr}_{0.75} \mathrm{Ce}_{0.17} \mathrm{TiO}_{3}{ }^{*}$ & $R \overline{3} c$ & 5.5062 & 5.5062 & 13.4989 & $90^{\circ}$ & 6 & 3.8946 \\
\hline $\mathrm{Sr}_{0.63} \mathrm{Ce}_{0.25} \mathrm{TiO}_{3}{ }^{*}$ & $R \overline{3} c$ & 5.5005 & 5.5005 & 13.4797 & $90^{\circ}$ & 6 & 3.8900 \\
\hline
\end{tabular}




\begin{tabular}{|c|c|c|c|c|c|c|c|}
\hline $\mathrm{Sr}_{0.4} \mathrm{Ce}_{0.4} \mathrm{TiO}_{3}{ }^{* *}$ & $C 2 / c$ & 9.5228 & 5.4869 & 5.4818 & $125.22^{\circ}$ & 4 & 3.8819 \\
\hline$\dagger=[41]$ & & & & & & & \\
\hline$\ddagger=[22]$ & & & & & & & \\
\hline$*=[19]$ & & & & & & & \\
\hline$* *=[20]$ & & & & & & & \\
\hline
\end{tabular}

Table $3 \mathrm{~Pb}_{1-3 x} \mathrm{La}_{2 x} \mathrm{TiO}_{3}$ refinement results

\begin{tabular}{|c|c|c|c|c|c|c|}
\hline Composition & SG & $a(\AA)$ & $b(\AA)$ & $c(\AA)$ & $\mathbf{Z}$ & $a_{p c(\exp t)}(\AA)$ \\
\hline $\mathrm{PbTiO}_{3}^{\dagger}$ & $P 4 m m$ & 3.9039 & 3.9039 & 4.1348 & 1 & 3.9794 \\
\hline $\mathrm{Pb}_{0.93} \mathrm{La}_{0.05} \mathrm{TiO}_{3}{ }^{*}$ & $P 4 m m$ & 3.9099 & 3.9099 & 4.0712 & 1 & 3.9629 \\
\hline $\mathrm{Pb}_{0.85} \mathrm{La}_{0.1} \mathrm{TiO}_{3}{ }^{*}$ & $P 4 m m$ & 3.9139 & 3.9139 & 4.0337 & 1 & 3.9534 \\
\hline $\mathrm{Pb}_{0.82} \mathrm{La}_{0.12} \mathrm{TiO}_{3}$ & $P 4 \mathrm{~mm}$ & 3.9174 & 3.9174 & 4.0194 & 1 & 3.9511 \\
\hline $\mathrm{Pb}_{0.78} \mathrm{La}_{0.15} \mathrm{TiO}_{3}{ }^{*}$ & $P 4 m m$ & 3.9207 & 3.9207 & 4.0007 & 1 & 3.9472 \\
\hline $\mathrm{Pb}_{0.7} \mathrm{La}_{0.2} \mathrm{TiO}_{3}{ }^{*}$ & $P 4 \mathrm{~mm}$ & 3.9185 & 3.9185 & 3.9647 & 1 & 3.9338 \\
\hline $\mathrm{Pb}_{0.63} \mathrm{La}_{0.25} \mathrm{TiO}_{3}^{*}$ & $P 4 m m$ & 3.9279 & 3.9279 & 3.947 & 1 & 3.9343 \\
\hline $\mathrm{Pb}_{0.55} \mathrm{La}_{0.3} \mathrm{TiO}_{3}{ }^{*}$ & $P m \overline{3} m$ & 3.9283 & 3.9283 & 3.9283 & 1 & 3.9283 \\
\hline $\mathrm{La}_{2 / 3} \mathrm{TiO}_{3}{ }^{\dagger}$ & $I 4 / \mathrm{mmm}$ & 3.8565 & 3.8565 & 24.645 & 6 & 3.9384 \\
\hline $\begin{array}{l}\dagger=[25] \\
+=[22] \\
*=[42]\end{array}$ & & & & & & \\
\hline
\end{tabular}

Table $4 \quad \mathrm{Ba}_{1-3 x} \mathrm{La}_{2 x} \mathrm{TiO}_{3}$ refinement results

\begin{tabular}{lllllll}
\hline Composition & SG & $\boldsymbol{a}(\AA)$ & $\boldsymbol{b}(\AA)$ & $\boldsymbol{c}(\AA)$ & $\mathbf{Z}$ & $\boldsymbol{a}_{\boldsymbol{p c}(\text { expt })}(\AA)$ \\
\hline $\mathrm{BaTiO}_{3}^{\dagger}$ & $P 4 m m$ & 3.994 & 3.994 & 4.038 & 1 & 4.0086 \\
\hline $\mathrm{Ba}_{0.97} \mathrm{La}_{0.02} \mathrm{TiO}_{3}$ & $P 4 m m$ & $\mathbf{3 . 9 9 9 3}$ & $\mathbf{3 . 9 9 9 3}$ & $\mathbf{4 . 0 2 7 6}$ & 1 & $\mathbf{4 . 0 0 8 7}$ \\
\hline $\mathrm{Ba}_{0.94} \mathrm{La}_{0.04} \mathrm{TiO}_{3}$ & $P 4 m m$ & $\mathbf{3 . 9 9 9 6}$ & $\mathbf{3 . 9 9 9 6}$ & $\mathbf{4 . 0 2 7 8}$ & 1 & $\mathbf{4 . 0 0 9 0}$ \\
\hline $\mathrm{Ba}_{0.91} \mathrm{La}_{0.06} \mathrm{TiO}_{3}$ & $P 4 m m$ & $\mathbf{3 . 9 9 9 5}$ & $\mathbf{3 . 9 9 9 5}$ & $\mathbf{3 . 9 9 9 6}$ & 1 & $\mathbf{3 . 9 9 9 5}$ \\
\hline $\mathrm{Ba}_{0.88} \mathrm{La}_{0.08} \mathrm{TiO}_{3}$ & $P 4 m m$ & $\mathbf{4 . 0 1 7 1}$ & $\mathbf{4 . 0 1 7 1}$ & $\mathbf{3 . 9 9 9 6}$ & 1 & $\mathbf{4 . 0 0 5 8}$ \\
\hline $\mathrm{La}_{2 / 3} \mathrm{TiO}_{3}^{\ddagger}$ & $I 4 / m m m$ & 3.8565 & 3.8565 & 24.645 & 6 & 3.9384 \\
\hline \hline
\end{tabular}

$\dagger=$ [43]

$\ddagger=[22]$

Table $5 \quad \mathrm{~Pb}_{1-3 x} \mathrm{La}_{2 x}\left(\mathrm{Zr}_{0.6} \mathrm{Ti}_{0.4}\right) \mathrm{O}_{3}$ refinement results

\begin{tabular}{lllllll}
\hline Composition & $\mathbf{S G}$ & $\boldsymbol{a}(\boldsymbol{\mathbf { A }})$ & $\boldsymbol{b}(\boldsymbol{\mathbf { A }})$ & $\boldsymbol{c}(\mathbf{\AA})$ & $\mathbf{Z}$ & $\boldsymbol{a}_{\text {pc(exptl) }}(\mathbf{\AA})$ \\
\hline $\mathrm{PbZr}_{0.6} \mathrm{Ti}_{0.4} \mathrm{O}_{3}$ & $R 3 c$ & 5.7587 & 5.7587 & 14.2390 & 6 & 4.0848 \\
\hline $\mathrm{Pb}_{0.997} \mathrm{La}_{0.002} \mathrm{Zr}_{0.6} \mathrm{Ti}_{0.4} \mathrm{O}_{3}$ & $R 3 c$ & 5.7533 & 5.7533 & 14.2298 & 6 & 4.0814 \\
\hline $\mathrm{Pb}_{0.9955} \mathrm{La}_{0.003} \mathrm{Zr}_{0.6} \mathrm{Ti}_{0.4} \mathrm{O}_{3}$ & $R 3 c$ & 5.7539 & 5.7539 & 14.2225 & 6 & 4.0809 \\
\hline $\mathrm{Pb}_{0.9925} \mathrm{La}_{0.005} \mathrm{Zr}_{0.6} \mathrm{Ti}_{0.4} \mathrm{O}_{3}$ & $R 3 c$ & 5.7525 & 5.7525 & 14.2224 & 6 & 4.0803 \\
\hline $\mathrm{Pb}_{0.9895} \mathrm{La}_{0.007} \mathrm{Zr}_{0.6} \mathrm{Ti}_{0.4} \mathrm{O}_{3}$ & $R 3 c$ & 5.7525 & 5.7525 & 14.2244 & 6 & 4.0805 \\
\hline $\mathrm{Pb}_{0.985} \mathrm{La}_{0.01} \mathrm{Zr}_{0.6} \mathrm{Ti}_{0.4} \mathrm{O}_{3}$ & $R 3 c$ & 5.7531 & 5.7531 & 14.2184 & 6 & 4.0802 \\
\hline $\mathrm{Pb}_{0.97} \mathrm{La}_{0.02} \mathrm{Zr}_{0.6} \mathrm{Ti}_{0.4} \mathrm{O}_{3}$ & $R 3 c$ & 5.7514 & 5.7514 & 14.2021 & 6 & 4.0778 \\
\hline $\mathrm{Pb}_{0.955} \mathrm{La}_{0.03} \mathrm{Zr}_{0.6} \mathrm{Ti}_{0.4} \mathrm{O}_{3}$ & $R 3 c$ & 5.7504 & 5.7504 & 14.1890 & 6 & 4.0761 \\
\hline $\mathrm{Pb}_{0.94} \mathrm{La}_{0.04} \mathrm{Zr}_{0.6} \mathrm{Ti}_{0.4} \mathrm{O}_{3}$ & $R 3 c$ & 5.7514 & 5.7514 & 14.1807 & 6 & 4.0758 \\
\hline $\mathrm{Pb}_{0.925} \mathrm{La}_{0.05} \mathrm{Zr}_{0.6} \mathrm{Ti}_{0.4} \mathrm{O}_{3}$ & $R 3 c$ & 5.7757 & 5.7757 & 14.0706 & 6 & 4.0766 \\
\hline
\end{tabular}




\begin{tabular}{lllllll}
\hline $\mathrm{Pb}_{0.91} \mathrm{La}_{0.06} \mathrm{Zr}_{0.6} \mathrm{Ti}_{0.4} \mathrm{O}_{3}$ & $P 4 m m$ & 4.0629 & 4.0629 & 4.0942 & 1 & 4.0733 \\
\hline $\mathrm{Pb}_{0.88} \mathrm{La}_{0.08} \mathrm{Zr}_{0.6} \mathrm{Ti}_{0.4} \mathrm{O}_{3}$ & $P 4 m m$ & 4.0594 & 4.0594 & 4.0943 & 1 & 4.0710 \\
\hline $\mathrm{Pb}_{0.85} \mathrm{La}_{0.1} \mathrm{Zr}_{0.6} \mathrm{Ti}_{0.4} \mathrm{O}_{3}$ & $P 4 m m$ & 4.0580 & 4.0580 & 4.0910 & 1 & 4.0689 \\
\hline $\mathrm{Pb}_{0.82} \mathrm{La}_{0.12} \mathrm{Zr}_{0.6} \mathrm{Ti}_{0.4} \mathrm{O}_{3}$ & $P m \overline{3} m$ & 4.0677 & 4.0677 & 4.0677 & 1 & 4.0677 \\
\hline $\mathrm{Pb}_{0.79} \mathrm{La}_{0.14} \mathrm{Zr}_{0.6} \mathrm{Ti}_{0.4} \mathrm{O}_{3}$ & $P m \overline{3} m$ & 4.0630 & 4.0630 & 4.0630 & 1 & 4.0630 \\
\hline $\mathrm{Pb}_{0.76} \mathrm{La}_{0.16} \mathrm{Zr}_{0.6} \mathrm{Ti}_{0.4} \mathrm{O}_{3}$ & $P m \overline{3} m$ & 4.0641 & 4.0641 & 4.0641 & 1 & 4.0641 \\
\hline $\mathrm{Pb}_{0.7} \mathrm{La}_{0.2} \mathrm{Zr}_{0.6} \mathrm{Ti}_{0.4} \mathrm{O}_{3}$ & $P m \overline{3} m$ & 4.0588 & 4.0588 & 4.0588 & 1 & 4.0588 \\
\hline
\end{tabular}

$\mathrm{a}=\overline{\text { Nominal compositions are shown. Compositions refined via wavelength-dispersive }}$ spectroscopy (WDS) are given in Ref. [37].

Table 6 Refinement results

\begin{tabular}{|c|c|c|c|c|c|c|c|}
\hline Composition & SG & $a(\AA)$ & $b(\AA)$ & $c(\AA)$ & $\beta$ & $\mathbf{Z}$ & $a_{p c(\text { exptl })}(\AA)$ \\
\hline $\mathrm{SrMg}_{0.3333} \mathrm{Nb}_{0.6667} \mathrm{O}_{3}^{\dagger}$ & $P \overline{3} m l$ & 5.66 & 5.66 & 6.98 & 90 & 3 & 4.0114 \\
\hline $\mathrm{Sr}_{0.97} \mathrm{La}_{0.02} \mathrm{Mg}_{0.3333} \mathrm{Nb}_{0.6667} \mathrm{O}_{3}$ & $P \overline{3} m 1$ & 5.6467 & 5.6467 & 6.9344 & 90 & 3 & 3.9964 \\
\hline $\mathrm{Na}_{0.5} \mathrm{La}_{0.5}\left(\mathrm{Mg}_{0.5} \mathrm{~W}_{0.5}\right) \mathrm{O}_{3}{ }^{*}$ & $P 2_{1} / m$ & 5.529 & 5.532 & 7.91 & 90.11 & 4 & 3.9254 \\
\hline $\mathrm{Na}_{0.3333} \mathrm{La}_{0.5556}\left(\mathrm{Mg}_{0.5} \mathrm{~W}_{0.5}\right) \mathrm{O}_{3}^{+}$ & $P 2_{1} / m$ & 5.539 & 5.535 & 7.912 & 90.08 & 4 & 3.9288 \\
\hline $\mathrm{Na}_{0.1667} \mathrm{La}_{0.6111}\left(\mathrm{Mg}_{0.5} \mathrm{~W}_{0.5}\right) \mathrm{O}_{3}$ & $P 2_{1} / m$ & 5.533 & 5.532 & 7.906 & 90.05 & 4 & 3.9257 \\
\hline $\mathrm{K}_{0.5} \mathrm{La}_{0.5}\left(\mathrm{Mg}_{0.5} \mathrm{~W}_{0.5}\right) \mathrm{O}_{3}^{\dagger}$ & $P 2_{1} / m$ & 5.57 & 5.571 & 7.962 & 90.02 & 4 & 3.9529 \\
\hline $\mathrm{K}_{0.3333} \mathrm{La}_{0.5556}\left(\mathrm{Mg}_{0.5} \mathrm{~W}_{0.5}\right) \mathrm{O}_{3}{ }^{\text {* }}$ & $P 2_{1} / m$ & 5.565 & 5.562 & 7.955 & 89.99 & 4 & 3.9484 \\
\hline $\mathrm{K}_{0.1667} \mathrm{La}_{0.6111}\left(\mathrm{Mg}_{0.5} \mathrm{~W}_{0.5}\right) \mathrm{O}_{3}^{*}$ & $P 2_{1} / m$ & 5.551 & 5.553 & 7.937 & 89.93 & 4 & 3.9400 \\
\hline
\end{tabular}

Table 7 Model values for $\mathrm{Ca}_{1-3 x} \mathrm{Ln}_{2 x} \mathrm{TiO}_{3}$

\begin{tabular}{|c|c|c|c|c|c|c|c|c|}
\hline Composition & $a_{p c(\text { expt })}(\AA)$ & $r_{0}(\AA)$ & $a_{p c}(\AA)$ & error & $a_{p c}{ }^{\prime}(\AA)$ & error & $a_{p c} "(\AA)$ & error \\
\hline $\mathrm{CaTiO}_{3}^{\dagger}$ & 3.8245 & 1.3110 & 3.8393 & $0.39 \%$ & 3.8444 & $0.52 \%$ & 3.8320 & $0.20 \%$ \\
\hline $\mathrm{Ca}_{0.97} \mathrm{La}_{0.02} \mathrm{TiO}_{3}$ & 3.8296 & 1.3112 & 3.8396 & $0.26 \%$ & 3.8453 & $0.41 \%$ & 3.8323 & $0.07 \%$ \\
\hline $\mathrm{Ca}_{0.94} \mathrm{La}_{0.04} \mathrm{TiO}_{3}$ & 3.8282 & 1.3115 & 3.8402 & $0.31 \%$ & 3.8462 & $0.47 \%$ & 3.8329 & $0.12 \%$ \\
\hline $\mathrm{Ca}_{0.91} \mathrm{La}_{0.06} \mathrm{TiO}_{3}$ & 3.8316 & 1.3118 & 3.8409 & $0.24 \%$ & 3.8474 & $0.41 \%$ & 3.8337 & $0.05 \%$ \\
\hline $\mathrm{Ca}_{0.7} \mathrm{La}_{0.2} \mathrm{TiO}_{3}$ & 3.8417 & 1.3173 & 3.8510 & $0.24 \%$ & 3.8590 & $0.45 \%$ & 3.8446 & $0.07 \%$ \\
\hline $\mathrm{Ca}_{0.55} \mathrm{La}_{0.3} \mathrm{TiO}_{3}$ & 3.8499 & 1.3241 & 3.8636 & $0.36 \%$ & 3.8715 & $0.56 \%$ & 3.8583 & $0.22 \%$ \\
\hline $\mathrm{Ca}_{0.4} \mathrm{La}_{0.4} \mathrm{TiO}_{3}$ & 3.8702 & 1.3334 & 3.8808 & $0.28 \%$ & 3.8874 & $0.45 \%$ & 3.8769 & $0.17 \%$ \\
\hline $\mathrm{La}_{2 / 3} \mathrm{TiO}_{3}{ }^{\dagger}$ & 3.9384 & 1.3702 & 3.9489 & $0.27 \%$ & 3.9469 & $0.22 \%$ & 3.9504 & $0.30 \%$ \\
\hline $\mathrm{Ca}_{0.97} \mathrm{Nd}_{0.02} \mathrm{TiO}_{3}$ & 3.8297 & 1.3112 & 3.8397 & $0.26 \%$ & 3.8428 & $0.34 \%$ & 3.8324 & $0.07 \%$ \\
\hline $\mathrm{Ca}_{0.94} \mathrm{Nd}_{0.04} \mathrm{TiO}_{3}$ & 3.8299 & 1.3116 & 3.8404 & $0.27 \%$ & 3.8413 & $0.30 \%$ & 3.8331 & $0.08 \%$ \\
\hline $\mathrm{Ca}_{0.91} \mathrm{Nd}_{0.06} \mathrm{TiO}_{3}$ & 3.8307 & 1.3120 & 3.8412 & $0.28 \%$ & 3.8400 & $0.24 \%$ & 3.8341 & $0.09 \%$ \\
\hline $\mathrm{Ca}_{0.85} \mathrm{Nd}_{0.1} \mathrm{TiO}_{3}$ & 3.8351 & 1.3134 & 3.8437 & $0.22 \%$ & 3.8379 & $0.07 \%$ & 3.8368 & $0.04 \%$ \\
\hline $\mathrm{Ca}_{0.97} \mathrm{Y}_{0.02} \mathrm{TiO}_{3}$ & 3.8248 & 1.3112 & 3.8397 & $0.39 \%$ & 3.8423 & $0.46 \%$ & 3.8324 & $0.20 \%$ \\
\hline $\mathrm{Ca}_{0.94} \mathrm{Y}_{0.04} \mathrm{TiO}_{3}$ & 3.8280 & 1.3116 & 3.8404 & $0.32 \%$ & 3.8403 & $0.32 \%$ & 3.8332 & $0.13 \%$ \\
\hline $\mathrm{Ca}_{0.85} \mathrm{Y}_{0.1} \mathrm{TiO}_{3}$ & 3.8230 & 1.3135 & 3.8439 & $0.55 \%$ & 3.8354 & $0.32 \%$ & 3.8370 & $0.36 \%$ \\
\hline \multicolumn{4}{|c|}{ AVERAGE RELATIVE ABSOLUTE ERROR } & $0.31 \%$ & & $0.37 \%$ & & $0.15 \%$ \\
\hline
\end{tabular}


Table 8 Model values for $\mathrm{Sr}_{1-3 x} \mathrm{Ln}_{2 x} \mathrm{TiO}_{3}$

\begin{tabular}{|c|c|c|c|c|c|c|c|c|}
\hline Composition & $a_{p c(\text { expt })}(\AA)$ & $r_{0}(\AA)$ & $a_{p c}(\AA)$ & error & $a_{p c}^{\prime}(\AA)$ & error & $a_{p c} "(\AA)$ & error \\
\hline $\mathrm{SrTiO}_{3}^{\dagger}$ & 3.9050 & 1.3623 & 3.9344 & $0.75 \%$ & 3.9179 & $0.33 \%$ & 3.9347 & $0.75 \%$ \\
\hline $\mathrm{Sr}_{0.97} \mathrm{La}_{0.02} \mathrm{TiO}_{3}$ & 3.9075 & 1.3604 & 3.9309 & $0.60 \%$ & 3.9157 & $0.21 \%$ & 3.9309 & $0.60 \%$ \\
\hline $\mathrm{Sr}_{0.85} \mathrm{La}_{0.1} \mathrm{TiO}_{3}$ & 3.9036 & 1.3542 & 3.9193 & $0.40 \%$ & 3.9090 & $0.14 \%$ & 3.9184 & $0.38 \%$ \\
\hline $\mathrm{Sr}_{0.7} \mathrm{La}_{0.2} \mathrm{TiO}_{3}$ & 3.8984 & 1.3493 & 3.9102 & $0.30 \%$ & 3.9048 & $0.16 \%$ & 3.9086 & $0.26 \%$ \\
\hline $\mathrm{Sr}_{0.55} \mathrm{La}_{0.3} \mathrm{TiO}_{3}$ & 3.8943 & 1.3476 & 3.9071 & $0.33 \%$ & 3.9051 & $0.28 \%$ & 3.9053 & $0.28 \%$ \\
\hline $\mathrm{Sr}_{0.5} \mathrm{La}_{0.33} \mathrm{TiO}_{3}$ & 3.8931 & 1.3478 & 3.9075 & $0.37 \%$ & 3.9063 & $0.34 \%$ & 3.9056 & $0.32 \%$ \\
\hline $\mathrm{Sr}_{0.4} \mathrm{La}_{0.4} \mathrm{TiO}_{3}$ & 3.8905 & 1.3492 & 3.9101 & $0.50 \%$ & 3.9101 & $0.50 \%$ & 3.9085 & $0.46 \%$ \\
\hline $\mathrm{Sr}_{0.33} \mathrm{La}_{0.44} \mathrm{TiO}_{3}$ & 3.8894 & 1.3510 & 3.9133 & $0.62 \%$ & 3.9137 & $0.63 \%$ & 3.9120 & $0.58 \%$ \\
\hline $\mathrm{Sr}_{0.25} \mathrm{La}_{0.5} \mathrm{TiO}_{3}$ & 3.8872 & 1.3541 & 3.9191 & $0.82 \%$ & 3.9196 & $0.83 \%$ & 3.9181 & $0.80 \%$ \\
\hline $\mathrm{La}_{2 / 3} \mathrm{TiO}_{3}{ }^{\dagger}$ & 3.9384 & 1.3694 & 3.9474 & $0.23 \%$ & 3.9457 & $0.18 \%$ & 3.9487 & $0.26 \%$ \\
\hline $\mathrm{Sr}_{0.97} \mathrm{Nd}_{0.02} \mathrm{TiO}_{3}$ & 3.9067 & 1.3602 & 3.9305 & $0.61 \%$ & 3.9129 & $0.16 \%$ & 3.9305 & $0.61 \%$ \\
\hline $\mathrm{Sr}_{0.94} \mathrm{Nd}_{0.04} \mathrm{TiO}_{3}$ & 3.9034 & 1.3583 & 3.9269 & $0.60 \%$ & 3.9082 & $0.12 \%$ & 3.9266 & $0.59 \%$ \\
\hline $\mathrm{Sr}_{0.91} \mathrm{Nd}_{0.06} \mathrm{TiO}_{3}$ & 3.9028 & 1.3565 & 3.9236 & $0.53 \%$ & 3.9036 & $0.02 \%$ & 3.9231 & $0.52 \%$ \\
\hline $\mathrm{Sr}_{0.8} \mathrm{Ce}_{0.13} \mathrm{TiO}_{3}$ & 3.8967 & 1.3522 & 3.9156 & $0.48 \%$ & 3.9071 & $0.27 \%$ & 3.9144 & $0.45 \%$ \\
\hline $\mathrm{Sr}_{0.75} \mathrm{Ce}_{0.17} \mathrm{TiO}_{3}$ & 3.8946 & 1.3506 & 3.9126 & $0.46 \%$ & 3.9057 & $0.28 \%$ & 3.9111 & $0.42 \%$ \\
\hline $\mathrm{Sr}_{0.63} \mathrm{Ce}_{0.25} \mathrm{TiO}_{3}$ & 3.8900 & 1.3481 & 3.9079 & $0.46 \%$ & 3.9044 & $0.37 \%$ & 3.9061 & $0.41 \%$ \\
\hline $\mathrm{Sr}_{0.4} \mathrm{Ce}_{0.4} \mathrm{TiO}_{3}$ & 3.8819 & 1.3492 & 3.9101 & $0.73 \%$ & 3.9101 & $0.73 \%$ & 3.9085 & $0.68 \%$ \\
\hline \multicolumn{4}{|c|}{ AVERAGE RELATIVE ABSOLUTE ERROR } & $0.52 \%$ & & $0.33 \%$ & & $0.49 \%$ \\
\hline
\end{tabular}

Table 9 Model values for $\mathrm{Ba}_{1-3 x} \mathrm{La}_{2 x} \mathrm{TiO}_{3}$

\begin{tabular}{|c|c|c|c|c|c|c|c|c|}
\hline Composition & $a_{p c(\text { expt } l)}(\AA)$ & $r_{0}(\AA)$ & $a_{p c}(\AA)$ & error & $a_{p c}(\AA)$ & error & $a_{p c} "(\AA)$ & error \\
\hline $\mathrm{BaTiO}_{3}{ }^{*}$ & 4.0086 & 1.4130 & 4.0281 & $0.49 \%$ & 4.0318 & $0.58 \%$ & 4.0359 & $0.68 \%$ \\
\hline $\mathrm{Ba}_{0.97} \mathrm{La}_{0.02} \mathrm{TiO}_{3}$ & 4.0087 & 1.4120 & 4.0263 & $0.44 \%$ & 4.0297 & $0.52 \%$ & 4.0340 & $0.63 \%$ \\
\hline $\mathrm{Ba}_{0.94} \mathrm{La}_{0.04} \mathrm{TiO}_{3}$ & 4.0090 & 1.4110 & 4.0245 & $0.39 \%$ & 4.0276 & $0.46 \%$ & 4.0320 & $0.58 \%$ \\
\hline $\mathrm{Ba}_{0.91} \mathrm{La}_{0.06} \mathrm{TiO}_{3}$ & 3.9995 & 1.4100 & 4.0227 & $0.58 \%$ & 4.0255 & $0.65 \%$ & 4.0301 & $0.76 \%$ \\
\hline $\mathrm{Ba}_{0.88} \mathrm{La}_{0.08} \mathrm{TiO}_{3}$ & 4.0058 & 1.4090 & 4.0208 & $0.37 \%$ & 4.0233 & $0.44 \%$ & 4.0280 & $0.55 \%$ \\
\hline $\mathrm{La}_{2 / 3} \mathrm{TiO}_{3}{ }^{*}$ & 3.9384 & 1.3717 & 3.9518 & $0.34 \%$ & 3.9491 & $0.27 \%$ & 3.9535 & $0.38 \%$ \\
\hline \multicolumn{4}{|c|}{ AVERAGE RELATIVE ABSOLUTE ERROR } & $0.43 \%$ & & $0.49 \%$ & & $0.60 \%$ \\
\hline
\end{tabular}

$\dagger=[43]$

$+=[22]$

Table 10 Model values for $\mathrm{Pb}_{1-3 x} \mathrm{La}_{2 x} \mathrm{TiO}_{3}$

\begin{tabular}{|c|c|c|c|c|c|c|c|c|}
\hline Composition & $a_{p c(\text { expt })}(\AA)$ & $r_{0}(\AA)$ & $a_{p c}(\AA)$ & error & $a_{p c}^{\prime}(\AA)$ & error & $a_{p c} "(\AA)$ & error \\
\hline $\mathrm{PbTiO}_{3}{ }^{*}$ & 3.9794 & 1.3871 & 3.9803 & $0.02 \%$ & 3.9601 & $-0.49 \%$ & 3.9843 & $0.12 \%$ \\
\hline $\mathrm{Pb}_{0.93} \mathrm{La}_{0.05} \mathrm{TiO}_{3}$ & 3.9629 & 1.3811 & 3.9691 & $0.15 \%$ & 3.9523 & $-0.27 \%$ & 3.9722 & $0.23 \%$ \\
\hline $\mathrm{Pb}_{0.85} \mathrm{La}_{0.1} \mathrm{TiO}_{3}$ & 3.9534 & 1.3758 & 3.9593 & $0.15 \%$ & 3.9456 & $-0.20 \%$ & 3.9616 & $0.21 \%$ \\
\hline $\mathrm{Pb}_{0.82} \mathrm{La}_{0.12} \mathrm{TiO}_{3}$ & 3.9511 & 1.3739 & 3.9557 & $0.12 \%$ & 3.9432 & $-0.20 \%$ & 3.9578 & $0.17 \%$ \\
\hline $\mathrm{Pb}_{0.78} \mathrm{La}_{0.15} \mathrm{TiO}_{3}$ & 3.9472 & 1.3713 & 3.9509 & $0.09 \%$ & 3.9400 & $-0.18 \%$ & 3.9525 & $0.14 \%$ \\
\hline $\mathrm{Pb}_{0.7} \mathrm{La}_{0.2} \mathrm{TiO}_{3}$ & 3.9338 & 1.3675 & 3.9439 & $0.26 \%$ & 3.9355 & $0.04 \%$ & 3.9450 & $0.28 \%$ \\
\hline $\mathrm{Pb}_{0.63} \mathrm{La}_{0.25} \mathrm{TiO}_{3}$ & 3.9343 & 1.3645 & 3.9384 & $0.11 \%$ & 3.9321 & $-0.05 \%$ & 3.9390 & $0.12 \%$ \\
\hline $\mathrm{Pb}_{0.55} \mathrm{La}_{0.3} \mathrm{TiO}_{3}$ & 3.9283 & 1.3623 & 3.9343 & $0.15 \%$ & 3.9298 & $0.04 \%$ & 3.9346 & $0.16 \%$ \\
\hline $\mathrm{La}_{2 / 3} \mathrm{TiO}_{3}{ }^{*}$ & 3.9384 & 1.3696 & 3.9477 & $0.24 \%$ & 3.9460 & $0.19 \%$ & 3.9491 & $0.27 \%$ \\
\hline \multicolumn{4}{|c|}{ AVERAGE RELATIVE ABSOLUTE ERROR } & $0.14 \%$ & & $0.18 \%$ & & $0.19 \%$ \\
\hline
\end{tabular}




$$
\begin{aligned}
& *=[25] \\
& * *=[22]
\end{aligned}
$$

\begin{tabular}{|c|c|c|c|c|c|c|c|c|}
\hline Composition & $a_{p c(\text { expt })}(\AA)$ & $r_{0}(\AA)$ & $a_{p c}(\AA)$ & error & $a_{p c}(\AA)$ & error & $a_{p c} "(\AA)$ & error \\
\hline $\mathrm{PbTiO}_{3}{ }^{*}$ & 3.9794 & 1.3856 & 3.9774 & $-0.05 \%$ & 3.9651 & $-0.36 \%$ & 3.9812 & $0.04 \%$ \\
\hline $\mathrm{Pb}_{093} \mathrm{La}_{005} \mathrm{TiO}_{3}$ & 3.9629 & 1.3795 & 3.9661 & $0.08 \%$ & 3.9573 & $-0.14 \%$ & 3.9690 & $0.15 \%$ \\
\hline $\mathrm{Pb}_{0.85} \mathrm{La}_{01} \mathrm{TiO}_{3}$ & 3.9534 & 1.3742 & 3.9563 & $0.07 \%$ & 3.9506 & $-0.07 \%$ & 3.9584 & $0.13 \%$ \\
\hline $\mathrm{Pb}_{0.82} \mathrm{La}_{0.12} \mathrm{TiO}_{3}$ & 3.9511 & 1.3723 & 3.9528 & $0.04 \%$ & 3.9482 & $-0.07 \%$ & 3.9546 & $0.09 \%$ \\
\hline $\mathrm{Pb}_{0.78} \mathrm{La}_{0.15} \mathrm{TiO}_{3}$ & 3.9472 & 1.3697 & 3.9480 & $0.02 \%$ & 3.9450 & $-0.06 \%$ & 3.9494 & $0.05 \%$ \\
\hline $\mathrm{Pb}_{0.7} \mathrm{La}_{0.2} \mathrm{TiO}_{3}$ & 3.9338 & 1.3660 & 3.9411 & $0.18 \%$ & 3.9405 & $0.17 \%$ & 3.9419 & $0.21 \%$ \\
\hline $\mathrm{Pb}_{0.63} \mathrm{La}_{0.25} \mathrm{TiO}_{3}$ & 3.9343 & 1.3630 & 3.9357 & $0.04 \%$ & 3.9372 & $0.08 \%$ & 3.9361 & $0.05 \%$ \\
\hline $\mathrm{Pb}_{0.55} \mathrm{La}_{0.3} \mathrm{TiO}_{3}$ & 3.9283 & 1.3609 & 3.9317 & $0.09 \%$ & 3.9350 & $0.17 \%$ & 3.9318 & $0.09 \%$ \\
\hline $\mathrm{La}_{2 / 3} \mathrm{TiO}_{3}{ }^{*}$ & 3.9384 & 1.3695 & 3.9477 & $0.23 \%$ & 3.9531 & $0.37 \%$ & 3.9490 & $0.27 \%$ \\
\hline \multicolumn{4}{|c|}{ AVERAGE RELATIVE ABSOLUTE ERROR } & $0.09 \%$ & & $0.17 \%$ & & $0.12 \%$ \\
\hline
\end{tabular}

Table 11 Model values for $\mathrm{Pb}_{1-3 x} \mathrm{La}_{2 x} \mathrm{TiO}_{3}$ including SOJT distortion

\begin{tabular}{|c|c|c|c|c|c|c|c|c|}
\hline Composition & $a_{p c(\text { expt } t)}(\AA)$ & $r_{O}(\AA)$ & $a_{p c}(\AA)$ & error & $a_{p c}(\AA)$ & error & $a_{p c} "(\AA)$ & error \\
\hline $\mathrm{PbZr}_{0.6} \mathrm{Ti}_{0.4} \mathrm{O}_{3}$ & 4.0848 & 1.3747 & 4.0973 & $0.31 \%$ & 4.0704 & $-0.35 \%$ & 4.0982 & $0.33 \%$ \\
\hline $\mathrm{Pb}_{0.997} \mathrm{La}_{0.002} \mathrm{Zr}_{0.6} \mathrm{Ti}_{0.4} \mathrm{O}_{3}$ & 4.0814 & 1.3748 & 4.0932 & $0.29 \%$ & 4.0695 & $-0.29 \%$ & 4.0942 & $0.31 \%$ \\
\hline $\mathrm{Pb}_{0.9955} \mathrm{La}_{0.003} \mathrm{Zr}_{0.6} \mathrm{Ti}_{0.4} \mathrm{O}_{3}$ & 4.0809 & 1.3749 & 4.0918 & $0.27 \%$ & 4.0710 & $-0.24 \%$ & 4.0928 & $0.29 \%$ \\
\hline $\mathrm{Pb}_{0.9925} \mathrm{La}_{0.005} \mathrm{Zr}_{0.6} \mathrm{Ti}_{0.4} \mathrm{O}_{3}$ & 4.0803 & 1.3742 & 4.0993 & $0.47 \%$ & 4.0716 & $-0.21 \%$ & 4.1002 & $0.49 \%$ \\
\hline $\mathrm{Pb}_{0.9895} \mathrm{La}_{0.007} \mathrm{Zr}_{0.6} \mathrm{Ti}_{0.4} \mathrm{O}_{3}$ & 4.0805 & 1.3746 & 4.0909 & $0.26 \%$ & 4.0699 & $-0.26 \%$ & 4.0918 & $0.28 \%$ \\
\hline $\mathrm{Pb}_{0.985} \mathrm{La}_{0.01} \mathrm{Zr}_{0.6} \mathrm{Ti}_{0.4} \mathrm{O}_{3}$ & 4.0802 & 1.3745 & 4.0883 & $0.20 \%$ & 4.0697 & $-0.26 \%$ & 4.0893 & $0.22 \%$ \\
\hline $\mathrm{Pb}_{0.97} \mathrm{La}_{0.02} \mathrm{Zr}_{0.6} \mathrm{Ti}_{0.4} \mathrm{O}_{3}$ & 4.0778 & 1.3734 & 4.0860 & $0.20 \%$ & 4.0636 & $-0.35 \%$ & 4.0869 & $0.22 \%$ \\
\hline $\mathrm{Pb}_{0.955} \mathrm{La}_{0.03} \mathrm{Zr}_{0.6} \mathrm{Ti}_{0.4} \mathrm{O}_{3}$ & 4.0761 & 1.3723 & 4.0934 & $0.43 \%$ & 4.0650 & $-0.27 \%$ & 4.0941 & $0.44 \%$ \\
\hline $\mathrm{Pb}_{0.94} \mathrm{La}_{0.04} \mathrm{Zr}_{0.6} \mathrm{Ti}_{0.4} \mathrm{O}_{3}$ & 4.0758 & 1.3717 & 4.0843 & $0.21 \%$ & 4.0581 & $-0.43 \%$ & 4.0850 & $0.23 \%$ \\
\hline $\mathrm{Pb}_{0.925} \mathrm{La}_{0.05} \mathrm{Zr}_{0.6} \mathrm{Ti}_{0.4} \mathrm{O}_{3}$ & 4.0766 & 1.3710 & 4.0867 & $0.25 \%$ & 4.0604 & $-0.40 \%$ & 4.0873 & $0.26 \%$ \\
\hline $\mathrm{Pb}_{0.91} \mathrm{La}_{0.06} \mathrm{Zr}_{0.6} \mathrm{Ti}_{0.4} \mathrm{O}_{3}$ & 4.0733 & 1.3701 & 4.0844 & $0.27 \%$ & 4.0552 & $-0.45 \%$ & 4.0849 & $0.28 \%$ \\
\hline $\mathrm{Pb}_{0.88} \mathrm{La}_{0.08} \mathrm{Zr}_{0.6} \mathrm{Ti}_{0.4} \mathrm{O}_{3}$ & 4.0710 & 1.3685 & 4.0874 & $0.40 \%$ & 4.0539 & $-0.42 \%$ & 4.0877 & $0.41 \%$ \\
\hline $\mathrm{Pb}_{0.85} \mathrm{La}_{0.1} \mathrm{Zr}_{0.6} \mathrm{Ti}_{0.4} \mathrm{O}_{3}$ & 4.0689 & 1.3673 & 4.0822 & $0.33 \%$ & 4.0477 & $-0.52 \%$ & 4.0825 & $0.33 \%$ \\
\hline $\mathrm{Pb}_{0.82} \mathrm{La}_{0.12} \mathrm{Zr}_{0.6} \mathrm{Ti}_{0.4} \mathrm{O}_{3}$ & 4.0677 & 1.3664 & 4.0786 & $0.27 \%$ & 4.0471 & $-0.51 \%$ & 4.0788 & $0.27 \%$ \\
\hline $\mathrm{Pb}_{0.79} \mathrm{La}_{0.14} \mathrm{Zr}_{0.6} \mathrm{Ti}_{0.4} \mathrm{O}_{3}$ & 4.0630 & 1.3642 & 4.0758 & $0.31 \%$ & 4.0159 & $-1.16 \%$ & 4.0758 & $0.31 \%$ \\
\hline $\mathrm{Pb}_{0.76} \mathrm{La}_{0.16} \mathrm{Zr}_{0.6} \mathrm{Ti}_{0.4} \mathrm{O}_{3}$ & 4.0641 & 1.3644 & 4.0754 & $0.28 \%$ & 4.0420 & $-0.55 \%$ & 4.0755 & $0.28 \%$ \\
\hline $\mathrm{Pb}_{0.7} \mathrm{La}_{0.2} \mathrm{Zr}_{0.6} \mathrm{Ti}_{0.4} \mathrm{O}_{3}$ & 4.0588 & 1.3629 & 4.0721 & $0.33 \%$ & 4.0420 & $-0.41 \%$ & 4.0720 & $0.33 \%$ \\
\hline \multicolumn{4}{|c|}{ AVERAGE RELATIVE ABSOLUTE ERROR } & $0.30 \%$ & & $0.42 \%$ & & $0.31 \%$ \\
\hline
\end{tabular}

Table 12 Model values for $\mathrm{Pba}_{1-3 x} \mathrm{La}_{2 x}\left(\mathrm{Zr}_{0.6} \mathrm{Ti}_{0.4}\right) \mathrm{O}_{3}$

\begin{tabular}{|c|c|c|c|c|c|c|c|c|}
\hline Composition & $a_{p c(\text { exptl })}(\AA)$ & $r_{O}(\AA)$ & $a_{p c}(\AA)$ & error & $a_{p c}(\AA)$ & error & $a_{p c} "(\AA)$ & error \\
\hline $\mathrm{PbZr}_{0.6} \mathrm{Ti}_{0.4} \mathrm{O}_{3}$ & 4.0848 & 1.3684 & 4.0853 & $0.01 \%$ & 4.0871 & $0.06 \%$ & 4.0857 & $0.02 \%$ \\
\hline $\mathrm{Pb}_{0.997} \mathrm{La}_{0.002} \mathrm{Zr}_{0}$ & 4.0814 & 1.3685 & 4.0813 & $0.00 \%$ & 4.0861 & $0.12 \%$ & 4.0817 & $0.01 \%$ \\
\hline $\mathrm{Pb}_{0.9955} \mathrm{La}$ & 4.0809 & 1.3687 & 4.0798 & $-0.03 \%$ & 4.0876 & $0.16 \%$ & 4.0803 & $-0.02 \%$ \\
\hline $\mathrm{Pb}_{0.9925}$ & 4.0 & 3680 & 4.0873 & $0.17 \%$ & 4.0882 & $0.19 \%$ & 4.0877 & $0.18 \%$ \\
\hline $\mathrm{Pb}_{0.9895} \mathrm{La}_{0.007} \mathrm{Zr}_{0.6} \mathrm{Ti}_{0.4} \mathrm{O}_{3}$ & 4.0805 & 1.3683 & 4.0789 & $-0.04 \%$ & 4.0865 & $0.15 \%$ & 4.0793 & $-0.03 \%$ \\
\hline
\end{tabular}

Table 13 Model values for $\mathrm{Pba}_{1-3 x} \mathrm{La}_{2 x}\left(\mathrm{Zr}_{0.6} \mathrm{Ti}_{0.4}\right) \mathrm{O}_{3}$ including SOJT distortion 


\begin{tabular}{lllllllll}
\hline $\mathrm{Pb}_{0.985} \mathrm{La}_{0.01} \mathrm{Zr}_{0.6} \mathrm{Ti}_{0.4} \mathrm{O}_{3}$ & 4.0802 & 1.3683 & 4.0764 & $-0.09 \%$ & 4.0864 & $0.15 \%$ & 4.0768 & $-0.08 \%$ \\
\hline $\mathrm{Pb}_{0.97} \mathrm{La}_{0.02} \mathrm{Zr}_{0.6} \mathrm{Ti}_{0.4} \mathrm{O}_{3}$ & 4.0778 & 1.3672 & 4.0741 & $-0.09 \%$ & 4.0802 & $0.06 \%$ & 4.0744 & $-0.08 \%$ \\
\hline $\mathrm{Pb}_{0.955} \mathrm{La}_{0.03} \mathrm{Zr}_{0.6} \mathrm{Ti}_{0.4} \mathrm{O}_{3}$ & 4.0761 & 1.3660 & 4.0815 & $0.13 \%$ & 4.0816 & $0.14 \%$ & 4.0817 & $0.14 \%$ \\
\hline $\mathrm{Pb}_{0.94} \mathrm{La}_{0.04} \mathrm{Zr}_{0.6} \mathrm{Ti}_{0.4} \mathrm{O}_{3}$ & 4.0758 & 1.3655 & 4.0724 & $-0.08 \%$ & 4.0748 & $-0.03 \%$ & 4.0726 & $-0.08 \%$ \\
\hline $\mathrm{Pb}_{0.925} \mathrm{La}_{0.05} \mathrm{Zr}_{0.6} \mathrm{Ti}_{0.4} \mathrm{O}_{3}$ & 4.0766 & 1.3648 & 4.0748 & $-0.04 \%$ & 4.0772 & $0.01 \%$ & 4.0749 & $-0.04 \%$ \\
\hline $\mathrm{Pb}_{0.91} \mathrm{La}_{0.06} \mathrm{Zr}_{0.6} \mathrm{Ti}_{0.4} \mathrm{O}_{3}$ & 4.0733 & 1.3639 & 4.0726 & $-0.02 \%$ & 4.0719 & $-0.03 \%$ & 4.0726 & $-0.02 \%$ \\
\hline $\mathrm{Pb}_{0.88} \mathrm{La}_{0.08} \mathrm{Zr}_{0.6} \mathrm{Ti}_{0.4} \mathrm{O}_{3}$ & 4.0710 & 1.3625 & 4.0757 & $0.12 \%$ & 4.0708 & $0.00 \%$ & 4.0756 & $0.11 \%$ \\
\hline $\mathrm{Pb}_{0.85} \mathrm{La}_{0.1} \mathrm{Zr}_{0.6} \mathrm{Ti}_{0.4} \mathrm{O}_{3}$ & 4.0689 & 1.3613 & 4.0707 & $0.04 \%$ & 4.0647 & $-0.10 \%$ & 4.0705 & $0.04 \%$ \\
\hline $\mathrm{Pb}_{0.82} \mathrm{La}_{0.12} \mathrm{Zr}_{0.6} \mathrm{Ti}_{0.4} \mathrm{O}_{3}$ & 4.0677 & 1.3604 & 4.0673 & $-0.01 \%$ & 4.0642 & $-0.09 \%$ & 4.0670 & $-0.02 \%$ \\
\hline $\mathrm{Pb}_{0.79} \mathrm{La}_{0.14} \mathrm{Zr}_{0.6} \mathrm{Ti}_{0.4} \mathrm{O}_{3}$ & 4.0630 & 1.3585 & 4.0649 & $0.05 \%$ & 4.0333 & $-0.73 \%$ & 4.0644 & $0.03 \%$ \\
\hline $\mathrm{Pb}_{0.76} \mathrm{La}_{0.16} \mathrm{Zr}_{0.6} \mathrm{Ti}_{0.4} \mathrm{O}_{3}$ & 4.0641 & 1.3586 & 4.0645 & $0.01 \%$ & 4.0593 & $-0.12 \%$ & 4.0641 & $0.00 \%$ \\
\hline $\mathrm{Pb}_{0.7} \mathrm{La}_{0.2} \mathrm{Zr}_{0.6} \mathrm{Ti}_{0.4} \mathrm{O}_{3}$ & 4.0588 & 1.3574 & 4.0616 & $0.07 \%$ & 4.0597 & $0.02 \%$ & 4.0610 & $0.06 \%$ \\
\hline $\mathbf{A V E R A G E ~ R E L A T I V E ~ A B S O L U T E ~ E R R O R ~}$ & & $\mathbf{0 . 0 6 \%}$ & & $\mathbf{0 . 1 3 \%}$ & & $\mathbf{0 . 0 6 \%}$ \\
\hline
\end{tabular}

Table 14 Model values

\begin{tabular}{|c|c|c|c|c|c|c|c|c|}
\hline Composition & $a_{p c(\text { expt })}(\AA)$ & $r_{O}(\AA)$ & $a_{p c}(\AA)$ & error & $a_{p c}^{\prime}(\AA)$ & error & $a_{p c},(\AA)$ & error \\
\hline $\mathrm{SrMg}_{0.3333} \mathrm{Nb}_{0.6667} \mathrm{O}_{3}$ & 4.0114 & 1.3538 & 4.0418 & $0.76 \%$ & 4.0246 & $0.33 \%$ & 4.0409 & $0.74 \%$ \\
\hline $\mathrm{Sr}_{0.97} \mathrm{La}_{0.02} \mathrm{Mg}_{0.3333} \mathrm{Nb}_{0.6667} \mathrm{O}_{3}$ & 3.9964 & 1.3526 & 4.0396 & $1.08 \%$ & 4.0199 & $0.59 \%$ & 4.0385 & $1.06 \%$ \\
\hline \multicolumn{4}{|c|}{ AVERAGE RELATIVE ABSOLUTE ERROR } & $0.92 \%$ & & $0.46 \%$ & & $0.90 \%$ \\
\hline $\mathrm{Na}_{0.5} \mathrm{La}_{0.5}\left(\mathrm{Mg}_{0.5} \mathrm{~W}_{0.5}\right) \mathrm{O}_{3} *$ & 3.9254 & 1.3320 & 3.9871 & $1.57 \%$ & 3.9843 & $1.50 \%$ & 3.9841 & $1.50 \%$ \\
\hline $\mathrm{Na}_{0.3333} \mathrm{La}_{0.5556}\left(\mathrm{Mg}_{0.5} \mathrm{~W}_{0.5}\right) \mathrm{O}_{3} *$ & 3.9288 & 1.3361 & 3.9948 & $1.68 \%$ & 3.9596 & $0.78 \%$ & 3.9922 & $1.61 \%$ \\
\hline $\mathrm{Na}_{0.1667} \mathrm{La}_{0.6111}\left(\mathrm{Mg}_{0.5} \mathrm{~W}_{0.5}\right) \mathrm{O}_{3} *$ & 3.9257 & 1.3532 & 4.0274 & $2.59 \%$ & 3.9533 & $0.70 \%$ & 4.0265 & $2.57 \%$ \\
\hline \multicolumn{4}{|c|}{ AVERAGE RELATIVE ABSOLUTE ERROR } & $1.95 \%$ & & $1.00 \%$ & & $1.89 \%$ \\
\hline $\mathrm{K}_{0.5} \mathrm{La}_{0.5}\left(\mathrm{Mg}_{0.5} \mathrm{~W}_{0.5}\right) \mathrm{O}_{3} *$ & 3.9529 & 1.4065 & 4.1288 & $4.45 \%$ & 4.0892 & $3.45 \%$ & 4.1330 & $4.56 \%$ \\
\hline $\mathrm{K}_{0.3333} \mathrm{La}_{0.5556}\left(\mathrm{Mg}_{0.5} \mathrm{~W}_{0.5}\right) \mathrm{O}_{3} *$ & 3.9484 & 1.3998 & 4.1160 & $4.24 \%$ & 4.0494 & $2.56 \%$ & 4.1196 & $4.33 \%$ \\
\hline $\mathrm{K}_{0.1667} \mathrm{La}_{0.6111}\left(\mathrm{Mg}_{0.5} \mathrm{~W}_{0.5}\right) \mathrm{O}_{3} *$ & 3.9400 & 1.3860 & 4.0898 & $3.80 \%$ & 3.9996 & $1.51 \%$ & 4.0920 & $3.86 \%$ \\
\hline \multicolumn{4}{|c|}{ AVERAGE RELATIVE ABSOLUTE ERROR } & $4.16 \%$ & & $2.50 \%$ & & $4.25 \%$ \\
\hline
\end{tabular}

Table 15 Model values accounting for the effect of B-site ordering

\begin{tabular}{|c|c|c|c|c|c|c|c|c|}
\hline Composition & $a_{p c(\text { expt })}(\AA)$ & $r_{O}(\AA)$ & $a_{p c}(\AA)$ & error & $a_{p c}^{\prime}(\AA)$ & error & $a_{p c} "(\AA)$ & error \\
\hline $\mathrm{SrMg}_{0.3333} \mathrm{Nb}_{0.6667} \mathrm{O}_{3}$ & 4.0114 & 1.3565 & 3.9999 & $-0.29 \%$ & 3.9825 & $-0.72 \%$ & 3.9993 & $-0.30 \%$ \\
\hline $\mathrm{Sr}_{0.97} \mathrm{La}_{0.02} \mathrm{Mg}_{0.3333} \mathrm{Nb}_{0.6667} \mathrm{O}_{3}$ & 3.9964 & 1.3551 & 3.9972 & $0.02 \%$ & 3.9788 & $-0.44 \%$ & 3.9964 & $0.00 \%$ \\
\hline \multicolumn{4}{|c|}{ AVERAGE RELATIVE ABSOLUTE ERROR } & $0.15 \%$ & & $\mathbf{0 . 5 8 \%}$ & & $0.15 \%$ \\
\hline $\mathrm{Na}_{0.5} \mathrm{La}$ & & 1.3332 & 3.9 & & & & 3.9 & \\
\hline $\mathrm{Na}_{0.3333} \mathrm{La}_{0.5556}\left(\mathrm{Mg}_{0.5} \mathrm{~W}_{0.5}\right) \mathrm{O}_{3} *$ & 3.9 & 38 & 3.9301 & 0. & 47 & $-0.36 \%$ & 3.9 & $-0.05 \%$ \\
\hline $\mathrm{Na}_{0.1667} \mathrm{La}_{0.6111}\left(\mathrm{Mg}_{0.5} \mathrm{~W}_{0.5}\right) \mathrm{O}_{3} *$ & 3.9257 & 1.3480 & 3.9566 & $0.79 \%$ & & $-0.02 \%$ & 3.9549 & $0.75 \%$ \\
\hline \multicolumn{4}{|c|}{ AVERAGE RELATIVE ABSOLUTE ERROR } & $0.30 \%$ & & $0.14 \%$ & & $0.27 \%$ \\
\hline $\mathrm{K}_{0.5} \mathrm{La}_{0.5}\left(\mathrm{Mg}_{0.5} \mathrm{~W}_{0.5}\right) \mathrm{O}_{3} *$ & & 1.4071 & 3.9442 & & & $-0.61 \%$ & 3.9529 & \\
\hline $\mathrm{K}_{0.333} \mathrm{La}_{0.5556}\left(\mathrm{Mg}_{0.5} \mathrm{~W}_{0.5}\right) \mathrm{O}_{3} *$ & 3.9 & 1.4049 & 3.9402 & -0 . & 3.9490 & $0.02 \%$ & 3.9485 & $0.00 \%$ \\
\hline $\mathrm{K}_{0.1667} \mathrm{La}_{0.6111}\left(\mathrm{Mg}_{0.5} \mathrm{~W}_{0.5}\right) \mathrm{O}_{3} *$ & 3.9400 & 1.3949 & 3.9222 & $-0.45 \%$ & 3.9584 & $0.47 \%$ & 3.9287 & $-0.29 \%$ \\
\hline \multicolumn{4}{|c|}{ AVERAGE RELATIVE ABSOLUTE ERROR } & $0.29 \%$ & & $0.36 \%$ & & $\mathbf{0 . 1 0 \%}$ \\
\hline
\end{tabular}

$*=[36]$ 
Table 16 Model values for $\mathrm{Na}_{(1-3 x) / 2} \mathrm{La}_{(1+x) / 2} \mathrm{TiO}_{3}$

\begin{tabular}{|c|c|c|c|c|c|c|c|c|}
\hline Composition & $a_{p c(\text { exptl })}(\AA)$ & $r_{O}(\AA)$ & $a_{p c}(\AA)$ & error & $a_{p c}(\AA)$ & error & $a_{p c} "(\AA)$ & error \\
\hline $\mathrm{Na}_{0.5} \mathrm{La}_{0.5} \mathrm{TiO}_{3} *$ & 3.8742 & 1.3348 & 3.8835 & $0.24 \%$ & 3.7871 & $-2.25 \%$ & 3.8797 & $0.14 \%$ \\
\hline $\mathrm{Na}_{0.42} \mathrm{La}_{0.5267} \mathrm{TiO}_{3} * *$ & 3.8727 & 1.3320 & 3.8783 & $0.14 \%$ & 3.8007 & $-1.86 \%$ & 3.8741 & $0.04 \%$ \\
\hline $\mathrm{Na}_{0.24} \mathrm{La}_{0.5867} \mathrm{TiO}_{3} * *$ & 3.8749 & 1.3374 & 3.8882 & $0.34 \%$ & 3.8478 & $-0.70 \%$ & 3.8848 & $0.25 \%$ \\
\hline $\mathrm{Na}_{0.1625} \mathrm{La}_{0.6125} \mathrm{TiO}_{3} * *$ & 3.8753 & 1.3446 & 3.9016 & $0.68 \%$ & 3.8750 & $-0.01 \%$ & 3.8993 & $0.62 \%$ \\
\hline \multicolumn{4}{|c|}{ AVERAGE RELATIVE ABSOLUTE ERROR } & $0.24 \%$ & & $1.28 \%$ & & $0.14 \%$ \\
\hline
\end{tabular}

$*=$ [50]

$* *=$ [49]

Table 17

\begin{tabular}{|c|c|c|c|c|c|c|c|c|}
\hline Composition & $a_{p c}(\AA)$ & $r_{O}(\AA)$ & $a_{p c}(\AA)$ & error & $a_{p c}^{\prime}(\AA)$ & error & $a_{p c} "(\AA)$ & error \\
\hline $\mathrm{Sr}_{0.748} \mathrm{Ca}_{0.252} \mathrm{TiO}_{3}$ & 3.8914 & 1.3489 & 3.9096 & $0.47 \%$ & 3.8970 & $0.14 \%$ & 3.9079 & $0.42 \%$ \\
\hline $\mathrm{Sr}_{0.7042} \mathrm{Ca}_{0.2658} \mathrm{La}_{0.02} \mathrm{TiO}_{3}$ & 3.8927 & 1.3473 & 3.9066 & $0.35 \%$ & 3.8923 & $-0.01 \%$ & 3.9046 & $0.31 \%$ \\
\hline $\mathrm{Sr}_{0.5082} \mathrm{Ca}_{0.1918} \mathrm{La}_{0.2} \mathrm{TiO}_{3}$ & 3.8918 & 1.3403 & 3.8936 & $0.05 \%$ & 3.8886 & $-0.08 \%$ & 3.8907 & $-0.03 \%$ \\
\hline $\mathrm{Sr}_{0.2904} \mathrm{Ca}_{0.1096} \mathrm{La}_{0.4} \mathrm{TiO}_{3}$ & 3.9020 & 1.3444 & 3.9012 & $-0.02 \%$ & 3.9013 & $-0.02 \%$ & 3.8989 & $-0.08 \%$ \\
\hline $\mathrm{Sr}_{0.0726} \mathrm{Ca}_{0.0274} \mathrm{La}_{0.6} \mathrm{TiO}_{3}$ & 3.8830 & 1.3611 & 3.9320 & $1.26 \%$ & 3.9317 & $1.25 \%$ & 3.9322 & $1.27 \%$ \\
\hline \multicolumn{4}{|c|}{ AVERAGE RELATIVE ABSOLUTE ERROR } & $0.43 \%$ & & $0.30 \%$ & & $0.42 \%$ \\
\hline
\end{tabular}




\section{TOC Summary and Graphic}

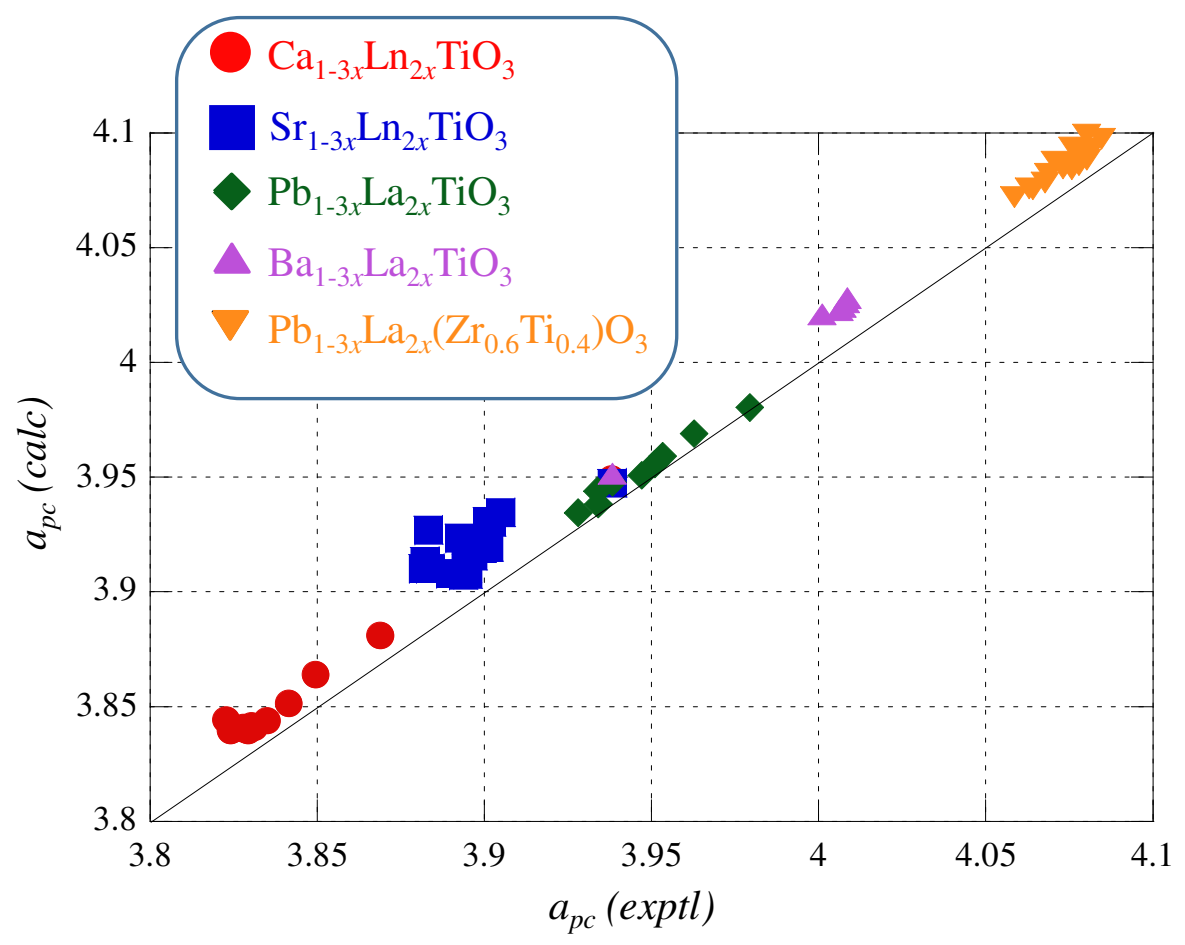

Comparison of calculated and experimental lattice constant values 


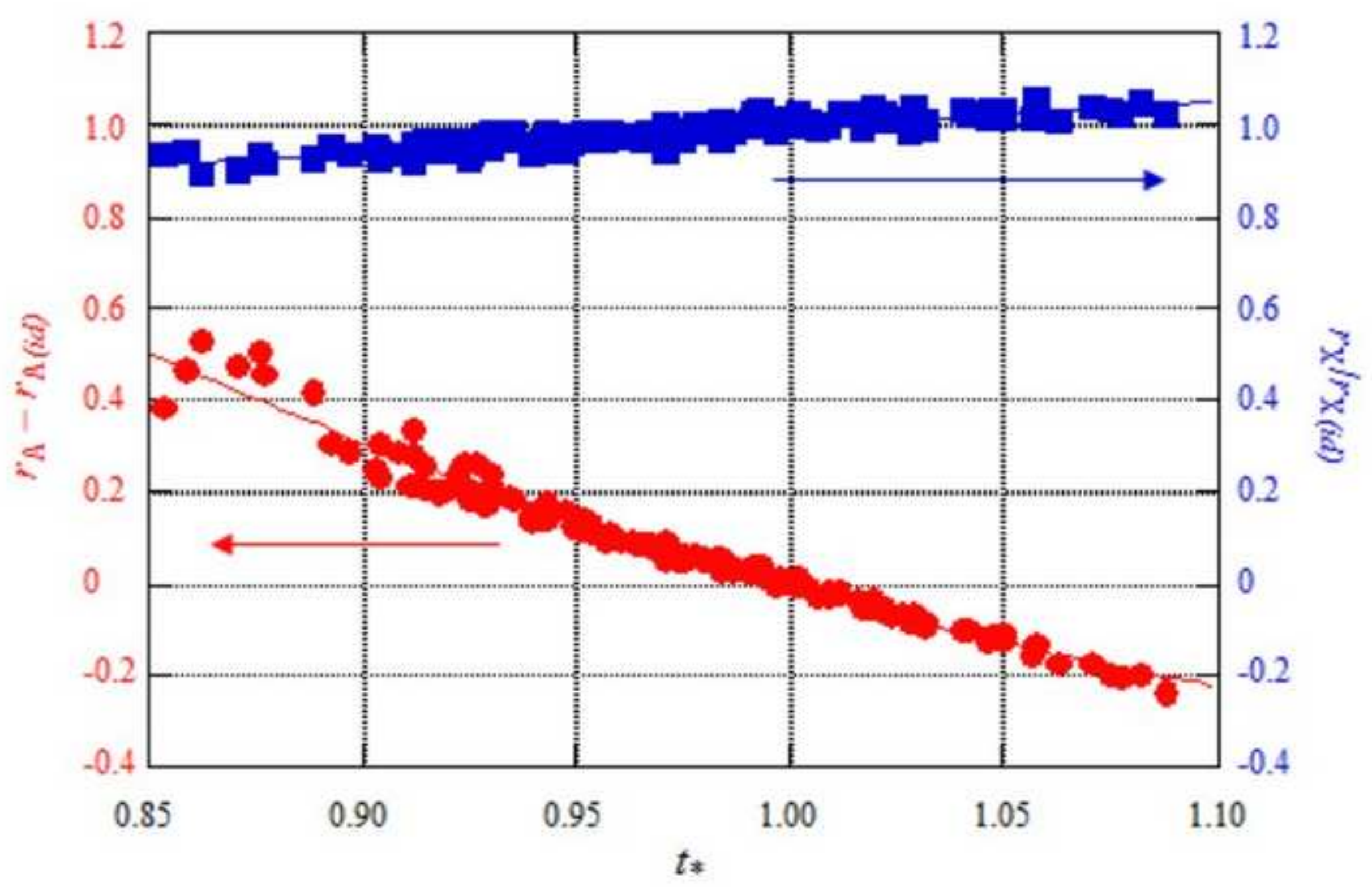




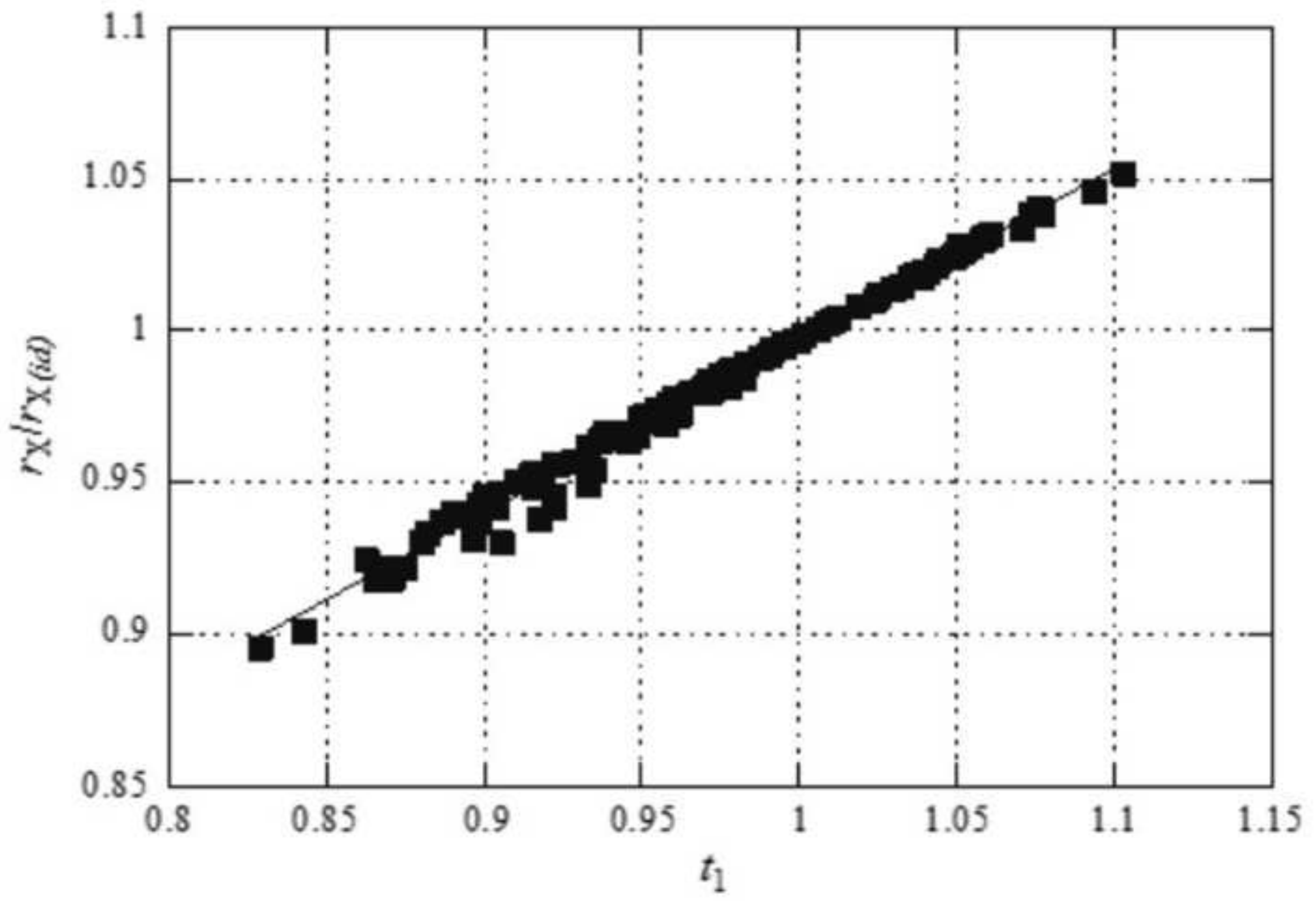


Figure 3

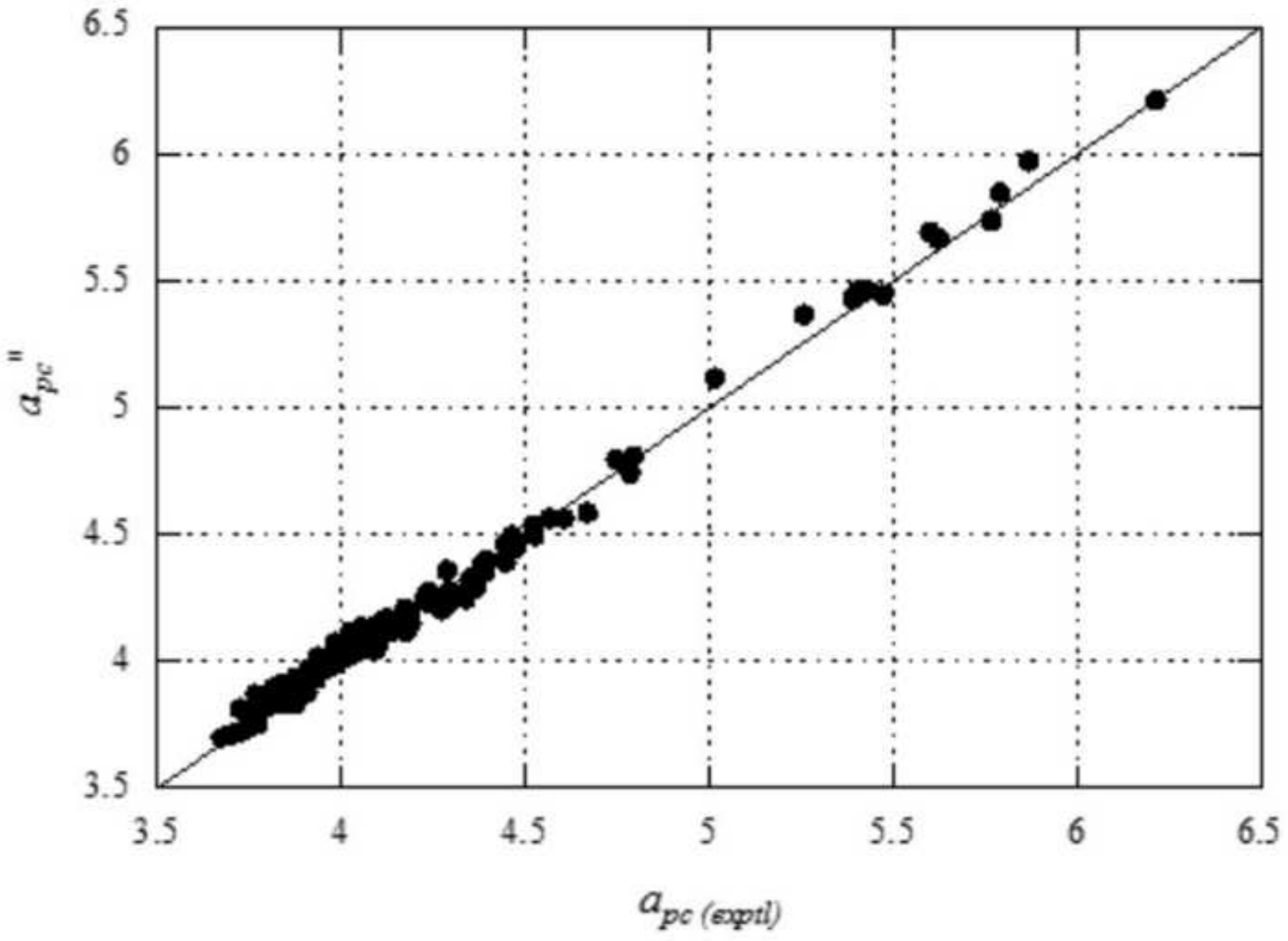




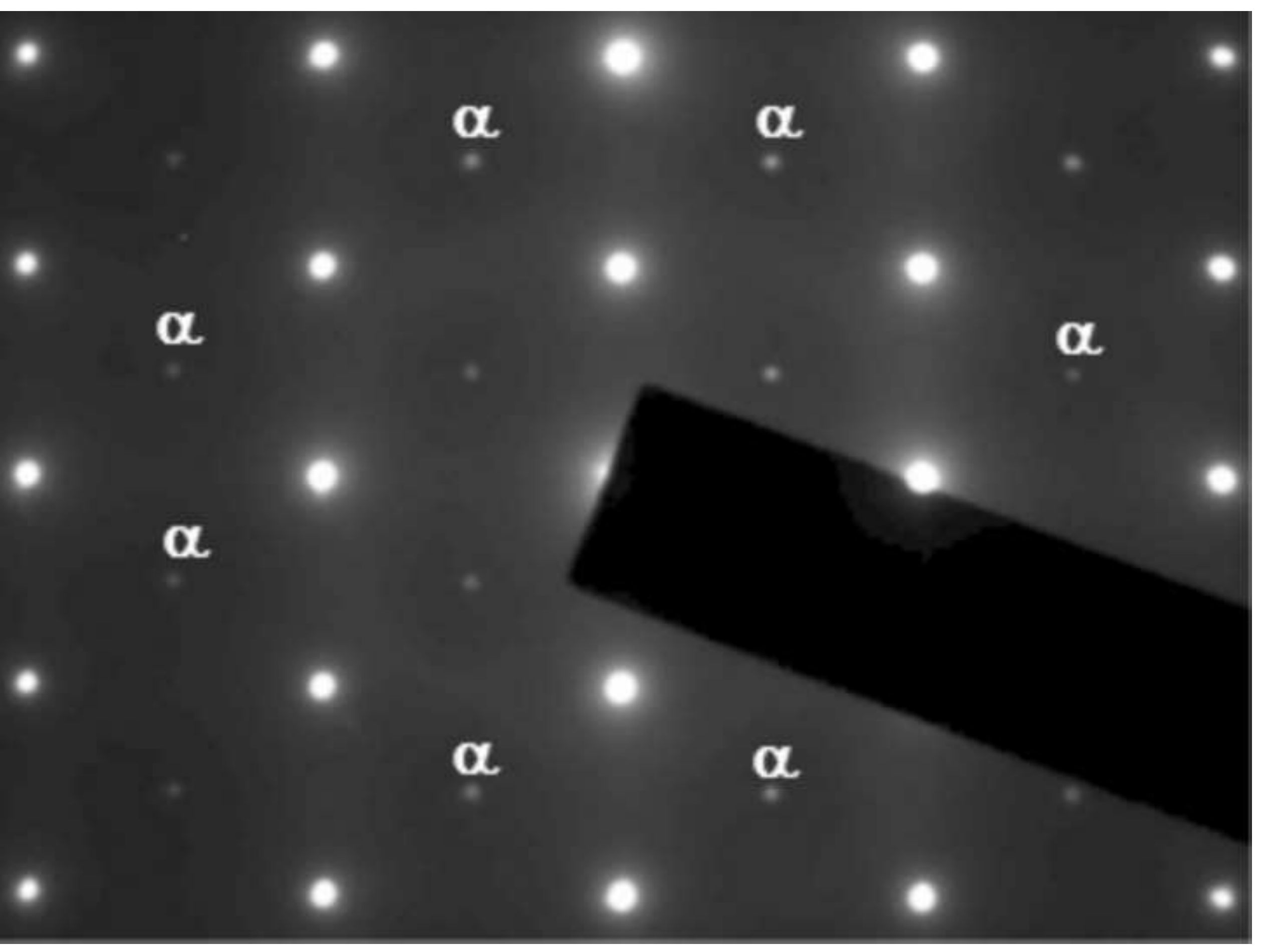

$\alpha$

$\alpha$

$\alpha$ $\alpha$ 


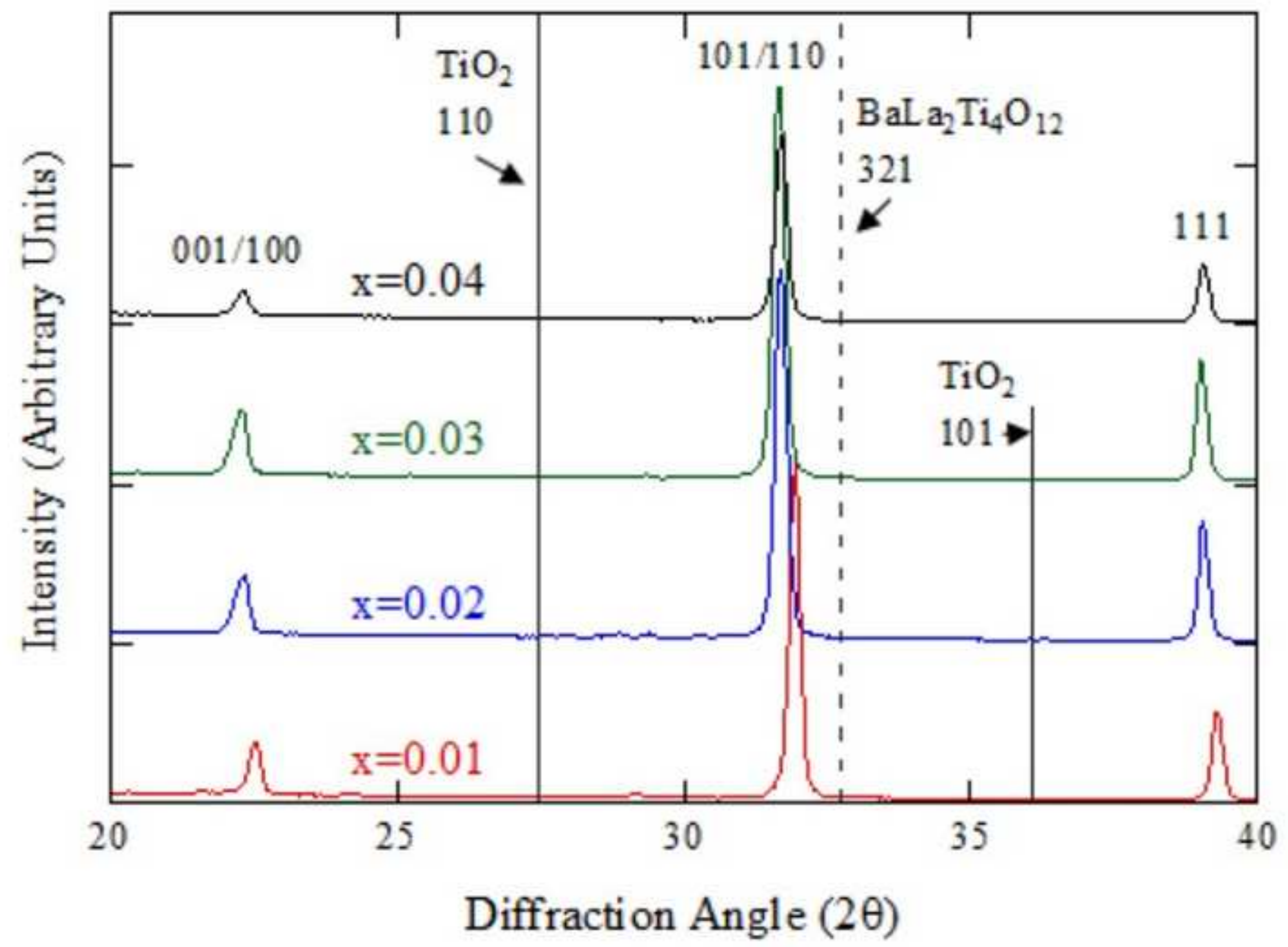




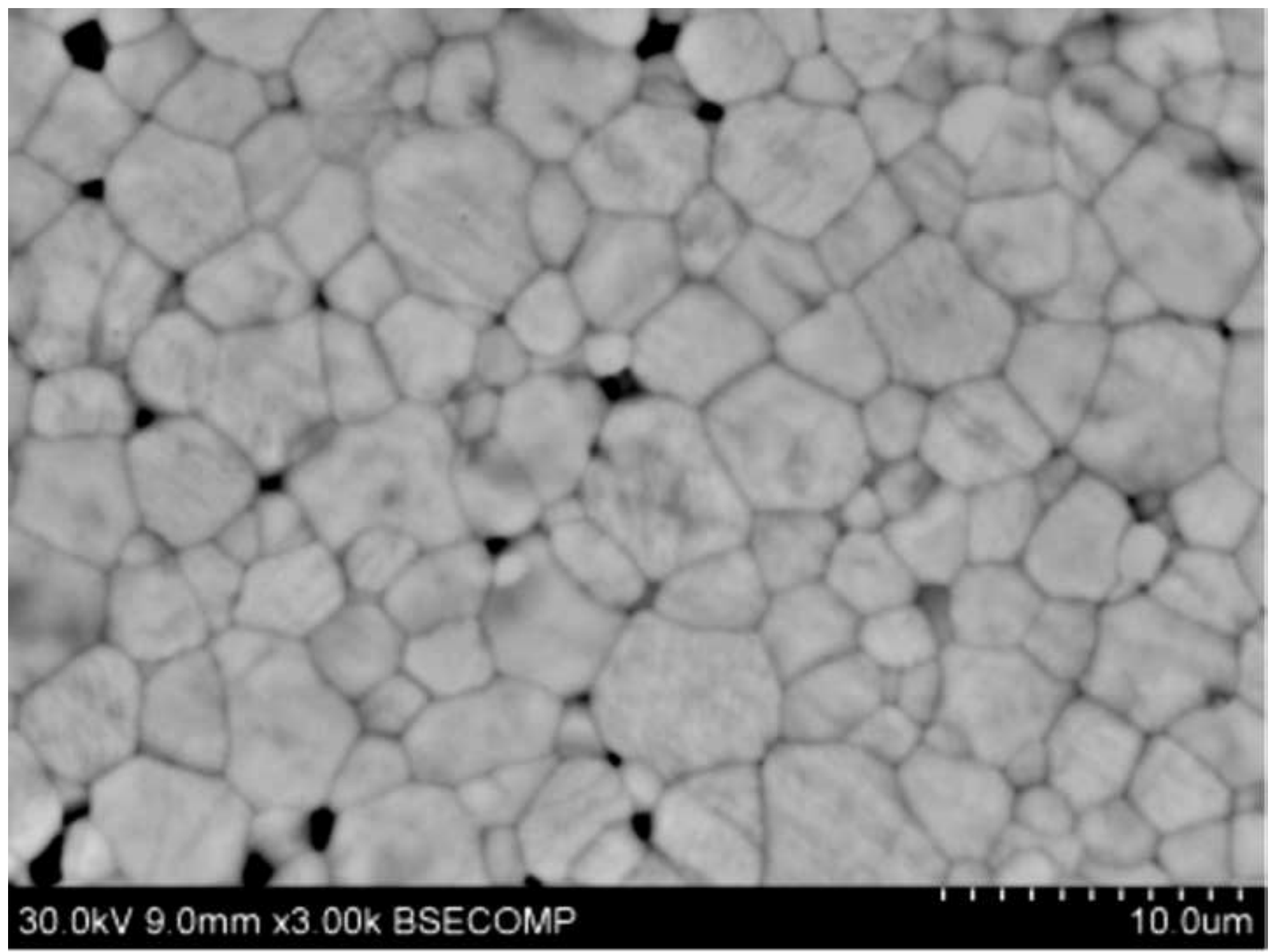




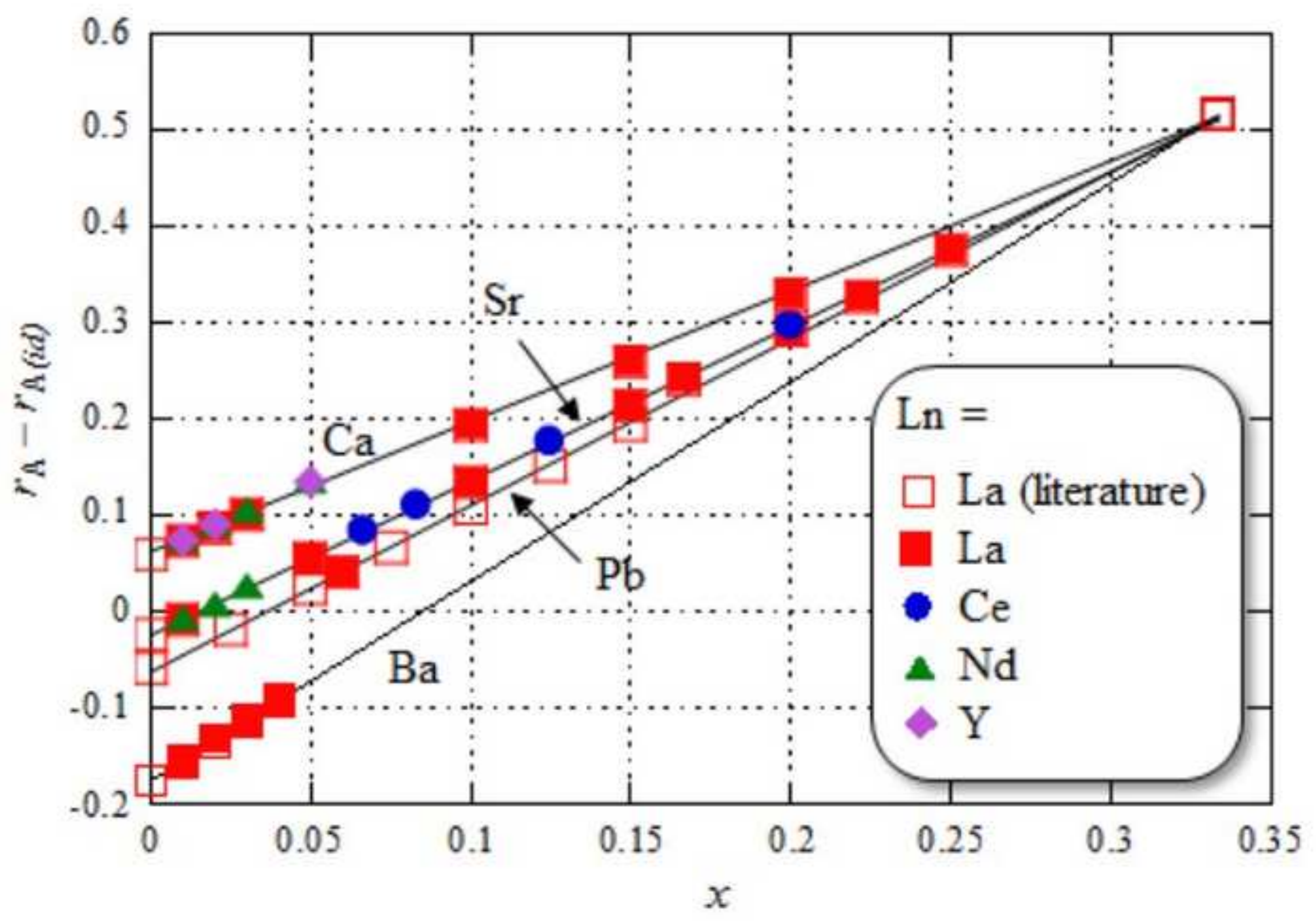




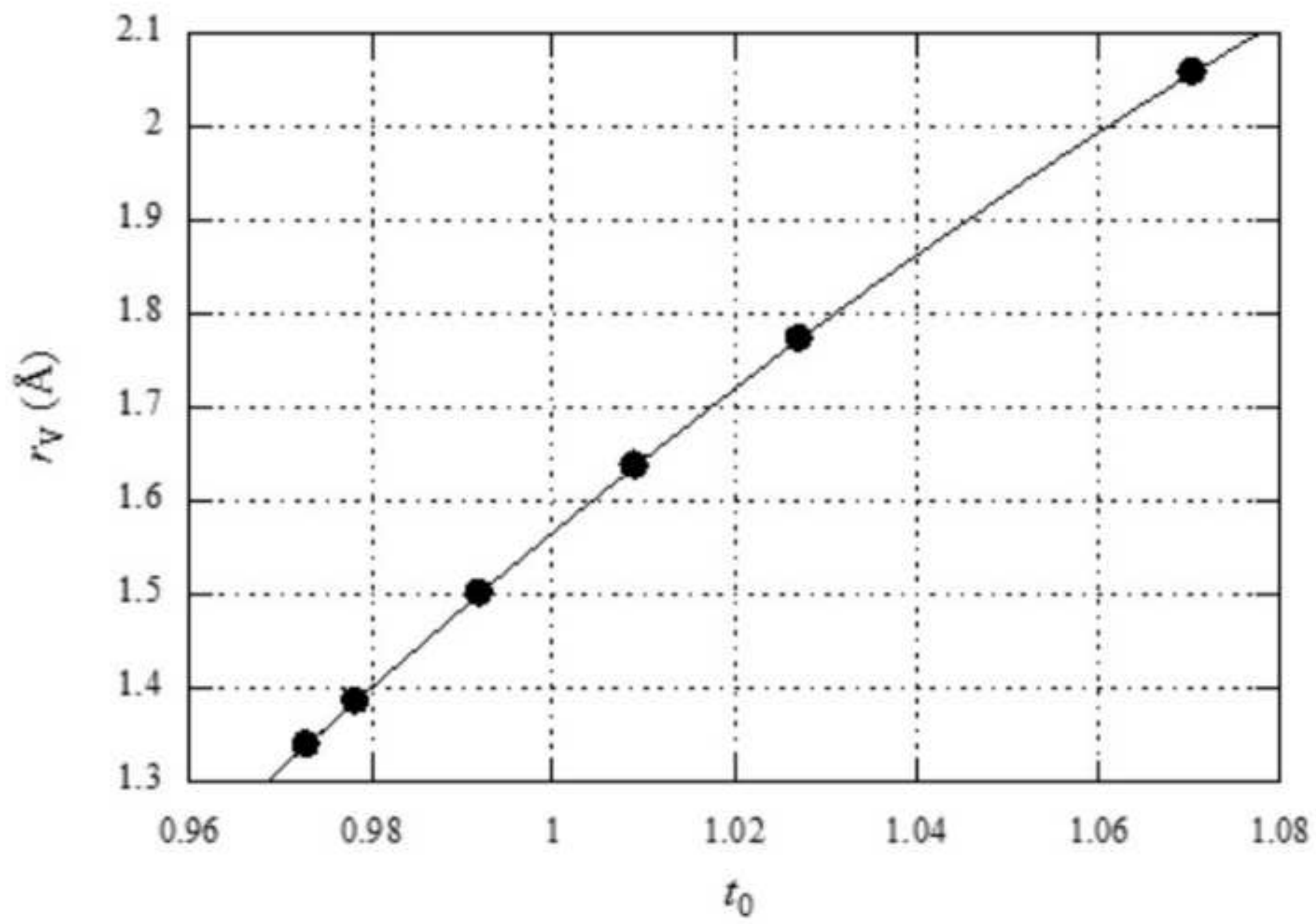




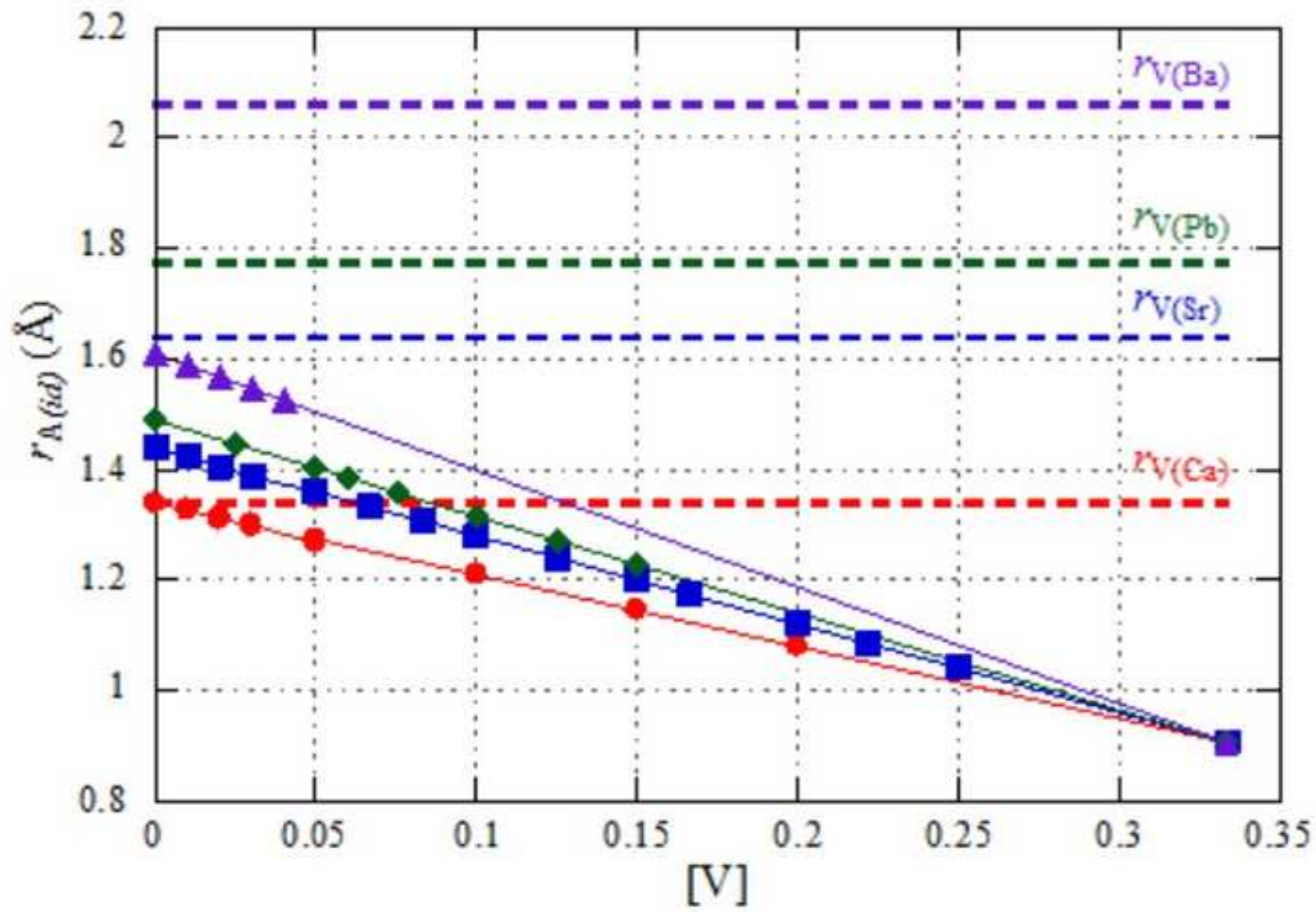




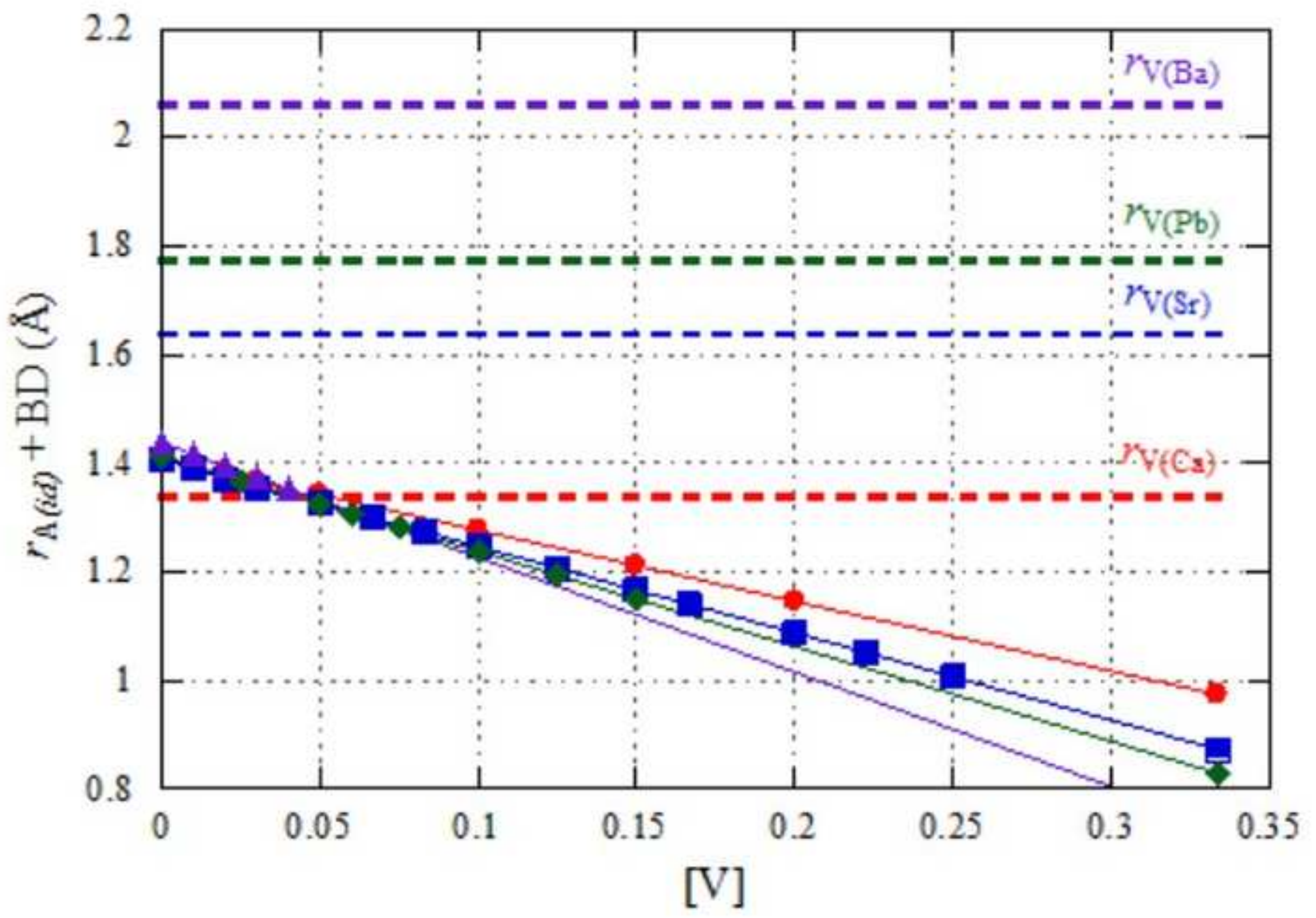




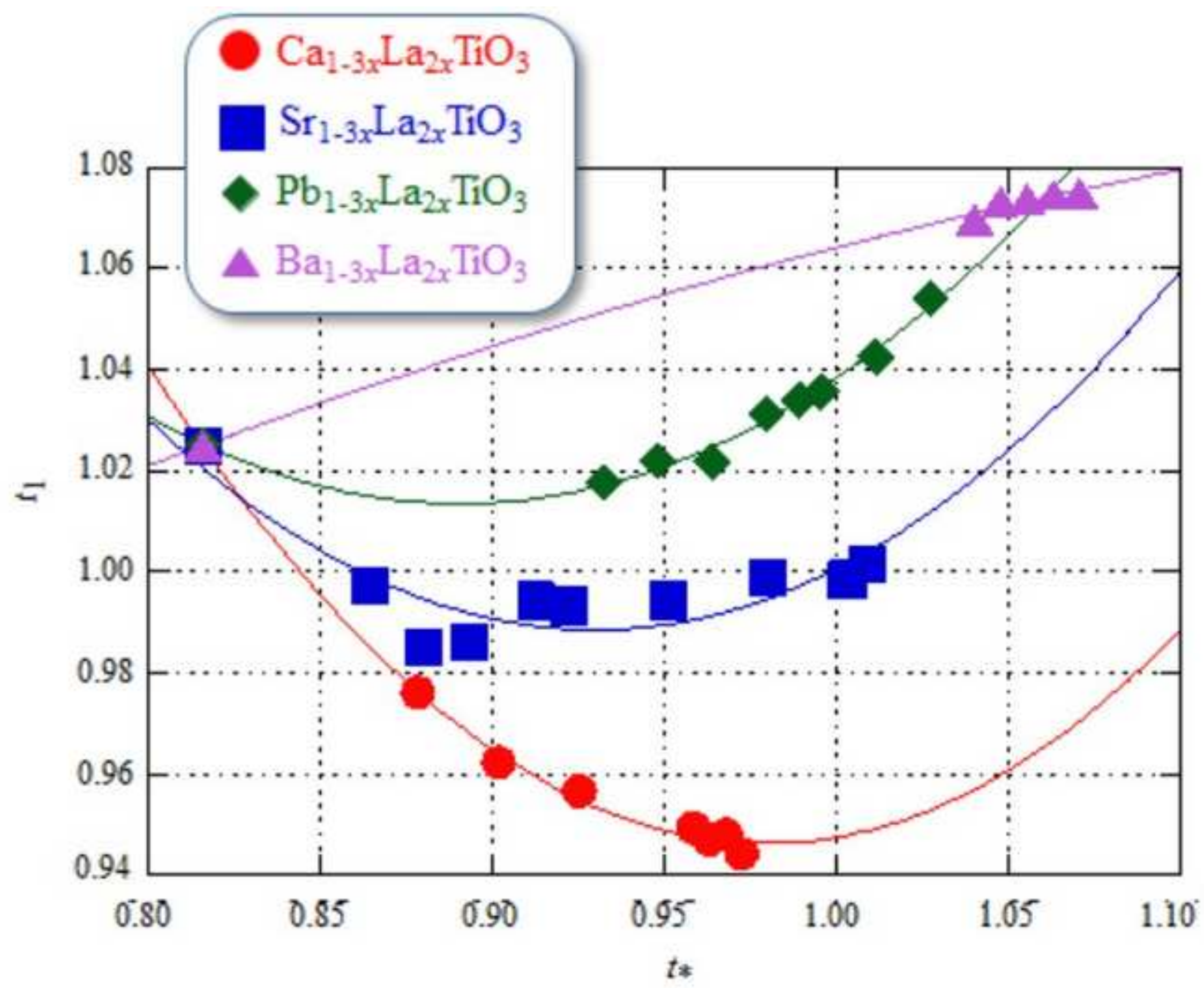




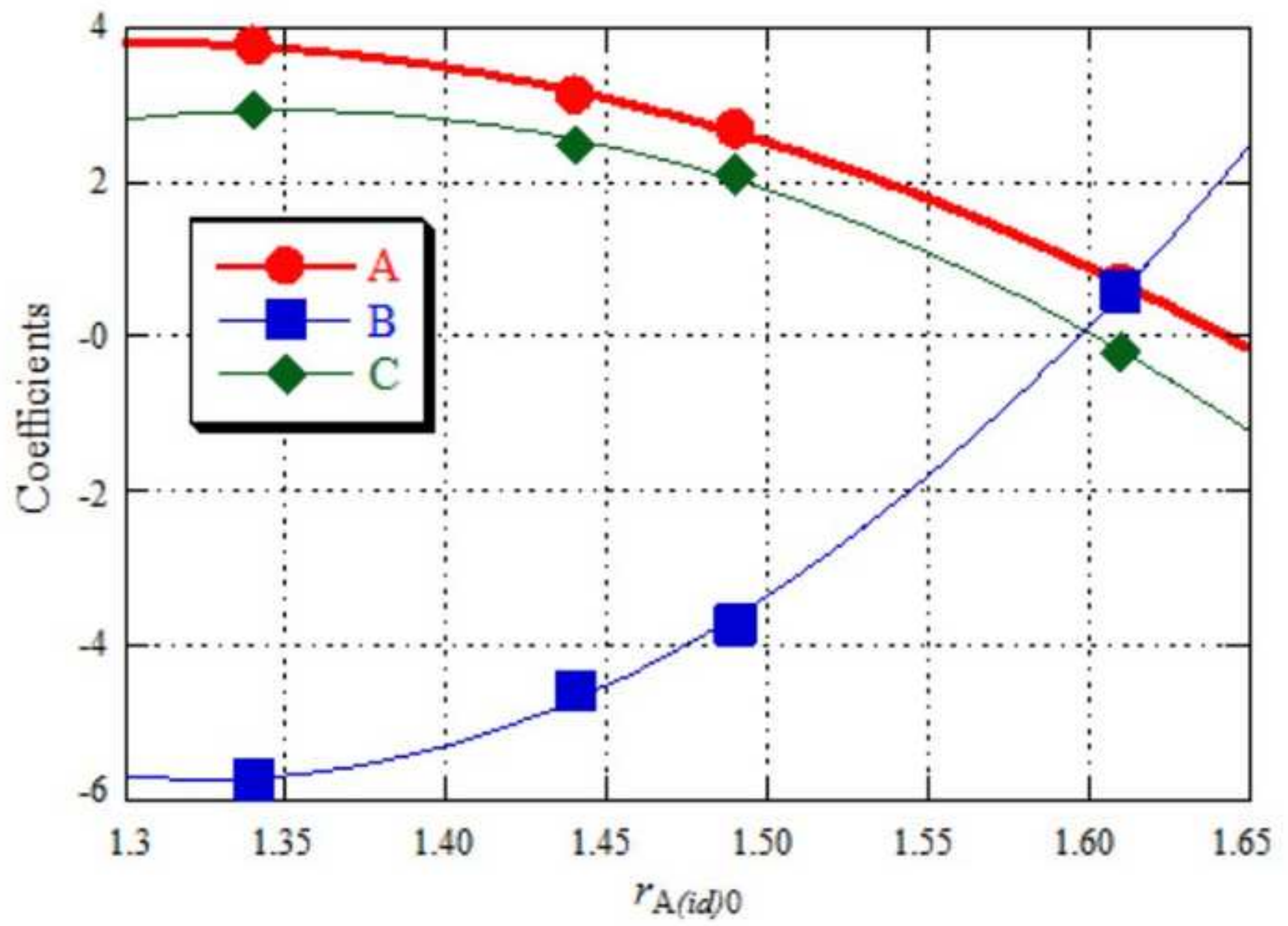




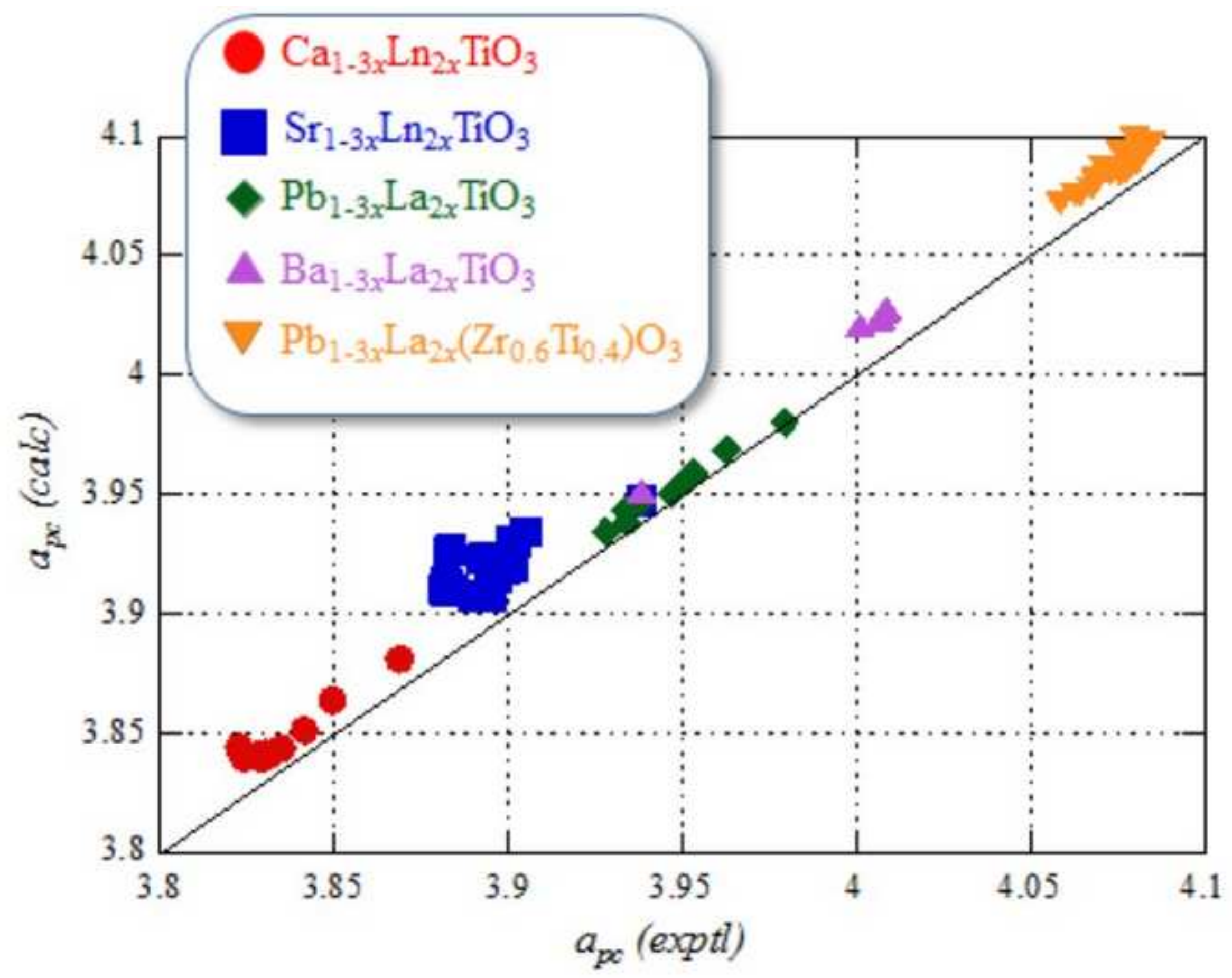




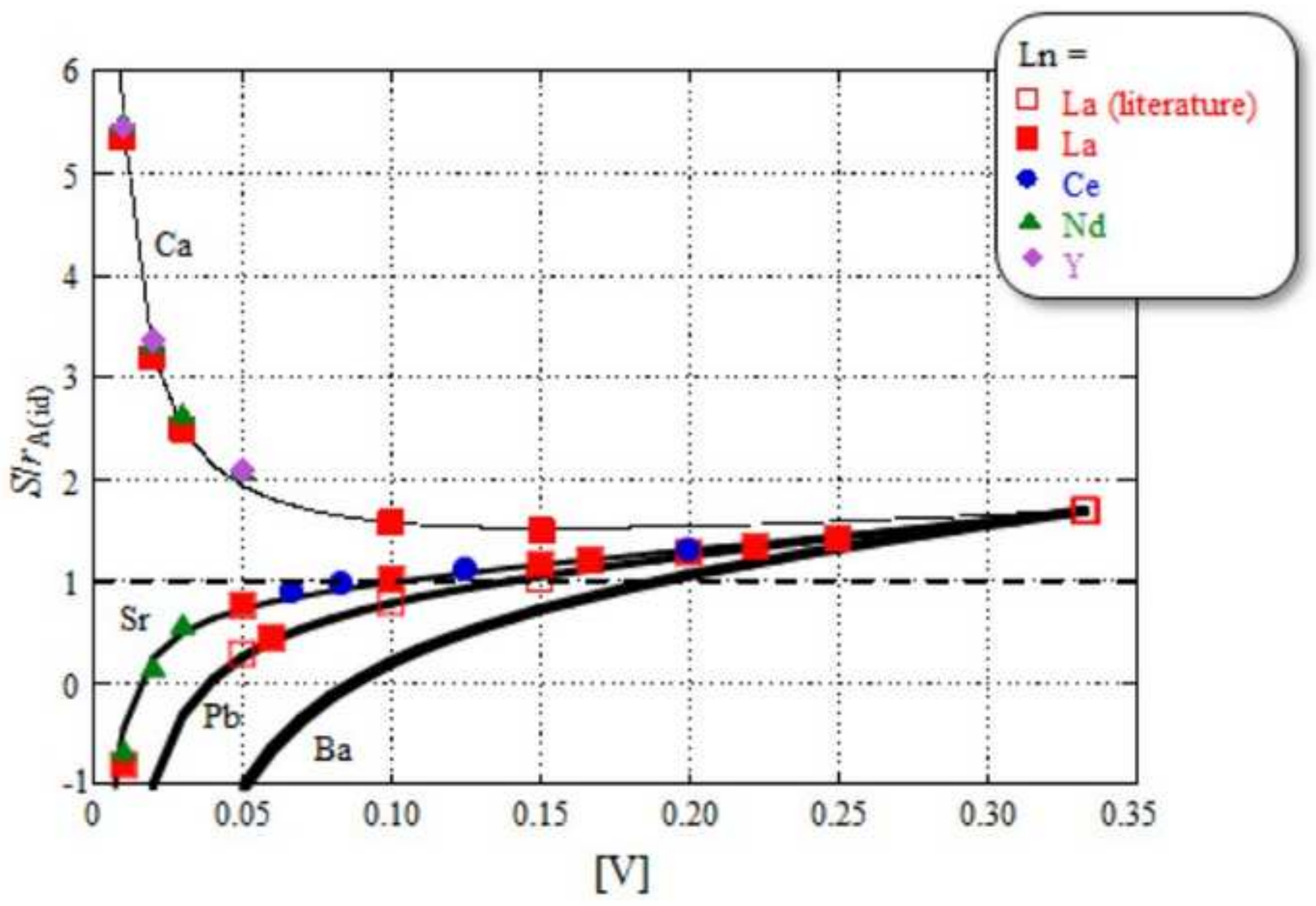

